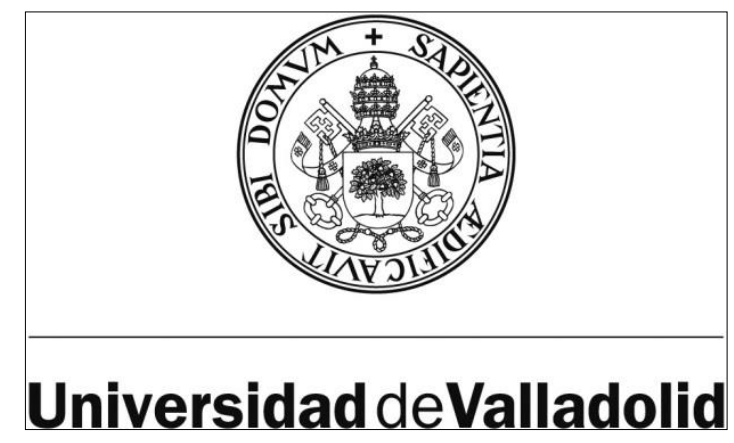

FACULTAD DE MEDICINA

DEPARTAMENTO DE ANATOMÍA Y RADIOLOGÍA

ÁREA DE ANATOMÍA Y EMBRIOLOGÍA HUMANA

TESIS DOCTORAL

\title{
PROCTALGIA EN EL SÍNDROME DE ATRAPAMIENTO DEL NERVIO PUDENDO
}

Presentada por JOSÉ FELIPE REOYO PASCUAL para optar al grado de doctor por la Universidad de Valladolid

Dirigida por:

Dra. Rosa Ma Martínez Castro

Dra. Natividad García Atares 
A mis padres, a mi abuela, hermana y a mi tio Epifanio, a los que debo lo que soy, por la confianza y el apoyo que siempre me han dado. 


\section{AGRADECIMIENTOS}

A la Dra. R.M. Martínez Castro, maestra, compañera y amiga, por su entusiásmo, orientación y dirección en la elaboración de esta Tesis Doctoral, sin cuya gran ayuda no hubiera visto la luz ni este ni otros proyectos de mi carrera.

A la Dra N. García Atares, por su inestimable ayuda y estímulo, reabrirnos las puertas de la facultad y de su departamento, y por haber creido en nuestro estudio desde sus orígenes.

Al Dr. J.M. Adot Zurbano por su iniciativa en el planteamiento y desarrollo de este proyecto, y a sus enfermeras de la Unidad de Urodinámica por acogerme afectuosamente cuantas veces las he necesitado.

Al Dr. J. L. Seco Gil, al que le debo gran parte de mi formación quirúrgica, por haberme prestado su confianza y apoyo, colaborando en éste y tantos logros de mi carrera.

A la Srta. Diana Armesto, por su colaboración en el estudio estadístico de esta tesis, y a la Dra. M.J. Coma del Corral, por haber puesto a nuestra disposición los medios de la unidad de investigación.

Al Dr. J.M. de Vicente, por haberme explicado cuantos detalles he precisado para la elaboración de este texto.

A mis compañeros del Servicio de Cirugía General y del Apto. Digestivo del Hospital Universitario de Burgos, por su estímulo durante el desarrollo de este proyecto.

A los pacientes, sin cuya colaboración este estudio no hubiese sido posible. 
ÍNDICE

1.INTRODUCCIÓN

2.HIPÓTESIS Y OBJETIVOS

3.MARCO TEÓRICO

3.1 DATOS HISTÓRICOS

3.2 ANATOMÍA DEL NERVIO PUDENDO 13

3.3 FISIOPATOLOGÍA DEL SANP 17

3.4 ETIOLOGÍA $\quad 19$

3.5 CLÍNICA $\quad 21$

3.6 DIAGNÓSTICO 22

3.7 DIAGNÓSTICO DIFERENCIAL 32

3.8 TRATAMIENTO 33

3.9 LITERATURA PUBLICADA $\quad 44$

3.10 DOLOR PERSISTENTE TRAS LA DESCOMPRESIÓN 45

4.MATERIAL Y MÉTODOS $\quad 46$

4.1 SELECCIÓN DE PACIENTES

4.2 ENTREVISTA CLÍNICA $\quad 48$

4.3 EXPLORACIÓN FÍSICA $\quad 49$

4.4 PRUEBAS ESPECÍFICAS $\quad 49$

4.5 PRUEBAS COMPLEMENTARIAS 50

4.6 TRATAMIENTO 50

4.7 SEGUIMIENTO

4.8 GRUPOS DE TRABAJO

4.9 MÉTODO ESTADÍSTICO 53

4.9.1 MÉTODO DESCRIPTIVO 53

4.9.2 MÉTODO COMPARATIVO 53 
PÁGS.

5.RESULTADOS 53

5.1 ESTUDIO DESCRIPTIVO SOBRE LA PROCTALGIA EN EL SANP` 54

5.1.1 EN RELACIÓN AL SEXO Y A LAS RAMAS AFECTAS

5.1.2 EN RELACIÓN A LA EDAD $\quad 58$

5.1.3 EN RELACIÓN A LOS ANTECEDENTES PERSONALES 60

5.1.4 EN RELACIÓN A LOS SIGNOS CLÍNICOS 60

5.1.5 EN RELACIÓN A LAS PRUEBAS COMPLEMENTARIAS 60

5.1.6 EN RELACIÓN A LA PUNTUACIÓN EN ESCALA EVA 61

5.1.6.1 EN RELACIÓN A PUNTUACIÓN EVA PREPUNCIÓN 61

5.1.6.2 EN RELACIÓN A PUNTUACIÓN EVA INMEDIATA POSTPUN. 61

5.1.6.3 EN RELACIÓN A PUNTUACIÓN EVA A PARTIR DE 6 MESES 61

5.1.7 EN RELACIÓN A LA SINTOMATOLOGÍA PRESENTE

A LOS 6 MESES TRAS LA PRIMERA PUNCIÓN 62

5.1.8 EN RELACIÓN A LA SEGUNDA “TANDA"

DE PUNCIÓN ANESTÉSICA

63

5.1.9 EN RELACIÓN A LAS COMPLICACIONES

DE LAS PUNCIONES ANESTÉSICAS

63 
PÁGS.

5.2 ESTUDIO COMPARATIVO ENTRE PACIENTES

RESPONDEDORES/ NO RESPONDEDORES A LA PUNCIÓN

ANESTÉSICA COMO TRATAMIENTO PARA LA PROCTALGIA

EN EL SANP $\quad 64$

5.2.1 EN RELACIÓN AL SEXO 64

5.2.2 EN RELACIÓN A LA EDAD 65

5.2.3 EN RELACIÓN A LOS ANTECEDENTES PERSONALES 66

5.2.4 EN RELACIÓN A LAS RAMAS AFECTAS 67

5.2.5 EN RELACIÓN A LOS SIGNOS CLÍNICOS 68

5.2.6 EN RELACIÓN AL TEST DE LATENCIA MOTORA DISTAL 69

5.2.7 EN RELACIÓN A LA PUNTUACIÓN EN ESCALA EVA

5.2.7.1 EN RELACIÓN A PUNTUACIÓN EVA PREPUNCIÓN

5.2.7.2 EN RELACIÓN A PUNTUACIÓN EVA INMEDIATA 72

5.2.7.3 EN RELACIÓN A PUNTUACIÓN EVA A PARTIR DE 6 MESES 73

5.3 PRUEBAS DE ASOCIACIÓN ESTADÍSTICA ENTRE VARIABLES

$\begin{array}{ll}\text { Y RESPUESTA AL TRATAMIENTO } & 75\end{array}$

5.3.1 ASOCIACIÓN ENTRE VARIABLES Y RESPUESTA

AL TTO. SIN SIGNIFICACIÓN ESTADÍSTICA

5.3.2 VARIACIÓN PORCENTUAL DE EVA 76

5.3.3 ASOCIACIÓN EVA PREPUNCIÓN/POST-PUNCIÓN 77

PÁGS. 
6.1 DE LA INCIDENCIA

6.2 DEL SEXO

6.3 DE LA EDAD

6.4 DE LOS ANTECEDENTES PERSONALES

6.5 DE LA CLÍNICA

6.6 DE LOS SIGNOS CLÍNICOS

6.7 DEL TEST DE LATENCIA MOTORA DISTAL DEL NERVIO

6.8 DE OTRAS PRUEBAS COMPLEMENTARIAS

6.9 DEL TRATAMIENTO

6.10 DE LA PUNTUACIÓN EVA PREPUNCIÓN

6.11 DE LA PUNTUACIÓN INMEDIATA POST-PUNCIÓN

6.12 DE LA PUNTUACIÓN A PARTIR DE LOS 6 MESES

6.13 DE LA SINTOMATOLOGÍA PRESENTE A PARTIR DE LOS 6 MESES POST-PUNCIÓN

6.14 DE LAS OPCIONES DISPONIBLES TRAS EL FRACASO

DE LA 1ạ PUNCIÓN 
1.INTRODUCCIÓN 


\section{PROCTALGIA EN EL SÍNDROME DE ATRAPAMIENTO DEL NERVIO PUDENDO}

El síndrome de atrapamiento del nervio pudendo (SANP) fue descrito por primera vez en 1987 por el Dr. Amarenco como síndrome de la parálisis perineal del ciclista. Desde entonces hasta nuestros días se han llevado a cabo varios intentos, la mayoría de ellos poco productivos, para esclarecer su etiología, los procedimientos diagnósticos y terapéuticos.

Esta entidad comprende un amplio abanico de síntomas que varían en localización e intensidad en el transcurso de la enfermedad pero haciendo referencia a la anatomía del nervio pudendo, sobre todo teniendo en cuenta sus tres ramas terminales, podemos definirlo como un síndrome cuya principal manifestación es el dolor perineal y/o pelviano y que puede asociar disfunción miccional, defecatoria o sexual.

En el ámbito de la medicina ambulatoria, los pacientes afectos de este síndrome suelen consultar en varias ocasiones a distintos especialistas (médico de atención primaria, internistas, cirujanos...) por dolor perianal de etiología incierta, junto a una sintomatología acompañante variada, y reciben muchas veces diagnósticos erróneos y tratamientos poco efectivos y desorientados.

Al tratarse de un nervio con una anatomía compleja, y dado que posee 3 ramas terminales (rectal inferior, perineal y dorsal del clítoris/pene), su patología abarca manifestaciones clínicas que entran en el campo de actuación de varios médicos especialistas como pueden ser el cirujano digestivo, el urólogo y el ginecólogo.

Por tanto, y con el objeto de acotar patología nos centraremos en la proctalgia como síntoma fundamental y de gran trascendencia en el ámbito de la cirugía general en el que desarrollo mi actividad laboral.

El diagnóstico de SANP se basa fundamentalmente en criterios clínicos (dolor, exploración física, etc), apoyado con estudios electrofisiológicos (St. Mark's...) y complementado en las últimas series por ecografía endorrectal. 
Para el tratamiento del dicha patología se han utilizado varios métodos que comprenden desde el tratamiento sintomático del dolor, las infiltraciones con anestésico local y/o corticoides y el tratamiento quirúrgico (ya sea por vía transperineal, transglútea, transvaginal o transisquiorrectal).

Nuestra exposición se fundamenta en un estudio prospectivo de los pacientes afectos de proctalgia con/sin sintomatología acompañante, utilizando pruebas de diagnóstico clínico, de imagen y electrofisiológico. Aquellos que cumplan los criterios, se etiquetarán de SANP y serán tratados mediante punción corticoideo-anestésica según técnica original descrita en material y métodos. Posteriormente, mediremos su respuesta desde el punto de vista clínico, favorable o desfavorable al tratamiento instaurado. 


\section{HIPÓTESIS Y OBJETIVOS}


La proctalgia es un motivo de consulta muy frecuente en la consulta de cirugía general. En la mayor parte de las ocasiones, se objetiva alguna causa médico-quirúrgica común del tipo fisura anal, hemorroides, etc... que puede justificar dicho síntoma, pero en otras ocasiones no se obtiene un diagnóstico certero, lo que conlleva la práctica de tratamientos sintomáticos secuenciales crónicos, no resolutivos, si no se tiene en cuenta que, en un porcentaje considerable, el SANP puede ser la causa de estos casos de dolor crónico.

Con el interés de dar a conocer este síndrome y su relación estrecha con la proctalgia, iniciamos un estudio observacional bajo las siguientes HIPÓTESIS :

- La proctalgia de causa no filiada y difícil control con tratamiento analgésico convencional, puede deberse a un Síndrome de Atrapamiento del Nervio Pudendo.

- Las infiltraciones anestésicas del nervio pudendo y selectivamente de sus ramas, pueden mejorar/curar la sintomatología rebelde a tratamientos analgésicos convencionales en pacientes afectos de dicho síndrome, evitando un gran consumo de recursos sanitarios y sufrimiento a los pacientes. 
Para ello, el OBJETIVO de nuestro estudio es triple:

1. Establecer la relación de la proctalgia con el SANP confirmado con los factores epidemiológicos, clínicos y diagnósticos establecido por distintos autores.

2. Comprobar la respuesta inmediata de los casos de proctalgia del SANP al tratamiento mediante infiltración anestésica en términos clínicos (nivel de dolor pre y postinfiltración).

3. Valorar los resultados clínicos postinfiltración y la eficacia del tratamiento en el seguimiento a medio plazo (6 meses). 
3. MARCO TEÓRICO 


\subsection{DATOS HISTÓRICOS}

El Síndrome de Atrapamiento del Nervio Pudendo es una entidad clínica de reciente descripción ya que se considera que su primera definición fue llevada a cabo en Paris por Amarenco hacia el año 1987 basado en el estudio de la neuralgia incoercible del territorio pudendo que sufría un ciclista y que por ello lo denominó "Síndrome de Parálisis Perineal del ciclista" (1).

A los pocos años, en 1991, fue el egipcio A. Shafik quién se encargó de describir el tratamiento para esta patología (2).

Desde estos primeros hitos hasta nuestros días, varios han sido los autores (Bautrant, Beco, Robert, Benson...) que sobre todo en la década 2000-2010, han intentado arrojar luz sobre esta patología; pese a ello, todavía quedan campos en el diagnóstico y en el tratamiento en los que es preciso seguir investigando. 


\subsection{ANATOMÍA DEL NERVIO PUDENDO}

El nervio pudendo posee una anatomía compleja, ampliamente estudiada, ya que realiza un largo recorrido en el curso del cual es frecuente identificar puntos críticos de posible atrapamiento.

Así, Robert y colaboradores (3) han estudiado profusamente los puntos anatómicos en los que el nervio pudendo puede ser atrapado, que son fundamentalmente la pinza formada entre el ligamento sacrotuberoso y sacroespinoso, el canal de Alcock y el proceso falciforme.

Desde El Cairo, Shafik realizó numerosos estudios en relación a la anatomía topográfica o quirúrgica para tratar de establecer aquellas vías de abordaje y mejor acceso al nervio afectado, que comentaremos posteriormente $(4,5)$.

La investigación en el campo de la neurofisiología ha sido llevada a cabo por varios estudiosos siendo Bisschop uno de los principales en sentar las bases anatomofisiológicas de esta patología $(6,7)$.

El nervio pudendo se origina en los segmentos medulares sacros S2, S3 y S4 y clásicamente se describen 3 zonas de recorrido (figs.1, 2):

1. PRIMER SEGMENTO: desde su origen hasta la región presacra.

2. SEGUNDO SEGMENTO: en el canal infrapiriforme. Tras su origen, el nervio pudendo penetra en la región glútea por debajo del músculo piriforme y cruza alrededor del segmento final del ligamento sacroespinoso entrando en contacto con el ligamento sacrotuberoso. Es esta región de gran importancia en el síndrome de atrapamiento del nervio pudendo ya que es donde puede producirse la "pinza" que comprima al nervio.

3. TERCER SEGMENTO - canal pudendo - de Alcock- : tras entrar en contacto con el ligamento sacroespinoso, el nervio se desplaza bajo el elevador del ano, a lo largo de la tuberosidad isquiática, a través de una vaina aponeurótica del músculo obturador interno, siendo también un lugar habitual donde producirse el atrapamiento del nervio. 


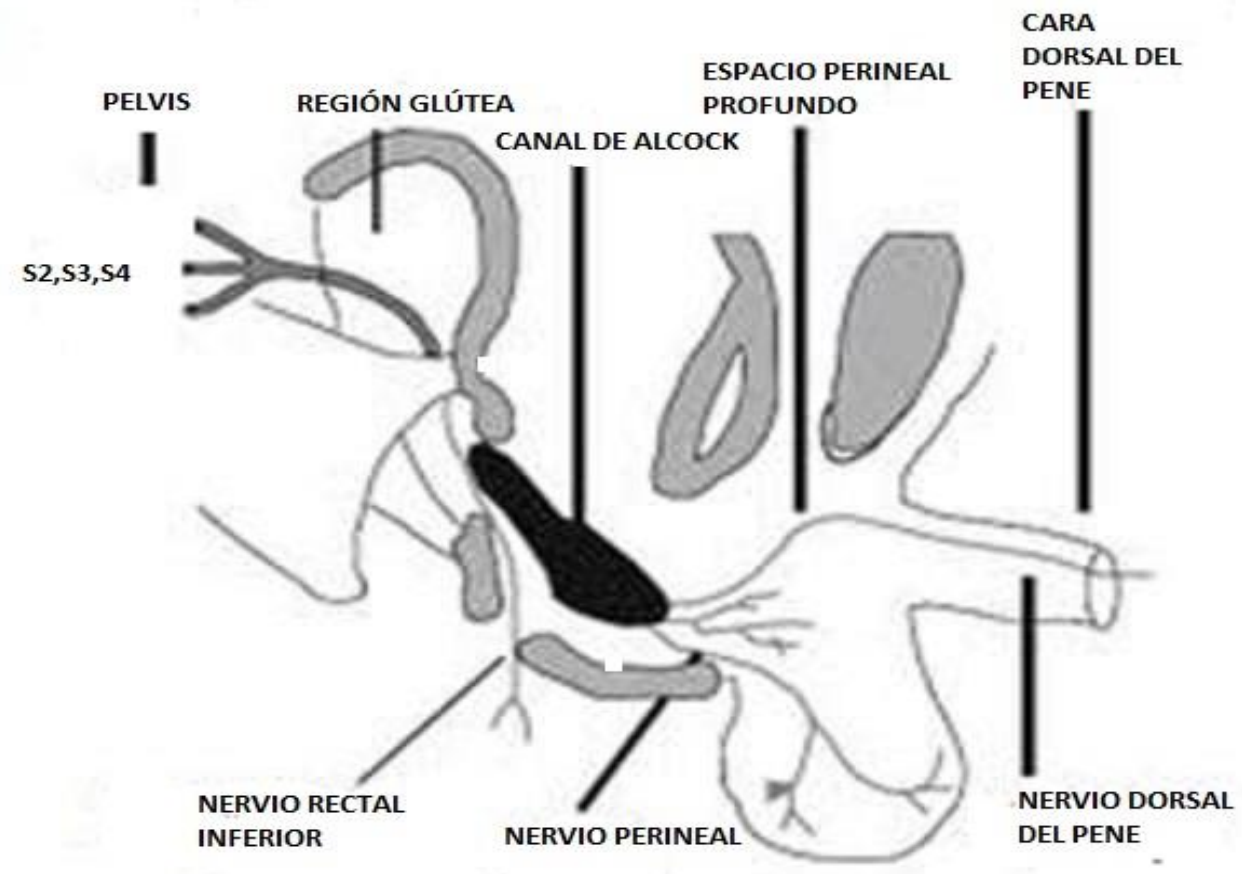

Fig.1 Esquema del recorrido del nervio pudendo.

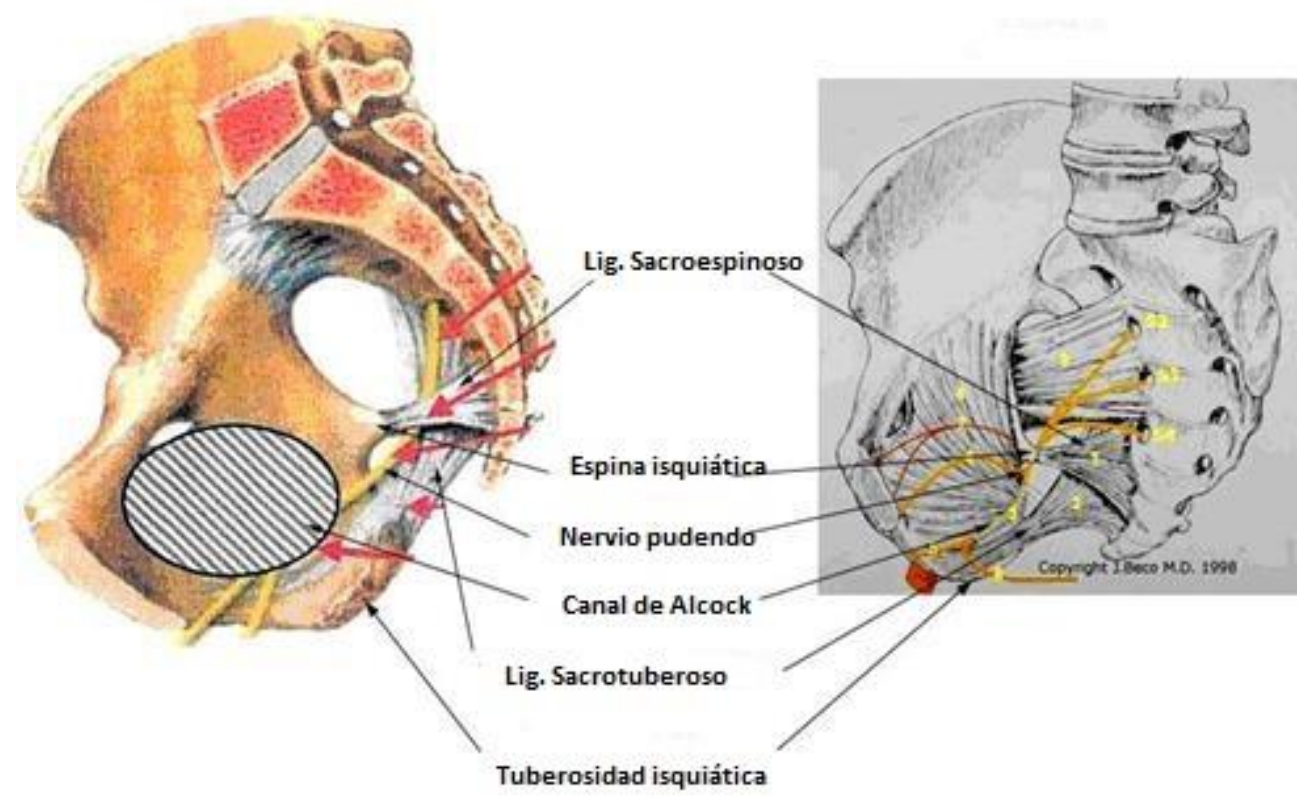

Fig.2. Relaciones anatómicas del nervio pudendo. 
El nervio pudendo posee fibras somáticas y vegetativas, motoras y sensitivas por lo que su patología puede manifestarse con sintomatología muy variada: estriomotora, visceral o con alteración de la sensibilidad. El $30 \%$ del nervio tiene componente autonómico y el $70 \%$ somático ( $50 \%$ sensitivo y $20 \%$ motor).

A lo largo de su trayecto, el nervio da lugar a varias ramas de las cuales cabe destacar (fig.3):

1. El nervio RECTAL INFERIOR suele comenzar en el canal de Alcok. Atraviesa la fosa isquiorrectal con los vasos hemorroidales inferiores. Sus ramas terminales inervan el canal anal, tercio distal de recto, y región cutánea posterior de zona vulvar y perianal. Desde el punto de vista motor alcanza el elevador del ano y el esfínter anal externo. Tal y como observaron Roberts y Taylor en 1973 en 8 de 40 disecciones, el nervio rectal inferior puede originarse directamente del plexo sacro, perforar el ligamento sacrociático menor y conectar de nuevo con el nervio pudendo.

2. El nervio PERINEAL aparece tras la salida del pudendo del canal de Alcock y es la rama más larga del nervio pudendo. Discurre hacia delante por debajo de la arteria pudenda interna. Sensitivamente alcanza el tercio inferior de vagina, uretra, labios mayores y menores; desde el punto de vista motor afecta fundamentalmente al esfínter estriado de la uretra.

3. El nervio DORSAL DEL PENE/ CLÍTORIS emerge tras la salida del canal de Alcock, se dirige hacia delante por encima de la arteria pudenda interna junto con la rama isquiática y el borde de la rama púbica inferior por debajo de la aponeurosis inferior del diafragma urogenital. Posee rama para el clítoris o pene y para el pubis acompañando a la arteria dosal del pene entre las capas del ligamento suspensorio, terminando en el glande. 
El nervio pudendo posee también ramas musculares que inervan a los músculos bulboesponjoso, isquiocavernoso, elevador del ano, transverso perineal superficial y transverso perineal profundo.

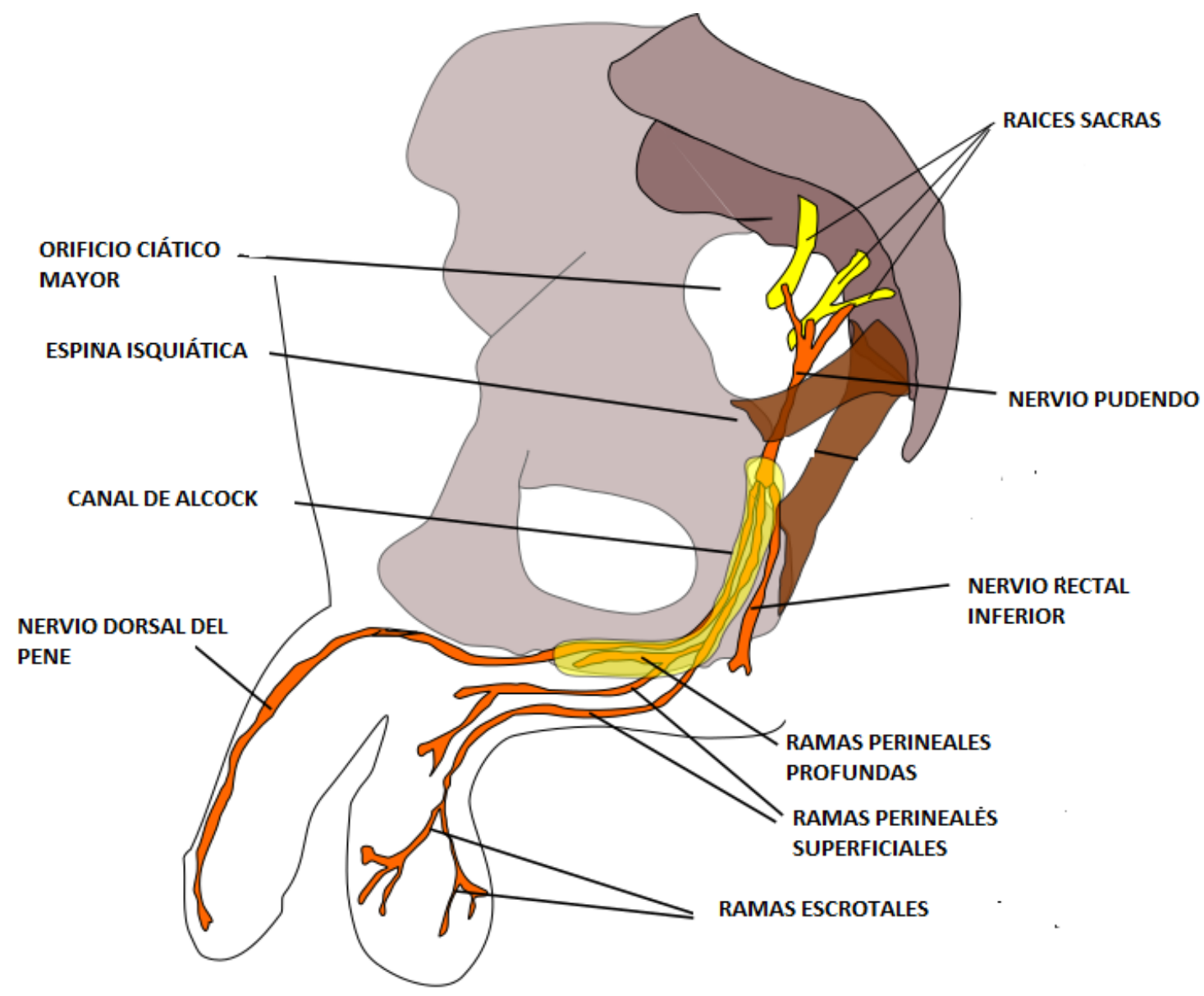

Fig.3. Distribución y ramas del nervio pudendo. 


\subsection{FISIOPATOLOGÍA DEL SÍNDROME DE ATRAPAMIENTO DEL NERVIO PUDENDO}

Las lesiones de los nervios periféricos en general obedecen a 3 causas fundamentales: IÓNICAS, MECÁNICAS y VASCULARES.

La importancia de cada una depende de la lesión en cuestión y del momento en el que la estemos estudiando $(9,11)$.

En situaciones de equilibrio homeostático, existe un gradiente de presión entre el nervio, los fluidos circundantes y los tejidos anexos que garantizan un flujo sanguíneo ininterrumpido para el tejido nervioso. La alteración de este gradiente es un hecho constatable en el atrapamiento nervioso (11). Sunderland en 1976 desarrolló un esquema que comprende tres estadíos distintos que pueden ocurrir tras el atrapamiento de un nervio: hipoxia, edema y fibrosis (9) tal y como aparece esquematizado en la figura 4. Con el estasis venoso y la consecuente hipoxia, se debilita la nutrición de la fibra nerviosa. La neuroisquemia es una probable causa de dolor y otros síntomas acompañantes como las parestesias. Con una hipoxia continua, la lesión del endotelio continúa y provoca una fuga de edema rico en proteínas. El aporte vascular a un nervio se realiza a través del mesoneuro, que permite los cambios de posición y tensión del mismo adaptándose a los movimientos. Los pequeños vasos entran en el epineuro del nervio dividiéndose en pequeñas ramas que forman un verdadero ovillo anastomótico que acaba subdividiéndose en un plexo vascular en el perineuro. Además el lecho capilar del propio nervio está incluido dentro de los fascículos nerviosos completando el patrón vascular (10).

Los fenómenos isquémicos en el nervio se traducen en un bloqueo de la transmisión nerviosa y puede tener tres causas:

. Tracción excesiva

- Tracciones mínimas en zonas donde hay adherencias

. Compresión mecánica

El desarrollo de estas alteraciones sería el siguiente:

- Obstrucción del retorno venoso con el consiguiente estasis venoso.

- Lesión anóxica directa que incrementa la permeabilidad.

- Edema en el tejido endoneural, con aumento de presión en el espacio intrafascicular, que incrementa el efecto de la compresión original 
Si se incrementa la compresión o el edema persiste durante un periodo prolongado, tiene lugar una proliferación fibroblástica dentro del nervio acompañado de un proceso de desmielinización. Si la causa persiste, se puede originar fibrosis que ocasiona anoxia segmentaria del nervio al alterar la circulación y el intercambio de nutrientes. Cuando una porción del axón sufre isquemia, se reduce la fosforilación oxidativa y la producción de ATP disminuyendo la eficacia de la bomba de sodio, el sistema de transporte axoplásmico y la integridad de la membrana celular, y en consecuencia, la disminución o pérdida en la transmisión a lo largo de la fibra nerviosa. Los nutrientes son aportados por distintos mecanismos de transporte axoplásmico anterógrado y los catabólicos por un sistema retrógrado. La interrupción en la síntesis o las alteraciones en el transporte en ambas direcciones parecen ser la explicación del fenómeno de doble o múltiple compresión ("doublé-crash"), que significa que un nervio con un trastorno en la conducción en un nivel es más vulnerable y aumentan las posibilidades de sufrir un trastorno en la conducción en una segunda o tercera localización. Inicialmente se observó que patologías neurológicas a nivel proximal predisponían el desarrollo de alteraciones distales y actualmente se conoce que alteraciones distales también predisponen al desarrollo de lesiones proximales $(8,9,10,11)$.

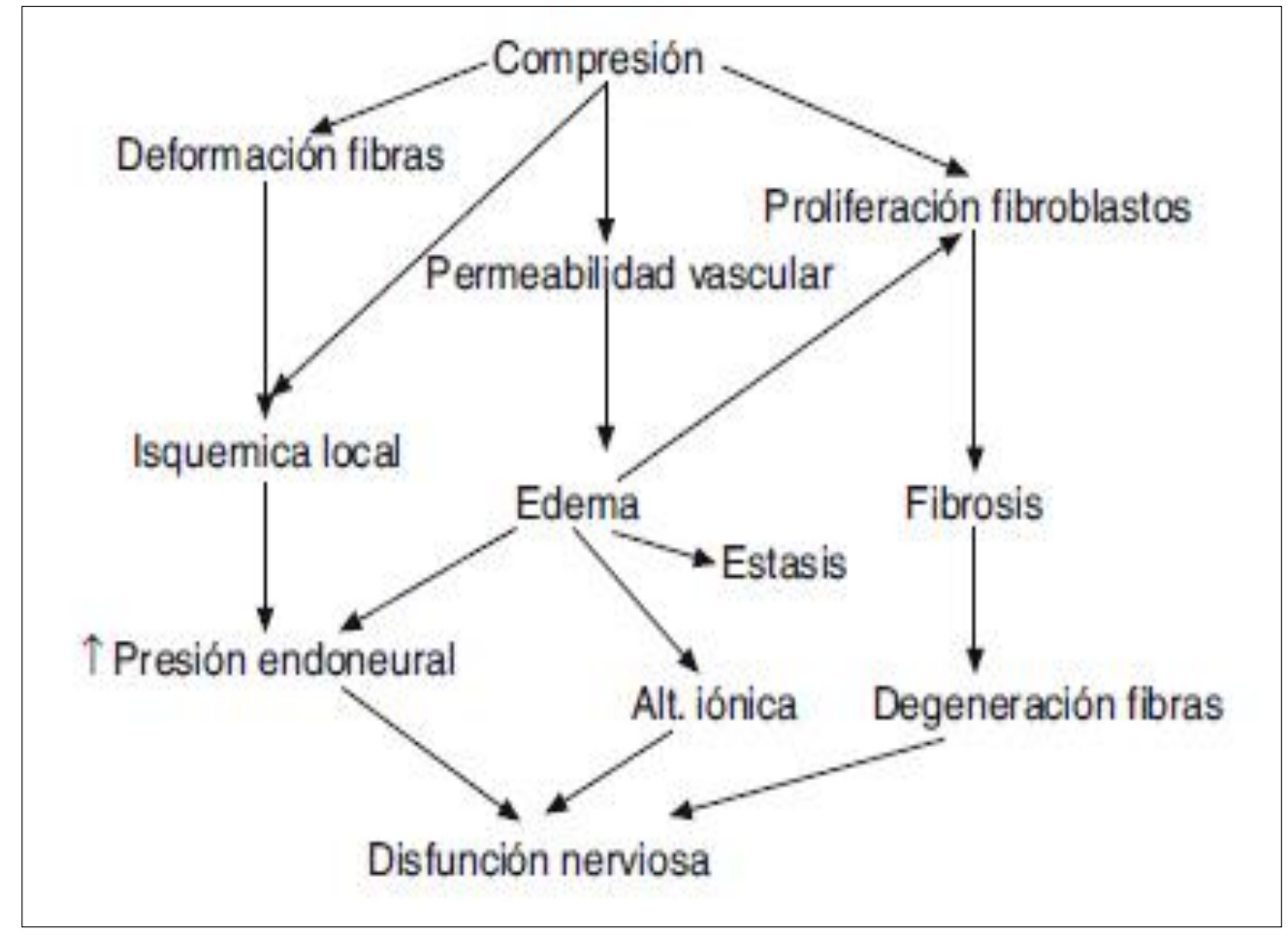

Fig. 4 Esquema explicativo de la fisiopatología del SANP. 


\subsection{ETIOLOGÍA}

Existen documentadas muchas causas posibles para este tipo de patología, destacando las siguientes:

- Actividad profesional o deportiva que implique permanecer en posición sentada durante un tiempo prolongado; es el caso de los ciclistas, en los que una compresión permanente del nervio en un sillín inadecuado puede causar este síndrome de "parálisis perineal del ciclista" $(1,11,13)$. Otras actividades relacionadas que por el mismo mecanismo pueden derivar en este síndrome, pueden ser todas aquellas en las que se utilicen sillas duras como la hípica, etc. La práctica de deporte en la juventud puede llevar a un desarrollo inadecuado del proceso espinoso del isquion que conlleve con el paso de los años, un proceso compresivo del nervio pudendo.

.Traumatismo. En general, los microtraumatismos repetidos en la zona perineal pueden arrastrar un SANP (14).

.Parto vaginal y episiotomía. La episiotomía puede ser el origen de algunos casos de síndrome de atrapamiento del nervio pudendo, por lo que hay que tenerlo en cuenta a la hora de realizarla, tal y como comunica Soga et al. en un estudio de 15 cadáveres de mujeres ancianas (15). El estiramiento del nervio durante el parto es otro factor involucrado en la etiología de este síndrome (16).

.Cirugía ginecológica pelviana previa, abdominal o vaginal. La cirugía que involucra la disección vulvar, puede dar lugar a una neuropatía compresiva del nervio pudendo tal y como documenta Benson (17).

.Radioterapia pelviana, que puede provocar cambios morfológicos y estructurales en los tejidos adyacentes que lleguen a comprimir el nervio pudendo.

.Defectos congénitos (óseos, musculares...) que impliquen atrapamiento. .Inestabilidad de la articulación sacroiliaca.

.Puntos gatillo en el músculo piriforme o piramidal.

.Puntos gatillo en el músculo elevador del ano y obturador interno.

.Respuesta inflamatoria; enfermedades autoinmunes.

.Estreñimiento crónico, incontinencia fecal y prolapso rectal.

El estreñimiento crónico y el descenso perineal es una de las primeras causas documentadas para este síndrome $(18,19)$. Shafik presentó un artículo que hace 
referencia a la importancia del acompañamiento del prolapso rectal a la incontinencia rectal para la producción de SANP. Se encuentra con valores electromiográficos y electroneurográficos anormales, así como una hipoestesia perianal, y obtuvieron buenos resultados tratándolo como una descompresión (20).

Asímismo, el dolor vulvar asociado al estreñimiento crónico y a la incontinencia podría estar ligado a la compresión del nervio pudendo de acuerdo a los estudios de Shafik sobre la vulvodinia idiopática. Tras la descompresión desapareció el dolor en nueve de once pacientes $(21,5)$.

Bautrant et al. analizaron exhaustivamente las posibles causas que pueden originar el SANP y encontraron que las causas más frecuentes de esta patología eran el parto, caídas, golpes directos y cirugías pélvicas (22). 


\subsection{CLÍNICA}

La clínica fundamental de este síndrome es el dolor en las zonas inervadas por el nervio pudendo o alguna de sus ramas (fig.5) , esto es, en el recto, periné, uretra y/o órganos genitales externos (clítoris, vagina, pene, testículos, escroto).

Las molestias suelen referirse en forma de quemazón, pérdida o aumento de la sensibilidad, descargas eléctricas, sensación de cuerpo extraño, sensación anormal de temperatura, molestias relacionadas con la defecación, disuria, coito doloroso y disfunción sexual. El dolor puede ser uni o bilateral y de instauración generalmente lenta y progresiva aunque también puede ser brusco. Como regla general, el dolor empeora a lo largo del día y al sentarse.

La forma de presentación de su patología puede ser muy variada pudiendo aparecer únicamente como dolor pero puede asociarse también a problemas urinarios, defecatorios, disfunción eréctil, problemas con la eyaculación o incluso como alteraciones funcionales sin dolor $(23,24,25)$

Shafik reporta dos series de pacientes sin dolor pero que presentan disfunción eréctil, alteraciones de la sensibilidad peneana, del periné y escroto. La descompresión del nervio en estos pacientes se mostró eficaz para alivio de dicha sintomatología. También se sugiere que la causa más probable en este caso sería el estreñimiento crónico que conduce a una subluxación del músculo elevador del ano y posteriormente a una compresión del nervio pudendo en el canal de Alcock.

Loeser comenta que las neuropatías por atrapamiento causan déficit neurológicos focales, dolor local e irradiado y parestesias que pueden presentarse o no por lo que podemos encontrarnos con una falta de correlación entre los hallazgos clínicos y electrofisiológicos $(25,5)$.
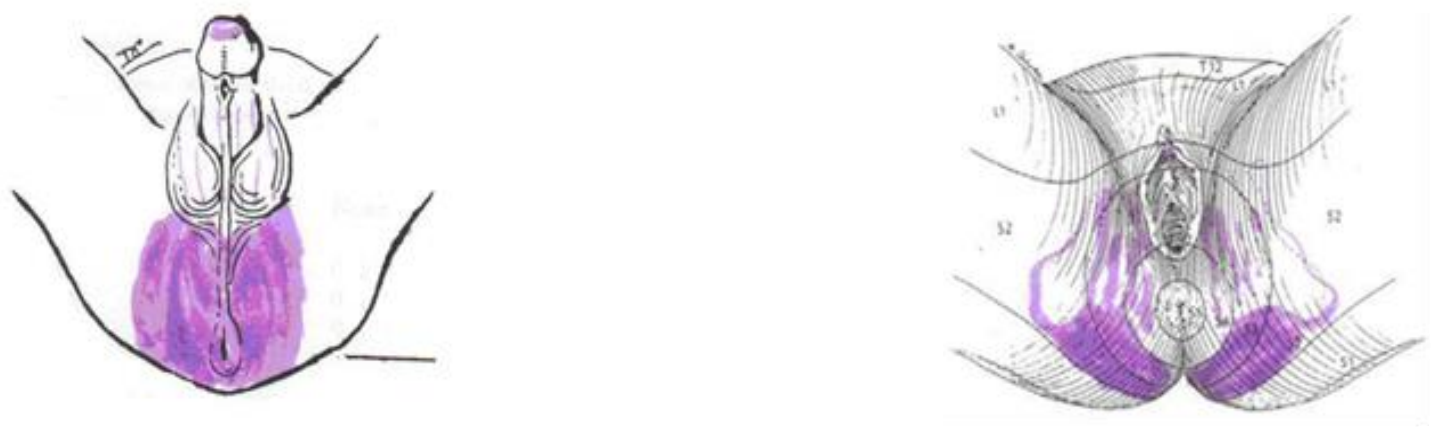

Fig. 5 Distribución típica del dolor en el SANP en hombres y mujeres. 


\subsection{DIAGNÓSTICO}

Como en cualquier otro síndrome, para su diagnóstico nos basaremos en la historia clínica, la exploración física y las pruebas complementarias.

\section{A) HISTORIA CLÍNICA}

. Dolor en territorio del nervio pudendo (perineal, rectal, clítoris/pene), uni o bilateral, que se incrementa en posición de sedestación y a lo largo del día, que no suele despertar al paciente por la noche y que disminuya de pie o tumbado. Clásicamente empeora al sentarse sobre una superficie plana y mejora en el inodoro. Además al entrevistar al paciente, llama la atención observar cómo cambia reiteradamente de posición, se sienta de lado, muestra incomodidad, etc. Como todo dolor neuropático puede definirse como quemante, eléctrico, en forma de descargas, asociado o no a prurito.

El dolor neuropático se caracteriza por distintos signos entre los que destacan:

- Allodinia: estímulo no doloroso que produce dolor.

- Formicación: sensación de insectos caminando en la piel.

- Parestesia: sensación anormal de quemazón, cosquilleo o cuerpo extraño.

- Cambios cutáneos: piel "anserina", "marmórea", "piel de naranja”.

- Hiper/hipoalgesia: respuesta aumentada/disminuida al dolor.

- Disestesia: reacción inapropiada al estímulo.

- Metestesia: respuesta prolongada al estímulo.

Disfunción sexual. En hombres, puede manifestarse en forma de dolor durante la erección, dificultad para mantenerla o dolor con la eyaculación. En las mujeres dispareunía, hipoestesia genital, etc.

Alteraciones miccionales. Puede aparecer en forma de polaquiuria, urgencia urinaria, tenesmo, incontinencia urinaria $(26) \ldots$ 
- Alteraciones de la defecación. En forma de estreñimiento, dolor desencadenado por la defecación que puede durar entre pocos minutos y una hora, incontinencia fecal (26)...

. Sensación de cuerpo extraño rectal (pelota de golf...)

En un estudio de 55 pacientes con SANP, realizado por Beco y cols (26) en 2004, se demuestra la asociación entre incontinencia fecal, incontinencia urinaria y dolor perineal. El 71\% de los pacientes presentaban asociación de dos de estos síntomas mientras que el $13 \%$ presentaban los tres.

\section{B) EXPLORACIÓN FÍSICA}

En la exploración física, lo más habitual es encontrarnos con músculos doloridos, con aumento de tono, puntos gatillo, menor umbral de respuesta a estímulos táctiles en periné y genitales, bandas tensas, etc.

Generalmente resulta dolorosa a la palpación la salida del conducto de Alcock. Asímismo se desencadena dolor al provocar compresión del nervio en puntos determinados como la espina isquiática (signo de Tinel) tal y como queda representado en la figura 6.
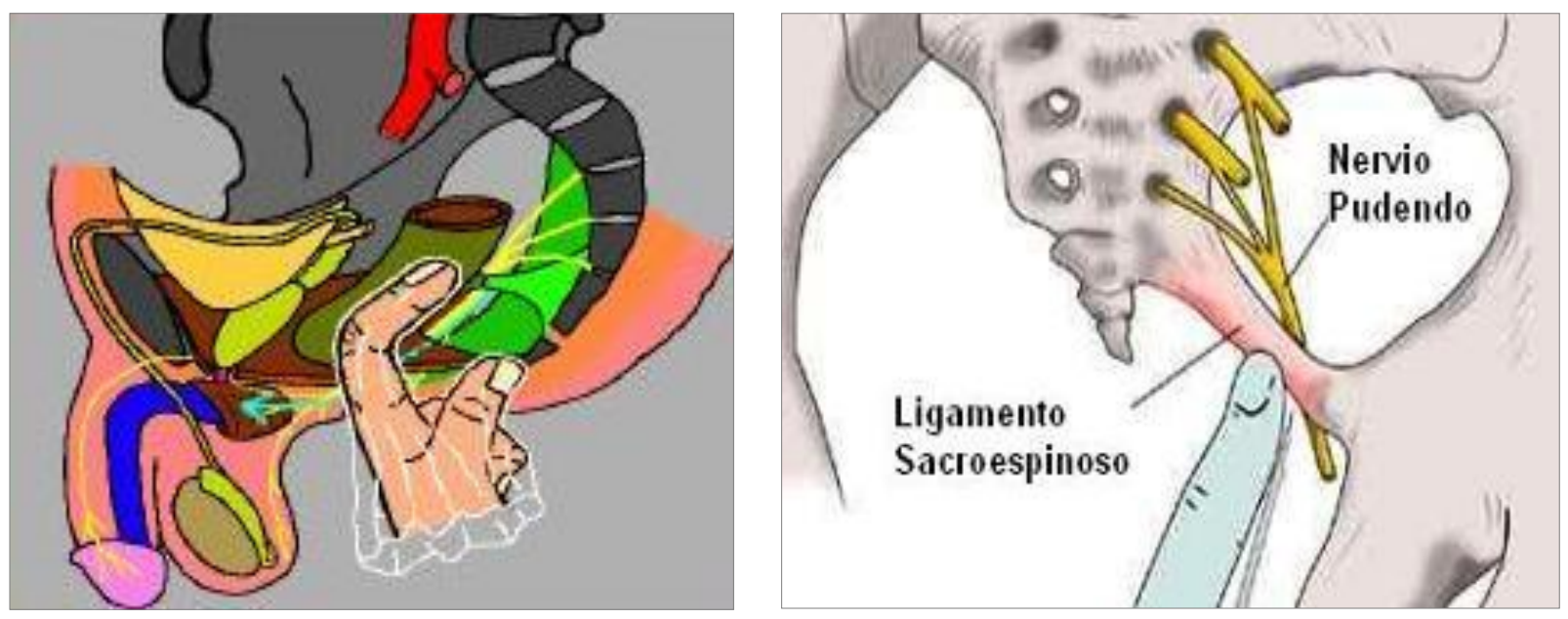

Fig. 6 Signo de TINEL. 
El "Rolling Test" o test de la pinza rodada es positivo en muchas ocasiones. Consiste en el desplazamiento de la piel y del tejido celular subcutáneo desde el ano hacia el pubis, sobre el trayecto de las ramas del nervio pudendo (fig.7). Al realizar esta maniobra en pacientes afectos de este síndrome, se reproducirá el dolor en la zona inervada (26).

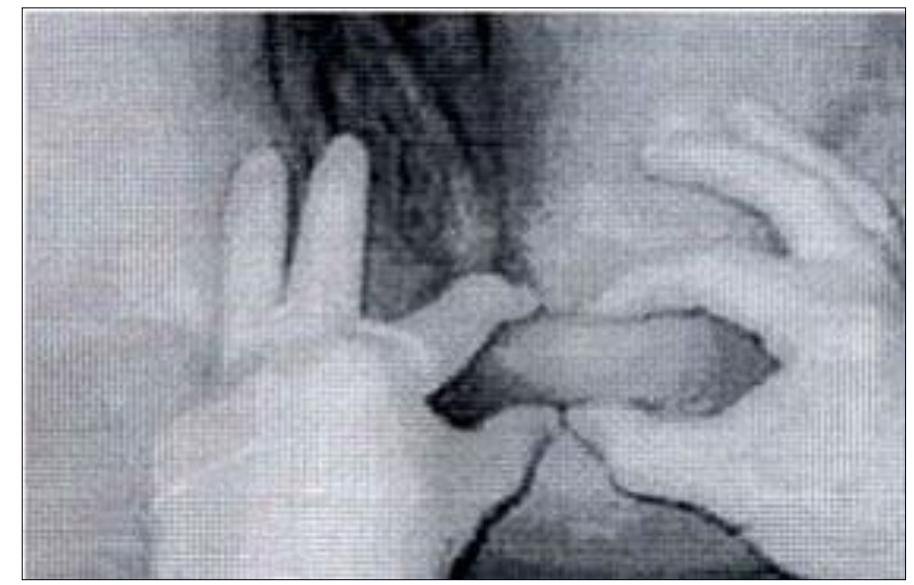

Fig.7 Rolling Test.

C) ELECTROFISIOLOGÍA

El estudio electrofisiológico del nervio pudendo abarca técnicas que examinan el funcionamiento motor, sensitivo y vegetativo del mismo, evaluando la extensión y severidad del daño presente (6,29-31). Para ello existen distintos estudios:

\section{C.1) ESTUDIO DE LA VÍA MOTORA}

También llamado Latencia Motora distal del nervio pudendo. Se trata de un test de conducción nerviosa que valora la función del nervio desde el punto de vista motor. Su fundamento es la medición de la velocidad de conducción nerviosa motora no valorando con ello la extensión de la lesión. Para esta técnica se ha desarrollado un electrodo específico en el St. Mark's London Hospital (Drs Kiff y Swash) de donde toma su nombre y que se ocupa de medir el tiempo que tarda un estímulo eléctrico en 
desplazarse desde una porción distal del nervio pudendo hasta el esfínter anal externo (fig.8). Es un sistema constituido por un estimulador bipolar fijado en el extremo distal del dedo índice de un guante y dos electrodos de registro situados a $3 \mathrm{~cm}$ de distancia. Utilizando la vía rectal se dirige el estimulador hacia la espina isquiática, quedando situado el electrodo de registro sobre el esfínter anal externo. El valor normal superior es 2,2 mseg. Si el nervio responde más despacio de lo normal, esto da una indicación de que el nervio puede estar atrapado, comprimido o dañado. Este test evalúa únicamente la función motora del nervio sin poder comprobar si las fibras sensoriales transmiten el dolor.

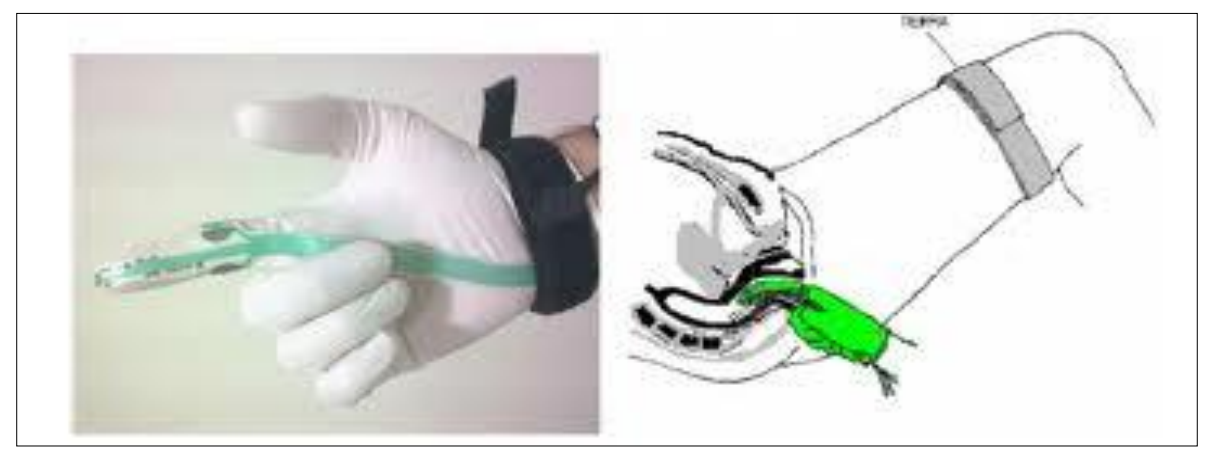

Fig 8 Electrodo y Test de St. Mark's.

\section{C.2) ESTUDIO DE LA VÍA SENSITIVA SOMÁTICA}

\section{C.2.1) UMBRALES SENSORIALES}

Mediante estímulación eléctrica creciente sobre el nervio dorsal del pene o del clítoris, determinamos el umbral de percepción y el umbral del dolor. Existen principalmente dos test sensitivos poco utilizados en nuestro medio, el Quantitative Sensitive Treshold (QST) y el Warm Treshold Detection (WTD), que se basan, a grandes rasgos, en determinar y cuantificar la sensibilidad anorrectal al estímulo eléctrico de la mucosa anal (64). 


\section{C.2.2) POTENCIALES EVOCADOS SENSORIALES DEL N. PUDENDO}

Mediante los potenciales evocados se estudia la vía sensitiva a nivel medular y periférico. Mide el tiempo que tarda un estímulo eléctrico en recorrer el nervio periférico hacia las raíces posteriores de cordones medulares posteriores y hasta que recogemos la respuesta cerebral, a nivel parietal. Este tiempo en sujetos normales se sitúa en torno a 40 milisegundos.

\section{C.3) ESTUDIO DE LA VÍA VEGETATIVA (Respuesta Simpático-Cutánea)}

El estudio de la vía autonómica se realiza mediante la estimulación de reflejos cutáneos, comparando la respuesta a nivel de la mano y los genitales. La respuesta simpático cutánea (RSC) mide la actividad refleja sudomotora con un cambio transitorio en el potencial eléctrico de la piel (64). La RSC tiene un componente central y otro periférico, y depende de un arco reflejo somato-simpático complejo con componentes medular, bulbar y suprabulbar; por esto puede verse alterada cuando existe afectación de la fibras simpáticas sudomotoras, pero también en lesiones de las vías sensoriales aferentes, de las conexiones centrales o de las propias glándulas sudoríparas. Es un reflejo multisináptico e intersegmentario, con un sistema eferente que cruza en varios niveles tanto el tronco del encéfalo como la médula espinal. Dado que la RSC puede ayudar a valorar lesiones silentes de las fibras preganglionares, se ha recomendado su uso clínico para la investigación de transtornos vegetativos en neuropatías periféricas como es el caso del SANP.

C.4) ELECTROMIOGRAFÍA DE MÚSCULOS INERVADOS POR EL NERVIO PUDENDO (bulbocavernoso, esfínter anal externo...)

Esta técnica mediante el análisis de la actividad muscular en reposo y en actividad voluntaria, nos permite determinar si existe denervación sobre la estructura muscular explorada y si el proceso es agudo o cronificado. Se puede determinar la topografía de la lesión para precisar el diagnóstico. 


\section{C.5) REFLEJOS SACROS}

La estimulación eléctrica del nervio dorsal del pene o del clítoris desencadena una contracción refleja del músculo bulbocavernoso. La medida del tiempo que tarde en establecerse el reflejo permite evaluar la conducción de las fibras motoras y sensitivas del nervio pudendo, así como de las raíces y segmentos medulares sacros de los que surge. En sujetos normales este arco reflejo se establece en un tiempo de 30-40 milisegundos. Una variación significativa de este tiempo es sugerente de lesión nerviosa.

\section{D) TÉCNICAS DE IMAGEN}

Por el momento, la Resonancia Magnética Nuclear y la Tomografía Computarizada. no son capaces de observar el trayecto de los nervios y su posible atrapamiento, pero nos puede ayudar al descartar otras patologías que pueda ser causantes de compresión nerviosa. Es fundamental obtener imágenes de la región lumbosacra y de la región pélvica para descartar entidades que puedan cursar con la misma sintomatología que el SANP, como pueden ser la endometriosis o lesiones tumorales.

\section{E) DOPPLER COLOR}

En los últimos años se está estudiando la utilización del Doppler Color orientado hacia determinados parámetros de la arteria pudenda interna como apoyo para el diagnóstico del SANP. Los valores o medidas de interés son fundamentalmente la velocidad "pico" sístólica y del tiempo de ascensión sistólico. Así, Murielle y cols (32), publicaron en 2009 un estudio de evaluación del Doppler Color frente a estudios electroneuromiográficos en el diagnóstico del atrapamiento pudendo y observaron que en 60 de 67 casos diagnosticados de SANP por electrofisiología, fueron positivos por Doppler lo que supone el $89,6 \%$ de sensibilidad y el $67,4 \%$ de especificidad, concluyendo que si bien el estudio por doppler no era el "gold stándar" para el diagnóstico del SANP podía servirnos como apoyo diagnóstico. 


\section{F) BLOQUEOS DIAGNÓSTICOS}

Consisten en la infiltración del nervio pudendo para bloquearlo o anestesiarlo confimando así el diagnóstico. Se suele utilizar anestésico como la lidocaina y se puede realizar en el glúteo para alcanzar el nervio pudendo en la espina isquiática, lugar frecuente de atrapamiento del mismo. Si el dolor disminuye o desaparece significativamente, esto es un indicador de que el nervio pudendo se encuentra comprometido de alguna manera, y en concreto que pueda estar atrapado en algún nivel de su amplio recorrido. Este bloqueo se realiza con apoyo de imagen, fundamentalmente el scanner. Esta técnica posee además efecto terapeútico que será analizado posteriormente. 


\section{CRITERIOS DIAGNÓSTICOS}

Con el objeto de uniformizar el diagnóstico se ha establecido una serie de criterios que serán el fundamento del protocolo diagnóstico del síndrome (fig.9): los criterios de Nantes (33).

Los 5 criterios diagnósticos esenciales que deben estar presentes para concluir un diagnóstico de síndrome de atrapamiento del nervio pudendo son:

\section{DOLOR EN EL TERRITORIO ANATÓMICO DEL NERVIO PUDENDO.}

Desde el ano hasta el pene/clítoris.

Se ha de excluir el dolor puramente coccígeo, púbico o sacro aunque en ocasiones el dolor del SANP puede referirse en dichas zonas.

\section{DOLOR QUE SE INTENSIFICA CON LA SEDESTACIÓN.}

El dolor se incrementa cuando el paciente se sienta, lo cual apoya la teoria del atrapamiento del nervio contra estructuras rígidas como pueden ser el proceso falciforme del ligamento sacrotuberoso.

\section{EL DOLOR NO DESPIERTA AL PACIENTE DURANTE LA NOCHE}

\section{NO EXISTE ALTERACIÓN SENSORIAL}

La presencia de alteraciones sensoriales es sugestivo de lesión del plexo sacro o incluso de lesión de la cauda equina.

\section{EL DOLOR SE ALIVIA CON EL BLOQUEO DIAGNÓSTICO DEL NERVIO PUDENDO}



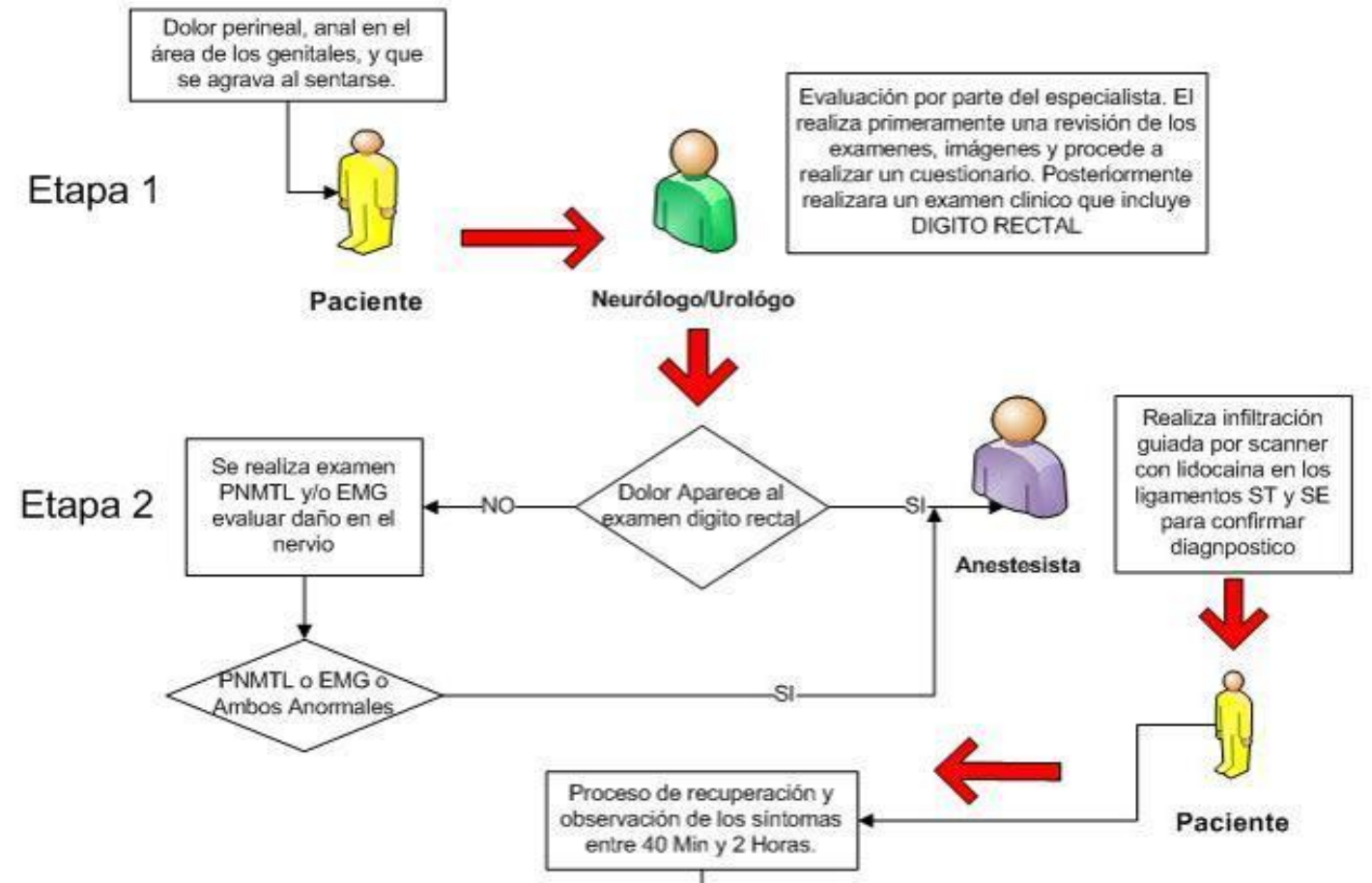

Etapa 3
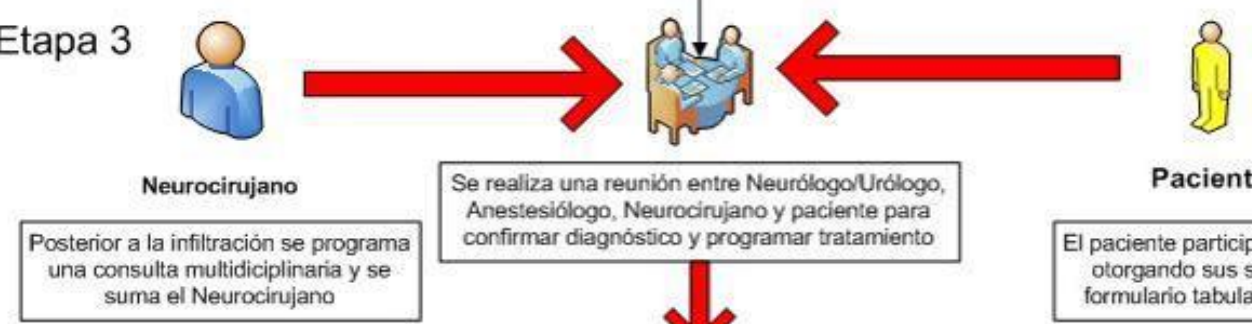

Se realiza una reunión entre NeurólogorUrólogo, Anestesiólogo, Neurocirujano y paciente para
confirmar diagnóstico y programar tratamiento

Paciente suma el Neurocirujano
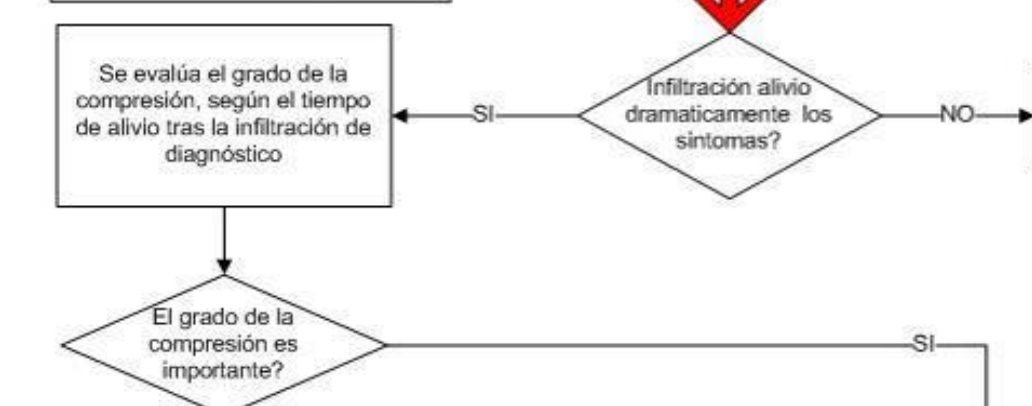

\section{Etapa 4}

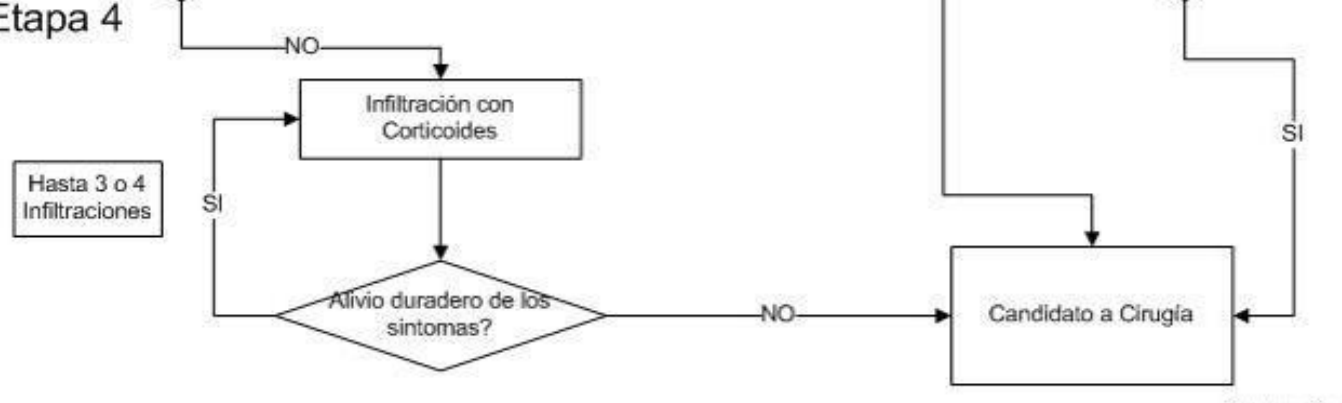

Fig. 9 Diagnóstico del SANP : Protocolo de NANTES. 
Existen además criterios diagnósticos complementarios como pueden ser:

. Sensación de quemazón, entumecimiento, etc del territorio inervado por el nervio.

\section{. Alodinia o hiperpatía}

. Sensación de cuerpo extraño a nivel rectal o vulvar (simpatalgia)

. Empeoramiento del dolor durante el día

. Dolor predominantemente unilateral

. Dolor desencadenado durante la defecación

. Hipersensibilidad a la palpación de la espina isquiática, en lo que se basa el signo de Tinnel.

\section{. Criterios neurofisiológicos}

Bautrant y cols. (22) colaboró en la creación de una tabla de criterios diagnóstico aunque fundamentándose en los Criterios de Nantes antes mencionados. Así considera diagnóstico de SANP la suma de:

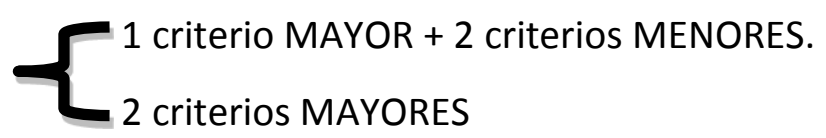

\section{A) CRITERIOS MAYORES}

1. Área dolorosa en terminación del nervio pudendo.

2. Reproducción del dolor al presionar el tronco del nervio pudendo (signo de Tinel)

3. Mejoría de al menos 12 horas tras inyección de lidocaína en lugares anatómicos concretos del recorrido del nervio pudendo.

\section{B) CRITERIOS MENORES}

1. Dolor con características neuropáticas.

2. Existencia de una posición dolorosa y/o antiálgica (empeora sentado, mejora tumbado).

3. Existencia de un factor etiológico: trauma, cirugía, parto, caída, deporte, etc.

4. Ausencia de otra causa de dolor en área pélvica, como puede ser la endometriosis, miomas uterinos o la presencia de fibromas uterinos. 
Asimismo para ayudar a la emisión de un diagnóstico certero, han de existir unos CRITERIOS DE EXCLUSIÓN entre los que se cita:

- Dolor exclusivamente coccígeo, glúteo, púbico o hipogástrico. Estas zonas no se corresponden con el territorio anatómico del nervio pudendo.

. Prurito. Es altamente sugestivo de lesión dermatológica.

- Dolor exclusivamente paroxístico

. Existen además signos que, pese a no ser diagnósticos del SANP, no excluyen su presencia:

- Dolor glúteo al sentarse.

- Dolor referido a la espina ciática.

- Dolor referido a la región medial del muslo.

- Dolor suprapúbico.

- Dolor con la eyaculación

- Dispareunía o dolor tras el acto sexual

- Disfunción eréctil.

. Pruebas neurofisiológicas normales

\subsection{DIAGNÓSTICO DIFERENCIAL}

En primer lugar, para emitir el diagnóstico de SANP se ha de excluir la posilidad de patología orgánica que justifique la sintomatología del paciente entre otras: endometriosis, adenomiosis, estreñimiento, tumores, metástasis, alteraciones vasculares, y otras lesiones que puedan provocar compresión o invasión del canal de Alcock $(34,35)$. 


\subsection{TRATAMIENTO}

Como se puede deducir de todo lo dicho anteriormente, al tratarse de un síndrome complejo, desconocido por muchos médicos, se ha de ser muy cauteloso a la hora de iniciar un tratamiento dejándolo en manos de los especialistas. Asimismo, el tratamiento ha de ser secuencial aplicando medidas en orden creciente de agresividad y replanteándose continuamente la buena o mala respuesta a las herramientas terapéuticas utilizadas.

En los protocolos internacionales, se dice que el tratamiento de este síndrome se compone de tres grandes pilares: tratamiento sintomático del dolor, infiltraciones y cirugía. La aplicación de una u otra medida dependerá, como en cualquier otra patología, de la situación personal de cada paciente teniendo en cuenta la variedad interpersonal de la misma patología.

\section{A. TRATAMIENTO MÉDICO}

\section{A.1 TRATAMIENTO SINTOMÁTICO DEL DOLOR}

Existen distintos fármacos, con distintos mecanismos de acción, enfocados únicamente a paliar el síntoma principal: el dolor. Se trata fundamentalmente de antidepresivos, entre ellos la amitriptilina, los antiepilépticos de última generación como la gabapentina o preglabalina o incluso anestésicos locales como la lidocaína al $5 \%$ en gel o parches (36). En general, la amitriptilina suele ser el primer fármaco que se viene utilizando en estos pacientes, y el que mejor resultados está ofreciendo hasta el momento actual $(37,38)$. El mecanismo por el cual este fármaco actúa sobre el dolor parece ser por la inhibición de la recaptación de noradrenalina y serotonina en los terminales presinápticos, activando de esta forma los sistemas inhibitorios del dolor endógeno en el cerebro que moderan la transmisión del dolor a las células de la médula espinal.

En 2005 Sator-Katzenschlager et al. (40) publicaron un estudio en el que se comentaba el efecto de la gabapentina para la mejora significativa, sola o en combinación con amitriptilina, en el tratamiento del dolor de este síndrome. 
Entre las benzodiacepinas utilizadas en este síndrome destaca el clonazepam (comenzando con dosis de 0,25 $\mathrm{mg}$ /día y aumentado 0,25/ semana hasta un máximo de 5-20 mg/ día) no considerándose ineficaz hasta que pasen 4 semanas desde el comienzo de su administración. Tal y como publican autores como Benson et al. (39), de cualquier modo, la respuesta a este tipo de tratamiento es de ligera a moderada mejoría con discretas variaciones entre pacientes.

Si se opta únicamente por este tipo de tratamiento no hay que perder de vista que en ningún caso solucionará el origen o la causa que ha ocasionado el síndrome, únicamente se paliará el síntoma, mejorando con ello la calidad de vida del paciente.

\section{A.2 TRATAMIENTO CON INFILTRACIONES CORTICOIDEAS- LIDOCAÍNA}

Se trata fundamentalmente de infiltraciones en la región perineural con la combinación de corticoides y anestésicos locales del tipo lidocaína / bupivacaína en el espacio interligamentoso y canal de Alcock (fig.10). Puede practicarse de forma uni o bilateral. Normalmente se realiza mediante la guía de una prueba de imagen (fig.11) como ultrasonidos o la tomografía computerizada $(41,42,43)$ aunque también en ocasiones se realiza guiado por tacto (transperineal) (fig.12-13).

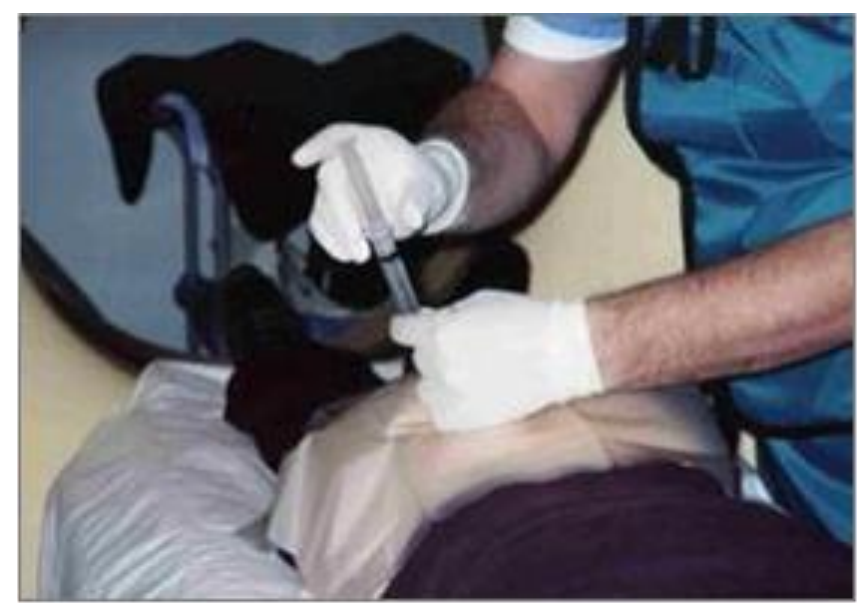

Fig.10 Técnica de infiltraciones corticoideo-anestésicas en el SANP 


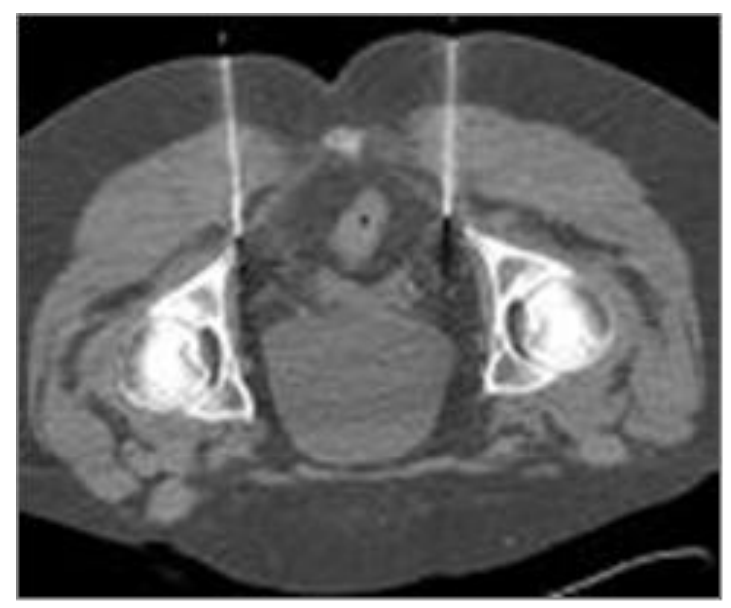

Fig.11 Infiltraciones del nervio pudendo guiadas por TAC.

Con este tratamiento suelen mejorar los síntomas en un alto porcentaje de pacientes con una duración que oscila entra las horas, semanas, meses e incluso la curación completa en determinados pacientes. El éxito de esta técnica es muy dependiente del profesional que la lleve a cabo, dado que sólo serán completamente satisfactorias aquellas que se practiquen en la región anatómica exacta, salvando las variaciones de la anatomía entre pacientes. Se suelen repetir cada 4 a 6 semanas hasta un máximo de 3 infiltraciones y en aquellos pacientes en los que no se observa mejoría se plantea el siguiente escalón en el arsenal terapéutico, la cirugía (22). Según series, el porcentaje de éxito suele ser del $70 \%$ aunque la desaparición total y absoluta de los síntomas se produce únicamente en el 15 al $20 \%$ de los casos.

Una variación de esta técnica es la desactivación de los puntos gatillo de los músculos afectados por la patología del nervio pudendo, consiguiendo la disminución de la sintomatología. Para ello, se suele utilizar infiltraciones locales de lidocaína (44).

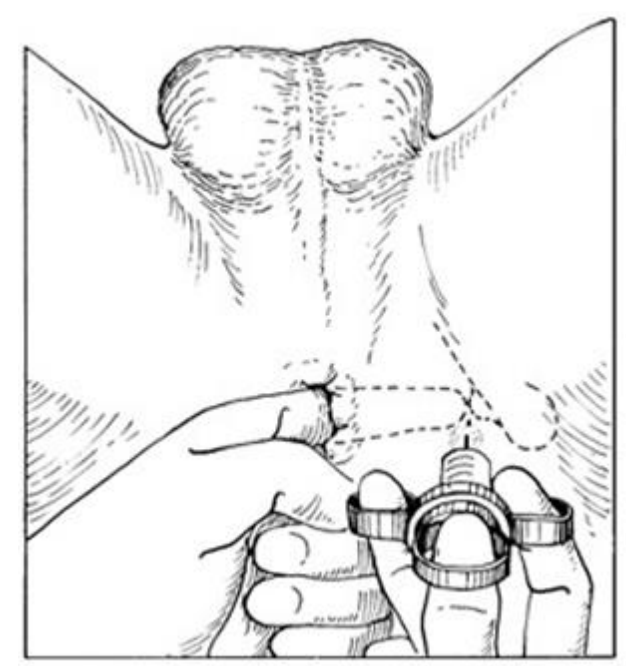

Fig. 12 Infiltración del nervio pudendo guiada por tacto rectal. 


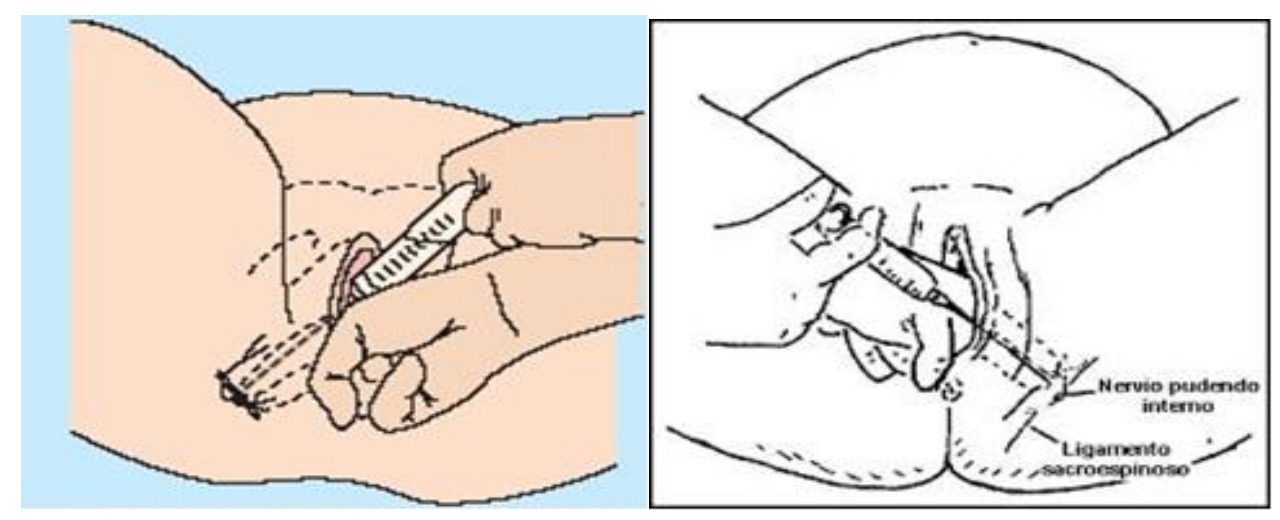

Fig.13 Técnica de infiltración guiada por tacto rectal (transperineal)

\section{A.3 TRATAMIENTO FISIOTERÁPICO}

Siguiendo el fundamento del atrapamiento nervioso, que puede depender de muchos y variados factores, la fisioterapia del suelo pélvico puede mejorar la sintomatología en determinados pacientes, no sólo por aliviar el dolor, sino por observarse mejoría en el ámbito de la disfunción urinaria, sexual, alteraciones sensoriales, etc $(45,46)$. El fundamento de este tratamiento es la movilización y consiguiente hipertrofia, aumento de tono y de fuerza de contracción de la musculatura del suelo pélvico.

\section{A.4 TRATAMIENTO CON TOXINA BOTULÍNICA}

En los últimos años se ha investigado el uso de la toxina botulínica en el tratamiento de la proctalgia fugax (dolor anorrectal intenso sin causa orgánica aparente) consiguiéndose el alivio del dolor como síntoma principal, con lo que, en principio, pudiera considerarse útil para el tratamiento del SANP. En este sentido, Sánchez Romero (47), publicó un estudio prospectivo en el que mediante la infiltración con toxina botulínica en 5 pacientes afectos de proctalgia fugax, se consiguió la curación, manteniéndose sin dolor hasta el final del seguimiento por lo que concluyen que la toxina botulínica puede considerarse como una potencial terapia para la proctalgia fugax con alta tasa de curación y sin complicaciones constatadas. Así, se podría intentar extender su ámbito de aplicación a los pacientes afectos de SANP rebeldes a otras terapias, aunque actualmente no ha sido comprobado científicamente. 


\section{B. TRATAMIENTO QUIRÚRGICO}

Partiendo del origen del problema, la compresión del nervio pudendo, su tratamiento quirúrgico tiene por objeto la descompresión del mismo. Al tratarse de un nervio complejo con un largo recorrido, muchos pueden ser los hallazgos operatorios que justifiquen su compresión, entre los que destacan (48):

. Ligamentos hipertróficos.

. Ligamentos fusionados (funicular).

. Adherencias.

. Bandas fibrosas que atraviesan el nervio.

. Unión y compresión contra el ligamento sacrotuberoso.

- Ramificación proximal: rama rectal inferior que penetra el ligamento sacroespinal.

. Tronco nervioso principal atravesando el músculo coccígeo.

. Espina isquiática elongada.

Así pues, resumiendo lo comentado anteriormente podemos señalar que los lugares más comunes de atrapamiento del nervio pudendo, con gran importancia para el tratamiento quirúrgico del SANP, son $(49,50)$ :

. 70\% entre el ligamento sacroespinoso y el ligamento sacrotuberoso, también conocido como pìnza interligamentosa.

. 20\%. en el canal de Alcock.

. $10 \%$ en el diafragma urogenital (nervio dorsal)

. En el $20 \%$ de los casos puede existir simultáneamente afectación en la pinza interligamentosa y en el canal de Alcock. 
Con respecto a la incidencia de la lesión nerviosa según la zona, se reparte de la siguiente forma (51):

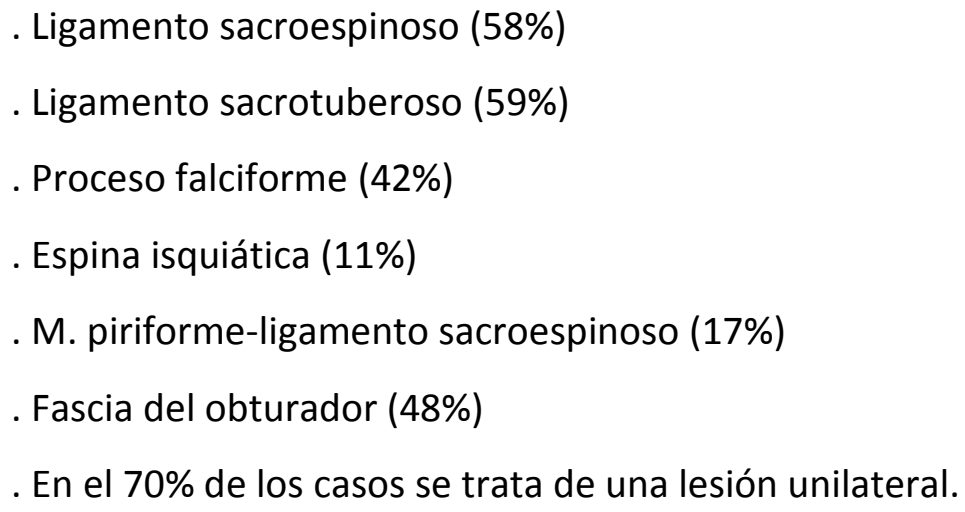

Como hemos comentado anteriormente, el tratamiento quirúrgico está dirigido a la descompresión del nervio, en la región anatómica que corresponda, seccionando, si procede, el ligamento sacroespinoso, liberando el nervio de la pinza interligamentosa y liberándolo también del canal de Alcock, para lo cual es abierto dicho tunel.

En el momento actual se definen tres vías quirúrgicas de abordaje:

\section{B.1 TÉCNICA TRANSPERINEAL}

B. 2 TÉCNICA TRANSGLÚTEA

B.3 TÉCNICA TRANSVAGINAL 


\section{B.1 TÉCNICA TRANSPERINEAL (Procedimiento Shafik)}

Descrita por Shafik en 1991, se trata de un procedimiento sencillo desde el punto de vista técnico, que comienza por una pequeña incisión paraanal, a través de la cual se accede a la fosa isquiorrectal y se sigue el trayecto del nervio rectal inferior hasta su entrada en el canal de Alcock, donde ayudados de una tijera, se hará un pequeño corte en la fascia del músculo obturador interno, que se despegará mediante disección digital, liberando así todo el trayecto comprometido del nervio pudendo (2, 52). En caso necesario, se puede tener acceso al espacio interligamentoso (fig.14).

Este procedimiento es de corta duración (aproximadamente 5-10 minutos por cada lado) y no se realiza sección de ligamentos pudiéndose efectuar de manera ambulatoria. En esta técnica se respeta el músculo elevador del ano. Tiene las ventajas de que es segura y sin complicaciones significativas pero tiene el inconveniente que es un procedimiento a ciegas con dificultad para aprenderlo y enseñarlo.

En casos en que, tras la realización de este procedimiento persista el dolor o las latencias distales elevadas, se puede realizar, mediante esta técnica, la liberación de la pinza interligamentosa obteniendo en determinados casos resultados favorables.

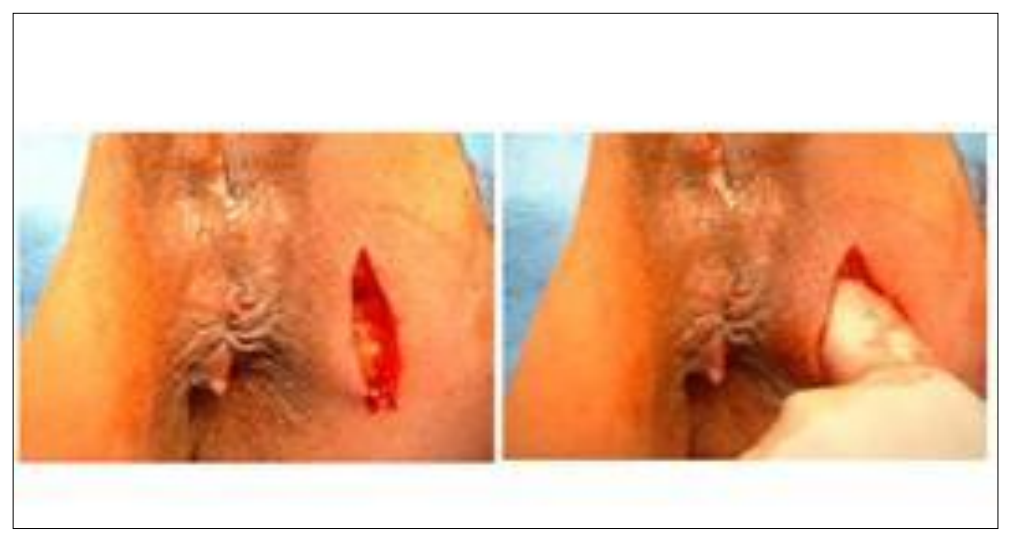

Fig. 14 Técnica transperineal (procedimiento de Shafik)

Cabe señalar que en el año 1997, Shafik publica su experiencia sobre el abordaje endoscópico del SANP mediante un estudio aplicado en 9 mujeres concluyendo que, la vía endoscópica para descompresión del nervio pudendo, es una vía fácil, sencilla y segura, que permite una mejor exposición del contenido de la fosa isquiorrectal que el procedimiento abierto, minimizando así el riesgo de lesión del nervio pudendo o de alguna de sus ramas (55) 


\section{B.2 TÉCNICA TRANSGLÚTEA}

Esta técnica fue descrita por el profesor Robert (Nantes, Francia) y se trata de un procedimiento sencillo, mediante la realización de una incisión transglútea de unos $7 \mathrm{~cm}$, siendo el objetivo fundamental, la sección de la pinza interligamentosa producida entre el ligamento sacroespinoso y sacrotuberoso, que, como se dijo anteriormente, es la responsable del $70 \%$ de los casos de SANP $(49,53,54)$. También en esta técnica se considera la liberación del nervio pudendo durante su recorrido en el canal de Alcock. Requiere de 2 a 3 días de hospitalización y vuelta a la vida laboral en un periodo que abarca desde los 10 días hasta los 3 meses. El postoperatorio no es muy doloroso y una de las principales ventajas de esta técnica sobre la técnica transperineal , es la visualización del nervio y el fácil acceso a la pinza interligamentosa (fig.15).

En general, Robert señala que tras 400 intervenciones realizadas, no ha tenido complicaciones significativas salvo retención urinaria en aproximadamente el $5 \%$ de los pacientes, y las mejorías resultaron evidentes durante el seguimiento efectuado a lo largo de 4 años, aunque reconoce, que en algunos casos es necesario el tratamiento rehabilitador.

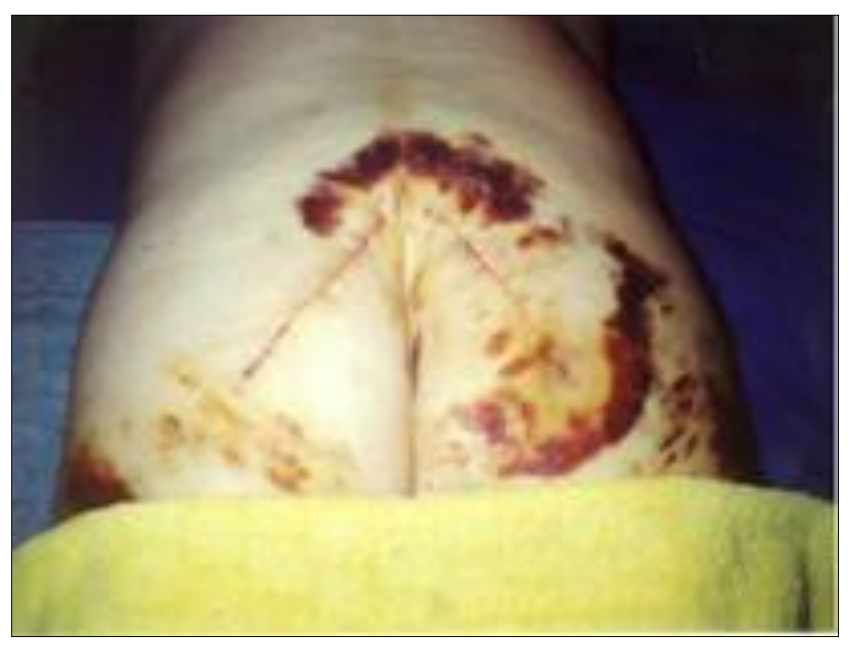

Fig. 15 Técnica transglútea. 


\section{B.3 TÉCNICA TRANSVAGINAL O TRANSISQUIORRECTAL}

Este procedimiento fue descrito por Bautrant hacia el año $2000(22,56)$ y se realiza por vía transvaginal en las mujeres y por vía transisquiorrectal en varones (fig.16). Mediante este procedimiento tenemos acceso, a través de la fosa isquiorrectal, a los tres segmentos anatómicos del nervio mencionados anteriormente. El paciente se encuentra en posición de litotomía. La disección del espacio isquiorrectal permite exponer la cara medial de cada lado de la pelvis, después de rechazar el recto y el elevador del ano. El fundamento de esta técnica en la descompresión de los lugares que produzcan compresión nerviosa por lo que no existe neurolisis ni disección cercana al nervio. La descompresión suele comenzar con la apertura del canal bajo el músculo piriforme, en el borde inferior del ligamento sacroespinoso, consiguiendo así alcanzar el tejido adiposo perineural y permitiendo la exploración de las posibles zonas de compresión nerviosa. Alrededor del $90 \%$ de los casos, se efectúa la sección del ligamento sacroespinoso con el objeto de liberar la pinza interligamentosa. En caso de ser preciso, se puede continuar la intervención con la sección del proceso falciforme del ligamento sacrotuberoso hasta penetrar en el canal de Alcock completando, mediante disección digital, la liberación del nervio durante su recorrido en el mencionado canal. Generalmente, se deja drenaje en la región isquiorrectal durante las primeras 48 horas con el objeto de prevenir la formación de hematomas en dicha zona.

Los pacientes intervenidos mediante esta técnica presentan durante su postoperatorio dolor intenso en la región glútea en el $38 \%$ de los casos, que parece atribuirse a la sección del ligamento sacroespinoso y a afectación de pequeñas ramas nerviosas. Este dolor disminuye paulatinamente durante el primer mes postoperatorio.

Con esta técnica, el promedio de hospitalización es de 3 a 4 días y todo el proceso terapéutico ha de acompañarse de rehabilitación mediante quinesiterapia y reeducación perineal. La regeneración nerviosa suele objetivarse en los siguientes 6 a 18 meses. 


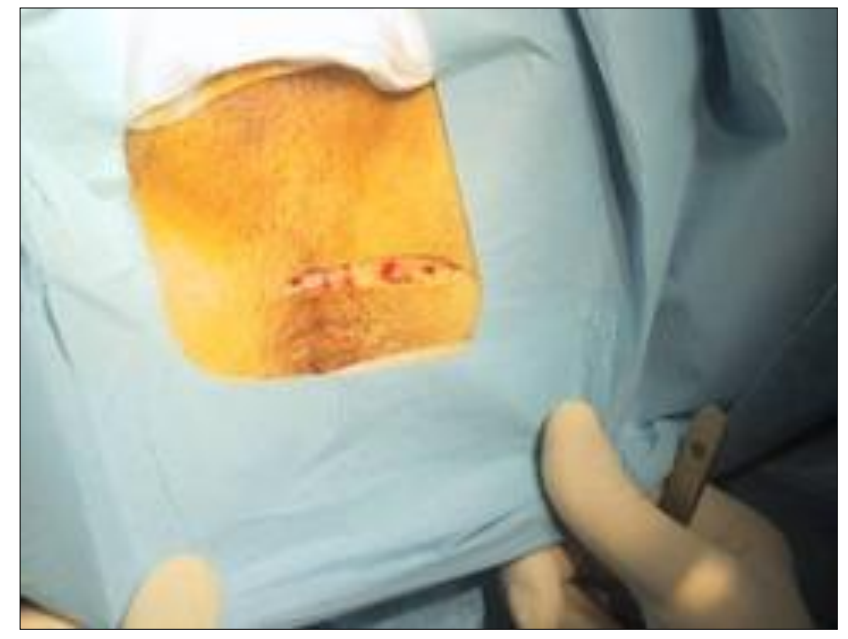

Fig. 16 Técnica transvaginal.

En la siguiente tabla puede observarse comparativamente las distintas vias de abordaje quirúrgico de esta patología comentadas anteriormente:

\begin{tabular}{|c|c|c|c|}
\hline & TRANSPERINEAL & TRANSGLÚTEA & TRANSVAGINAL \\
\hline INCISIÓN & Pequeña & Extensa & Pequeña \\
\hline $\begin{array}{ll}\text { CONTROL } & \text { VISUAL } \\
\text { DEL } & \text { CAMPO } \\
\text { OPERATORIO }\end{array}$ & - & ++ & +++ \\
\hline $\begin{array}{l}\text { ACCESO AL CANAL } \\
\text { DE ALCOCK }\end{array}$ & +++ & + & ++ \\
\hline $\begin{array}{l}\text { SECCIÓN DE LIG. } \\
\text { SACROESPINOSO }\end{array}$ & SIN & $\mathrm{CON}$ & $\mathrm{CON}$ \\
\hline $\begin{array}{l}\text { EFECTO SOBRE } \\
\text { CONTINENCIA }\end{array}$ & SI & ¿? & ¿? \\
\hline INCONVENIENTES & $\begin{array}{l}\text { Procedimiento } \\
\text { ciego.Dificil } \\
\text { aprendizaje }\end{array}$ & $\begin{array}{l}\text { Sección de } \\
\text { ligamento puede } \\
\text { ocasionar } \\
\text { disbalance de artic. } \\
\text { sacroiliaca. }\end{array}$ & $\begin{array}{l}\text { Sección de } \\
\text { ligamento puede } \\
\text { ocasionar } \\
\text { disbalance de artic. } \\
\text { sacroiliaca. }\end{array}$ \\
\hline
\end{tabular}

TABLA I. COMPARACIÓN DE LAS TRES PRINCIPALES VÍAS QUIRÚRGICAS DE ABORDAJE EN LA DESCOMPRESIÓN DEL NERVIO PUDENDO 


\section{COMPLICACIONES POSTOPERATORIAS}

Las complicaciones descritas en la cirugía descompresiva del nervio pudendo son menores, entre las que destacan (23):

. INFECCIOSAS: infección del tracto urinario (7\%), abscesos $(2,5 \%)$.

. HEMORRÁGICAS: debidas sobre todo a lesión de alguna rama de la arteria pudenda.

. No se ha demostrado la teórica desestabilización y consiguiente sobrecarga de la articulación sacroiliaca. 


\subsection{LITERATURA PUBLICADA}

A medida que se ha ido avanzando en el conocimiento de este síndrome, estableciendo unos criterios diagnósticos claros, y ampliando el abanico terapéutico, se han incrementado las series de pacientes publicadas. Las fundamentales han sido:

. Robert (53): 400 descompresiones desde 1989.

. Bautrant (22): 104 descompresiones.

. Beco (57): 74 descompresiones.

. Mouchel (58): 192 descompresiones.

. Popeny (48): 58 descompresiones.

Otros datos referentes a publicaciones relacionadas con la descompresión del nervio pudendo pueden observarse en la siguiente tabla:

\begin{tabular}{|l|l|l|l|l|l|l|l|}
\hline AUTOR & TRABAJO & AÑO & $\begin{array}{l}\text { NÚMERO } \\
\text { PACIENTES }\end{array}$ & $\begin{array}{l}\text { SEGUIMIENTO } \\
\text { MÁXIMO }\end{array}$ & MEJORIA & $\begin{array}{l}\text { MEJORIA } \\
\text { PARCIAL }\end{array}$ & $\begin{array}{l}\text { SIN } \\
\text { CAMBIOS }\end{array}$ \\
\hline BASCOM & $\begin{array}{l}\text { Prospectivo } \\
\text { descriptivo }\end{array}$ & 1988 & 7 & 19 MESES & $45 \%$ & $33 \%$ & $22 \%$ \\
\hline BAUTRANT & $\begin{array}{l}\text { Prospectivo } \\
\text { descriptivo }\end{array}$ & 2003 & 104 & 1 AÑO & $62 \%$ & $23 \%$ & $15 \%$ \\
\hline BECO & $\begin{array}{l}\text { Retrospectivo } \\
\text { comparativo }\end{array}$ & 2004 & 74 & 9 AÑOS & $61,10 \%$ & $13,60 \%$ & $22,3 \%$ \\
\hline ROBERT & $\begin{array}{l}\text { Controlado } \\
\text { randomizado }\end{array}$ & 2005 & 25 & 4 AÑOS & $71,40 \%$ & $12,60 \%$ & $16 \%$ \\
\hline BENSON & $\begin{array}{l}\text { Descriptivo } \\
\text { retrospectivo }\end{array}$ & 2005 & 10 & 2 AÑOS & $60 \%$ & - & - \\
\hline
\end{tabular}

TABLA II. EXPOSICIÓN DE SERIES PUBLICADAS BASADAS EN CIRUGÍA DESCOMPRESIVA DEL NERVIO PUDENDO (50) 


\subsection{DOLOR PERSISTENTE TRAS DESCOMPRESIÓN}

Según Weiss $(51,59)$, la persistencia de dolor tras la descompresión puede deberse a alguna de las siguientes causas:

.Puntos gatillo miofasciales en suelo pélvico que podían estar presentes preoperatoriamente y se agravan tras la intervención.

Sensibilidad del tejido celular subcutáneo.

.Disfunción de la articulación sacroiliaca tras la sección de los ligamentos sacroespinoso y sacrotuberoso.

.Patología intrínseca de las ramas del nervio pudendo. Muy resistente al tratamiento. .Otros: sensibilización central, stress, insomnio, hormonas, dieta.... 


\section{MATERIAL Y MÉTODOS}




\subsection{SELECCIÓN DE PACIENTES}

Los pacientes estudiados han sido derivados al Servicio de Cirugia General del Hospital Universitario de Burgos desde el propio hospital de Burgos y de centros hospitalarios del resto de Castilla y León, y de otras comunidades autónomas.

El periodo de estudio comprende desde el 1 de Junio de 2011 hasta el 30 de Junio de 2013.

Este estudio está constituido por el siguiente grupo de pacientes:

- 53 pacientes que presentan PROCTALGIA y que cumplen los Criterios de Nantes (33) para ser incluidos dentro del SÍNDROME DE ATRAPAMIENTO DEL NERVIO PUDENDO. A todos ellos se les ha practicado PUNCIÓN del nervio pudendo según técnica descrita en el apartado 4.6.

- Para la evaluación de los resultados de la infiltración hemos utilizado la Escala Visual Analógica del dolor (EVA) en tres momentos de la historia clínica del paciente:

- $\quad$ Nivel basal de dolor

- Tiempo inmediato post-punción ( a la primera hora postpunción).

- $\quad$ Evaluación en el seguimiento a partir de los 6 meses mediante entrevista clínica.

Para llevar a cabo el presente estudio se remitió proyecto al Comité Ético de Investigación del Hospital Universitario de Burgos, siendo aprobado para su realización con el número de orden del CEIC: 1026. 


\subsection{ENTREVISTA CLÍNICA}

La recogida de datos clínicos se realizó mediante entrevista personal, en la que, una vez revisada la historia clínica de forma exhaustiva, se interroga al paciente sobre:

- ANTECEDENTES PERSONALES: con especial interés a los antecedentes quirúrgicos colorrectales, ginecológicos, profesionales y otros antecedentes médicos potencialmente relacionados con el dolor crónico.

PROCTALGIA: se valora la presencia de proctalgia y la intensidad de la misma según la escala EVA.

La escala EVA permite medir la intensidad del dolor que describe el paciente con la máxima reproductibilidad entre los observadores. Consiste en una línea horizontal de 10 centímetros, en cuyos extremos se encuentran las expresiones extremas de un síntoma. En el izquierdo se ubica la ausencia o menor intensidad y en el derecho la mayor intensidad. Se pide al paciente que marque en la línea el punto que indique la intensidad y se mide con una regla milimetrada. La intensidad se expresa en centímetros o milímetros.

Sin dolor Máximo dolor

0 puntos 10 puntos

Hemos decidido utilizar esta escala porque su uso es universal en el ambiente científico actual. Es un método relativamente simple, que exige poco tiempo, aun cuando requiere de un cierto grado de comprensión y de colaboración por parte del paciente. Tiene buena correlación con las escalas descriptivas, buena sensibilidad y es fácilmente reproducible. 
Se constata la presencia de otros síntomas en relación con las otras ramas del nervio que pueden estar presentes en el síndrome:

- Rama ANTERIOR: presencia o no de sintomatología sexual del tipo dispareunia, eyaculación dolorosa, fenómeno "arousal", vulvodinia,...etc

- Rama MEDIA: presencia o no de sintomatología urológica del tipo incontinencia urinaria, cistalgia, urgencia miccional, dolor perineal....

- Rama POSTERIOR: además de la proctalgia se tendrá en cuenta presencia o no de otros síntomas rectales como formicación, incontinencia, urgencia defecatoria, etc.

\subsection{EXPLORACIÓN FÍSICA}

Se constatará la presencia de los siguientes signos (descritos en apartado 3.6 del marco teórico) :

- SIGNO DE TINEL: afirmativo o negativo. Uni o bilateral

- ROLLING Test: afirmativo o negativo. Uni o bilateral

- Presencia de otros datos significativos: hipertonía del esfínter, aspecto de la piel (piel anserina), etc.

\subsection{PRUEBAS ESPECÍFICAS}

- Test de LATENCIA MOTORA DISTAL DEL NERVIO (St. Mark's): se observará si resulta o no patológico y la lateralidad de la lesión.

Como se comentó en el apartado 3.6, el valor normal es superior a 2,2 mseg. Si el nervio responde más despacio de lo normal, esto da una indicación de que el nervio puede estar atrapado, comprimido o dañado. 


\subsection{PRUEBAS COMPLEMENTARIAS}

Como pruebas complementarias se han utilizado pruebas de imagen previas para el diagnóstico diferencial con otras patologías que pueden cursar con dolor analperianal, fundamentalmente la ecografia endorrectal, TAC, RMN y estudios urodinámicos (tabla III).

\begin{tabular}{|l|l|}
\hline MEDIOS DIAGNÓSTICOS & PACIENTES (n=53) \\
\hline HISTORIA CLINICA; EXPL. FISICA & TODOS (53) \\
\hline ST. MARK'S & TODOS (53) \\
\hline ECOGRAFIA ENDORRECTAL & 49 \\
\hline TAC PELVIS & 14 \\
\hline RMN PELVIS & TODOS (53) \\
\hline ESTUDIOS URODINÁMICOS & 41 \\
\hline
\end{tabular}

TABLA III. MEDIOS DIAGNÓSTICOS UTILIZADOS EN EL ESTUDIO

\subsection{TRATAMIENTO}

\section{A. TRATAMIENTOS PREVIOS DEL DOLOR}

- Se constatará la prescripción de tratamiento analgésico (antiinflamatorios, pregabalina, etc)

B. TRATAMIENTO DEL DOLOR CRÓNICO GRAVE

- Basado fundamentalente en el Neuromodulador sacro

- Neuroestimulación de otras raíces nerviosas.

C. TRATAMIENTO CON PUNDIONES CORTICOIDEO ANESTÉSICAS

- Detallado a continuación 


\section{DESCRIPCIÓN DE LA TÉCNICA DE PUNCIÓN CORTICOIDEO-ANESTÉSICA UTILIZADA COMO TRATAMIENTO EN NUESTRA SERIE}

Consiste fundamentalmente en la punción-hidrodistensión de la región perineural, dentro del canal de Alcock con una combinación de corticoides y anestésicos locales del tipo Ropivacaína al 0,2 \% a nivel del tronco y de las tres ramas terminales del nervio pudendo.

Para el bloqueo de las ramas nerviosas es esencial un exacto conocimiento anatómico del recorrido del nervio, utilizando valiosas referencias anatómicas fundamentales como son la tuberosidad isquiática y los ligamentos sacroespinosos y sacrotuberosos.

Resulta de gran ayuda la realización del tacto rectal para localizar dichos puntos anatómicos y llevar a cabo la técnica (fig.17).

La punción puede llevarse a cabo de forma unilateral, o en la mayor parte de las ocasiones y en toda nuestra serie, de manera bilateral.

La posición anatómica utilizada es la de litotomía por vía transdérmica.

Siempre se utiliza como guía la combinación de ecografía transanal con el neuroestimulador de nervios periféricos.

La punción se repite a la semana de la primera punción y pasadas dos semanas de la segunda punción hasta un total de 3 infiltraciones.

En aquellos pacientes en los que no se observa mejoría significativa de la clínica, se plantea una segunda "tanda" de punciones repitiendo el patrón descrito.

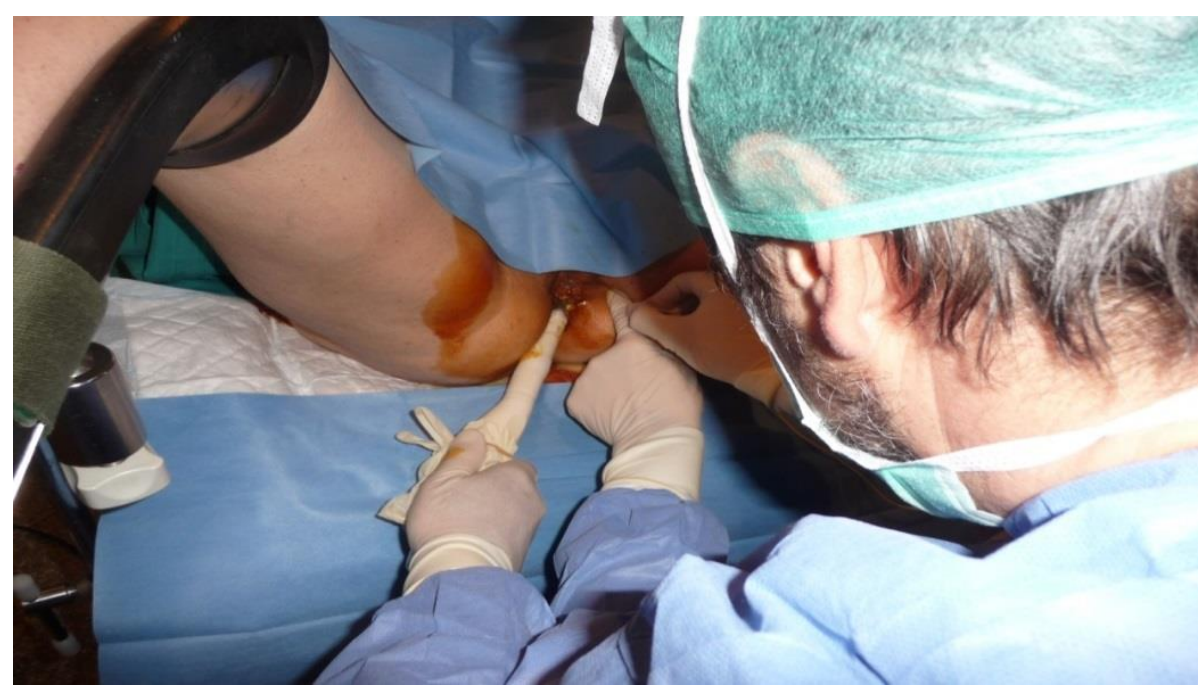

Fig. 17 Imagen real de la punción corticoideo anestésica.

\subsection{SEGUIMIENTO}


Se realiza nueva entrevista clínica a partir de los 6 meses tras la primera punción y se anotarán los siguientes aspectos:

. Tiempo que ha pasado desde la última infiltración

. Síntomas presentes (de rama anterior, media o posterior..)

. Si presenta PROCTALGIA, en puntuación según escala EVA.

. Tratamientos actuales

. Pruebas o tratamientos pendientes.

. Indicación de una segunda "tanda" de punción según presenten o no clínica.

\subsection{GRUPOS DE TRABAJO}

Con el objeto de saber cuál ha sido la respuesta a la punción, y poder relacionarla con los factores epidemiológicos, hemos clasificado a los pacientes en dos grandes grupos de trabajo:

- NO RESPONDEDORES: aquellos pacientes cuya reducción de puntuación de escala EVA a partir de los 6 meses de la primera punción ha sido MENOR DEL 30\%.

- RESPONDEDORES: aquellos pacientes cuya reducción de puntuación de escala EVA a partir de los 6 meses de la primera punción ha sido MAYOR O IGUAL DEL 30\% . 


\subsection{MÉTODO ESTADÍSTICO}

Se ha realizado un estudio OBSERVACIONAL PROSPECTIVO de 53 pacientes con PROCTALGIA, etiquetados dentro del SÍNDROME DE ATRAPAMIENTO DEL NERVIO PUDENDO y que han recibido tratamiento con punciones corticoideo-anestésicas selectivas según técnica descrita, evaluando su respuesta a partir de los 6 meses en términos clínicos de dolor.

\subsubsection{ESTUDIO DESCRIPTIVO}

Las variables cualitativas utilizadas en nuestro estudio han sido:

- Sexo (varón/ mujer).

- Antecedentes personales relacionados con la proctalgia (si/no y tipo).

- Sintomatología rama anterior acompañante prepunción (si/no y tipo de síntoma).

- Sintomatología rama media acompañante prepunción (si/no y tipo de síntoma).

- Sintomatología rama posterior que acompaña a la proctalgia (si/no y tipo).

- Signo de TINEL (afirmativo/negativo).

- Rolling Test (afirmativo / negativo).

- Test de St. Mark's (patológico/ normal)

- Síntomas presentes en la revisión (tipo rama anterior/ media/ posterior)

Las variables cuantitativas utilizadas son:

. Edad (años)

. Escala EVA prepunción (0-10)

. Escala EVA post-punción inmediata (0-10)

. Escala EVA revisión >6meses (0-10)

. Rangos de variación porcentual de mejora de escala EVA (0-100\%)

Los datos fueron incluidos en base de datos EXCEL y posteriormente analizados con la ayuda del programa estadístico SPSS.

\subsubsection{ESTUDIO COMPARATIVO}

Se ha realizado estudio comparativo de los 2 grupos (respondedores /no respondedores) relacionándolos con las variables anteriormente expuestas aplicando el Test de la Chi cuadrado, Wilcoxon y V de Cramer. 


\section{RESULTADOS}


5.1 ESTUDIO DESCRIPTIVO SOBRE LA PROCTALGIA EN EL SÍNDROME DE ATRAPAMIENTO DEL NERVIO PUDENDO

\subsubsection{EN RELACIÓN AL SEXO Y A LAS RAMAS AFECTAS}

Los 53 pacientes etiquetados de SANP según Criterios de Nantes, que presentan proctalgia entre su sintomatología, se han repartido por sexos de la siguiente forma (gráfica 1):

23 VARONES $(43,39 \%)$ Y 30 MUJERES $(56,61 \%)$

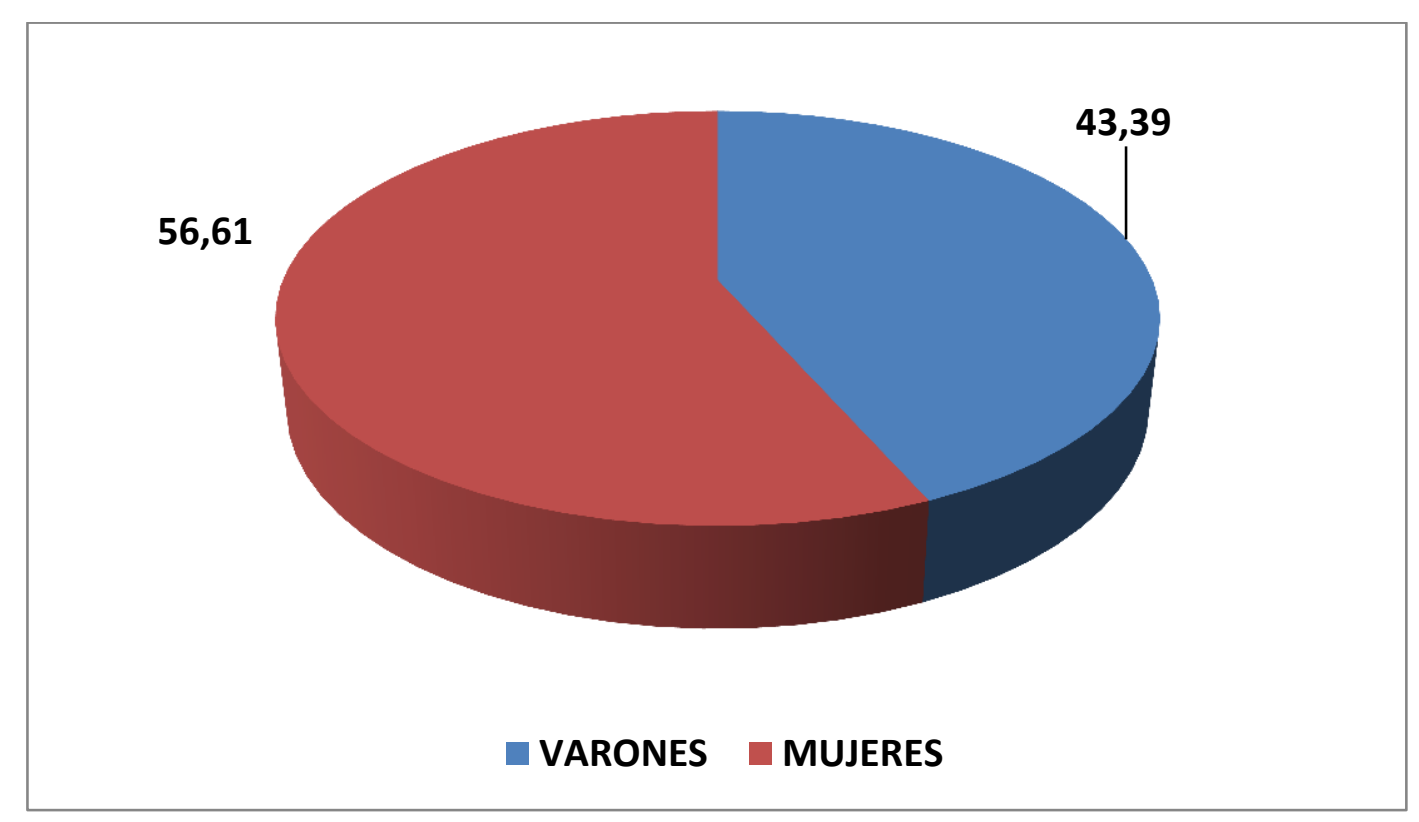

GRÁFICA 1. DISTRIBUCIÓN DE PACIENTES POR SEXO (\%) 
Referente a la distribución de la sintomatología presente según la rama afecta, teniendo en cuenta el sexo se ha mostrado de la siguiente forma (gráfica 2):

- VARONES (23)

- RAMA ANTERIOR+ MEDIA+ POSTERIOR: 13 CASOS (56,52\%)

- RAMA MEDIA + POSTERIOR: 5 CASOS (21,74\%)

- RAMA ANTERIOR + POSTERIOR: 5 CASOS $(21,74 \%)$

- SÓlO RAMA POSTERIOR: 0 CASOS (0\%)

- MUJERES (30)

- RAMA ANTERIOR+ MEDIA+ POSTERIOR: 21 CASOS (70\%)

- RAMA MEDIA + POSTERIOR: 4 CASOS (13,33\%)

- RAMA ANTERIOR + POSTERIOR: 2 CASOS (6,66\%)

- SÓlO RAMA POSTERIOR: 3 CASOS (10\%)

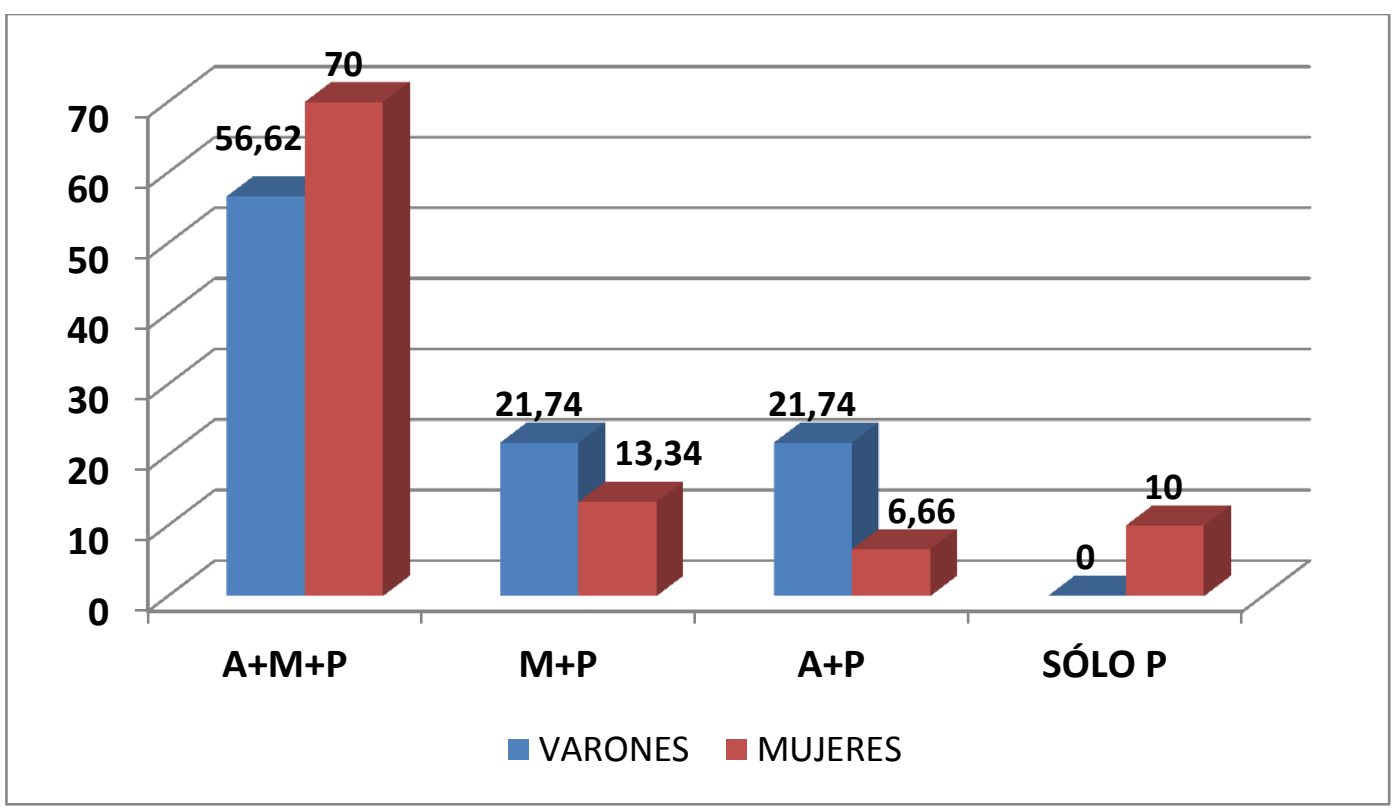

GRÁFICA 2. DISTRIBUCIÓN DE RAMAS SEGÚN SEXO \% (53 PACIENTES) 
Como hemos comentado anteriormente, este síndrome comprende sintomatología de rama anterior (sexuales), rama media (urológicos) y rama posterior (proctológicos). A parte de la presencia de proctalgia en todos nuestros pacientes estudiados, se han observado la presencia de afectación de rama acompañante en el siguiente número de pacientes:

- RAMA ANTERIOR + MEDIA + POSTERIOR: 34 PACIENTES

- RAMA MEDIA + POSTERIOR: 9 PACIENTES

- RAMA ANTERIOR + POSTERIOR: 7 PACIENTES

- SÓLO RAMA POSTERIOR: 3 PACIENTES

Dicho de otro modo, el $64,15 \%$ de los pacientes han presentado tres ramas afectas, el $30,18 \%$ dos ramas afectas y el $5,67 \%$ sólo una rama afecta, en concreto la rama posterior (gráfica 3).

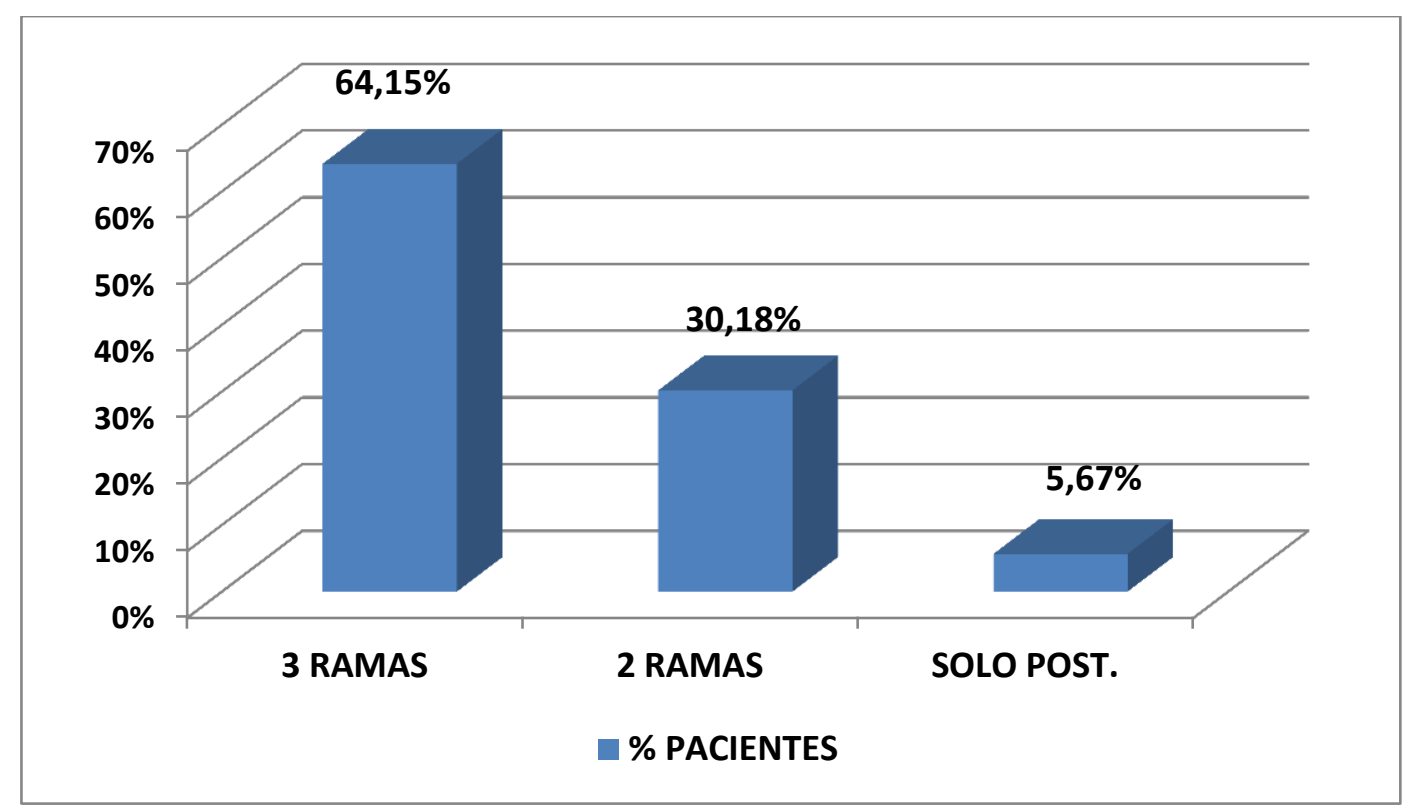

GRÁFICA 3. DISTRIBUCIÓN DEL TOTAL DE PACIENTES SEGÚN AFECTACIÓN DE RAMAS NERVIOSAS (53 PACIENTES) 


\subsubsection{EN RELACIÓN A LA EDAD}

La edad media de los pacientes estudiados ha sido de 56,8 años siendo el más joven de 24 años de edad, y el más anciano, de 85 años.

\subsubsection{EN RELACIÓN A LOS ANTECEDENTES PERSONALES}

Diferenciando entre hombres y mujeres, hemos constatado los siguientes antecedentes personales:

A) VARONES (23), tal y como queda reflejado en la gráfica 4:

- 8 sin antecedentes personales de interés (34,78\% de la muestra de varones).

- 5 con antecedentes de cirugia anorrectal (21,74\%):

- 1 amputación abdóminoperineal por neoplasia de recto

- 3 intervenciones por fisura anal

- 1 exéresis de sinus pilonidal

- 3 portadores de neuromodulador sacro $(13,04 \%)$.

- 2 ciclistas, lo cual supone el $8,69 \%$ de la muestra de varones

- 3 pacientes presentan otro tipo de patología $(13,04 \%)$ :

- 1 cistopatía

- 1 hernia discal

- 1 lupus

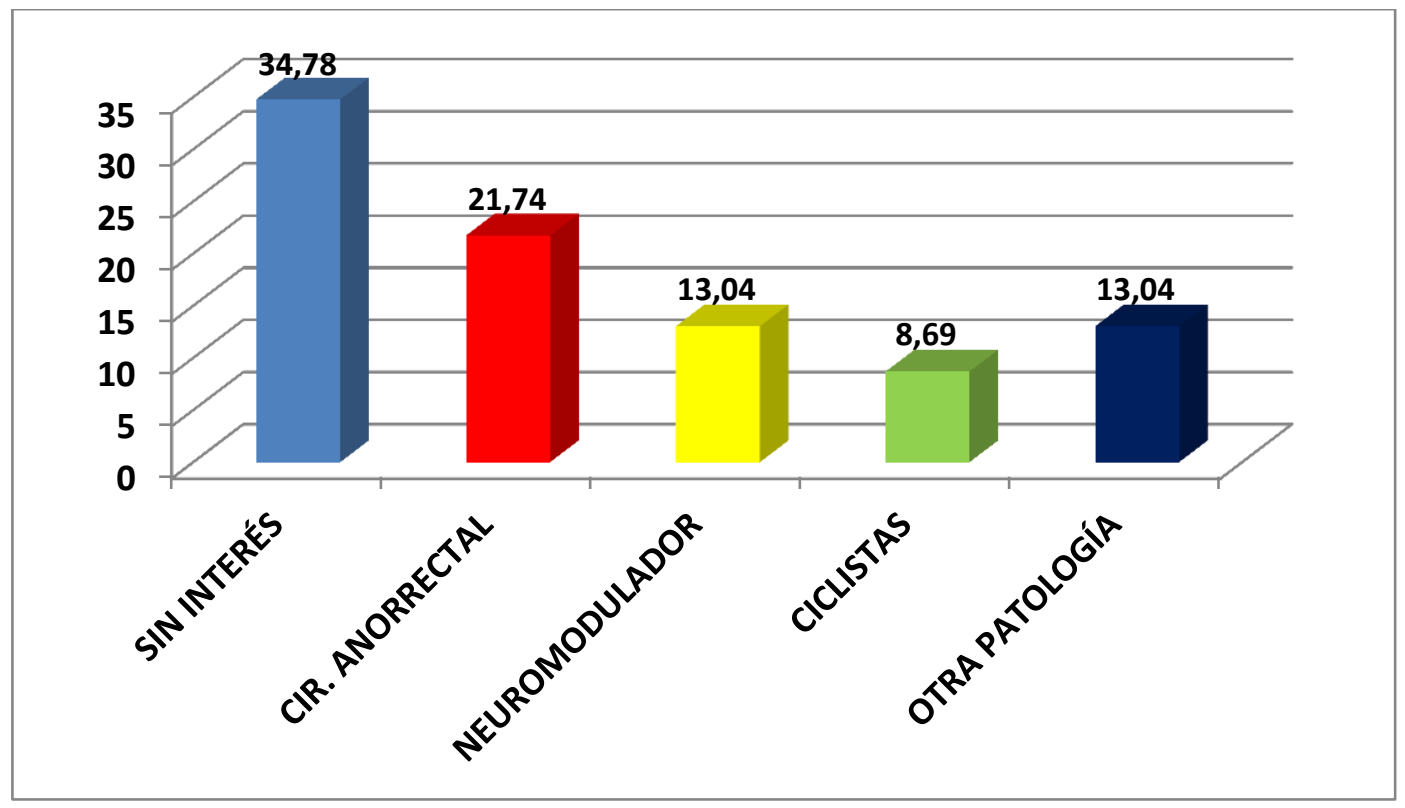

GRÁFICA 4. ANTECEDENTES PERSONALES EN VARONES (\%) 
B) MUJERES (30), como queda reflejado en la gráfica 5:

- 10 sin antecedentes personales de interés (33,33\% de la muestra de mujeres).

- 5 con antecedentes de cirugía anorrectal (16,67\%):

- 5 intervenciones por fisura anal.

- 10 con antecedentes ginecológicos (33,33\%):

- 7 histerectomías.

- 1 rotura rectal intraparto.

- 2 cirugias vaginales.

- 2 portadores de neuromodulador sacro (6,67\%).

- 2 ciclistas $(6,67 \%)$.

- 4 fibromialgias (13,33\%).

- 5 pacientes con otra patología $(16,67 \%)$ :

- 1 enfermedad de Rendu Osler Weber

- 1 cistopatía

- 1 colon espástico

- 1 hernia discal

- 1 amiloidosis

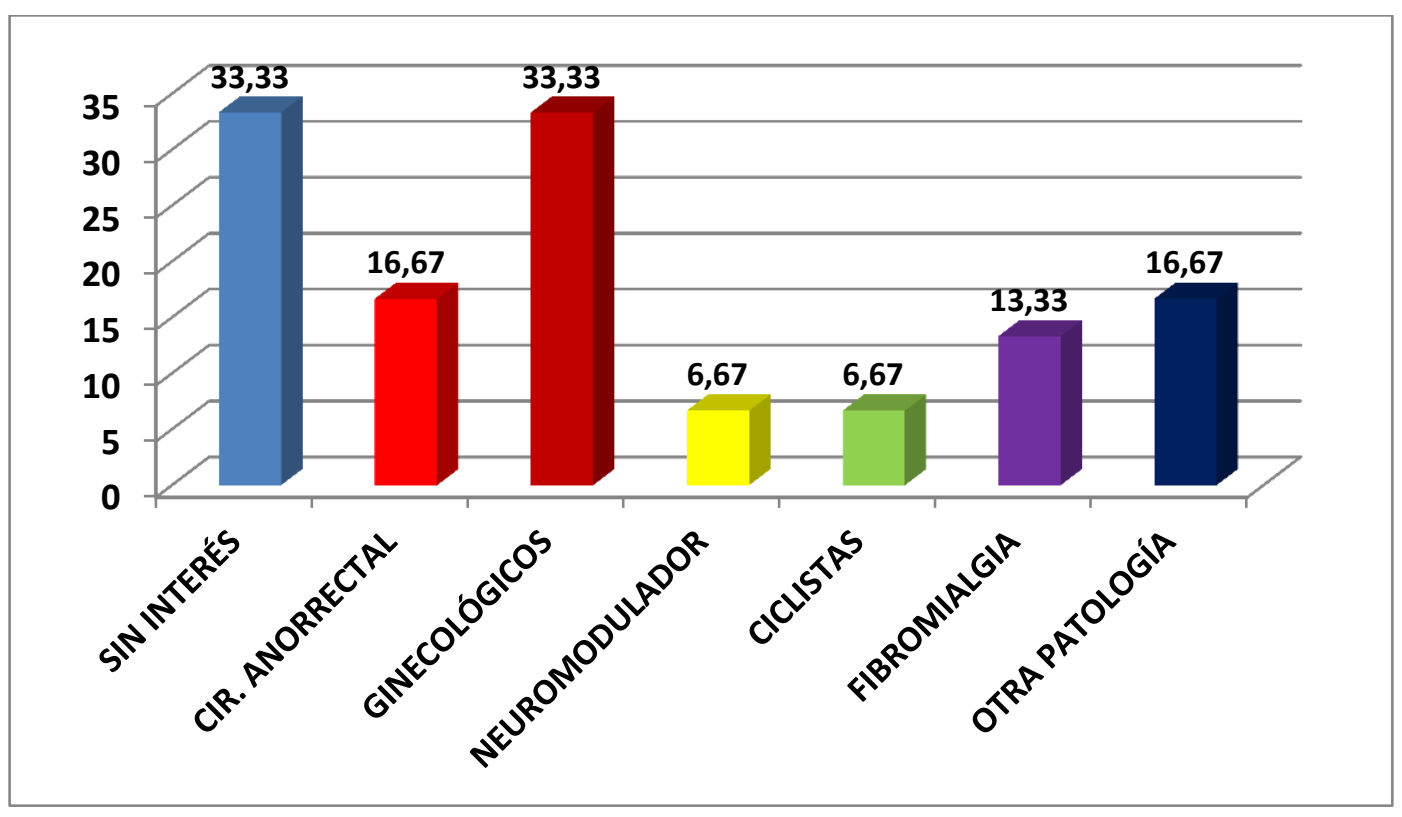

GRÁFICA 5. ANTECEDENTES PERSONALES EN MUJERES 


\subsubsection{EN RELACIÓN A LOS SIGNOS CLÍNICOS}

\section{- SIGNO DE TINEL:}

El signo de Tinel ha resultado positivo en 52 de los 53 pacientes estudiados, lo que supone el $98,1 \%$ de los casos. El caso negativo fue un paciente que no respondió al tratamiento con punciones.

\section{- ROLLING TEST:}

El Rolling Test resultó positivo en 20 de los 53 pacientes estudiados, lo que supone el $37,73 \%$ de los casos.

\subsubsection{EN RELACIÓN A LAS PRUEBAS COMPLEMENTARIAS}

Las pruebas complementarias fundamentales utilizadas para afianzar el diagnóstico de SANP, han sido las siguientes:

\section{- TEST DE LATENCIA MOTORA DISTAL DEL NERVIO (ST. MARK'S)}

Dicho test se ha llevado a cabo en 52 pacientes, ya que uno de ellos no permitió su realización debido a intensa proctalgia.

De los 52 test realizados, ha resultado patológico en 46 ocasiones lo que supone el $88,46 \%$ de los casos (gráfica 6).

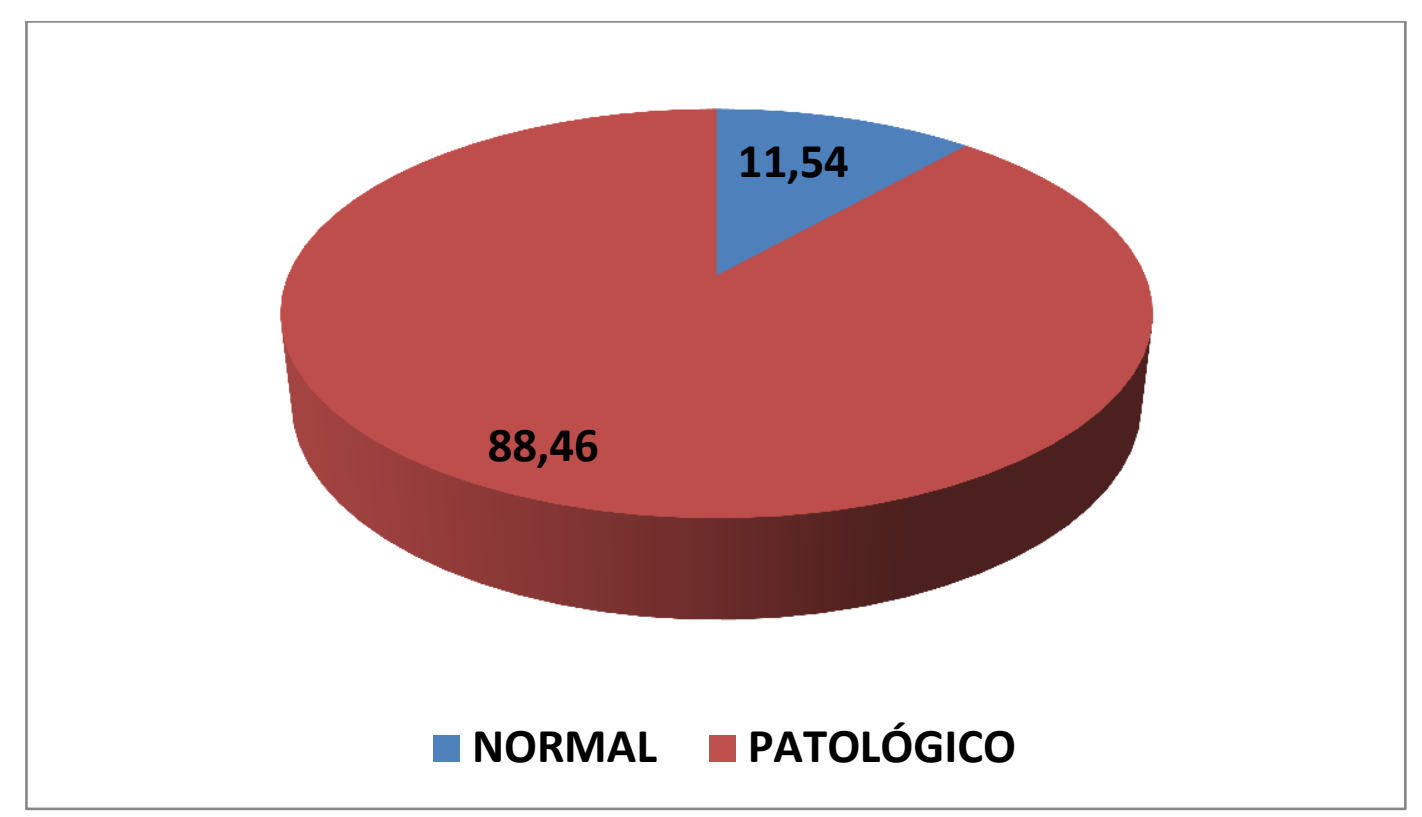

GRÁFICA 6. RESULTADOS DEL TEST DE ST. MARK'S EN LA MUESTRA TOTAL DE PACIENTES (\%) 


\subsubsection{EN RELACIÓN A LA PUNTUACIÓN EN LA ESCALA EVA}

\subsubsection{EVA PREPUNCIÓN}

Un aspecto fundamental en nuestro estudio es la puntuación en la escala visual analógica del dolor, también conocida como escala EVA referida por el paciente con respecto a la proctalgia.

La puntuación media en la escala EVA de la muestra total de 53 pacientes ha sido de 7,74 con un rango de 2,8 a 10.

\subsubsection{EVA INMEDIATA POST-PUNCIÓN}

Los 53 pacientes etiquetados de SANP han recibido, a parte del tratamiento médico mencionado anteriormente, punciones corticoideo-anestésicas selectivas de las ramas terminales del nervio pudendo.

La puntuación EVA media obtenida en el momento inmediato tras la punción ha sido de 1.19 con un rango que va de 0 a 10 .

En 42 pacientes la puntuación EVA inmediata tras infiltración ha sido 0 (respuesta completa), lo que supone el $79,25 \%$ de los casos.

\subsubsection{EVA POST-PUNCIÓN A PARTIR DE LOS 6 MESES}

Como se ha comentado anteriormente, se ha realizado seguimiento a los 53 pacientes sometiéndoles, a partir de los 6 meses de la primera punción, a evaluación clínica refiriendo, entre otros aspectos, nueva puntación en escala EVA.

La puntuación EVA media registrada a partir de los 6 meses tras la primera punción ha sido de 5,39 con un rango que va de 0 a 10.

En 13 pacientes la puntuación EVA post-punción a partir de los 6 meses ha sido 0, es decir, respuesta completa, lo que supone el 30,952\% de los casos.

Según el criterio de respuesta especificado en el apartado material y métodos, en el grupo de pacientes no respondedores se han incluido 32 pacientes, lo que supone el $60,38 \%$ del total de la muestra, mientras que en el grupo de respondedores, se han incluido 21 pacientes que supone el 39,62 \% de la muestra (gráfica 7). 


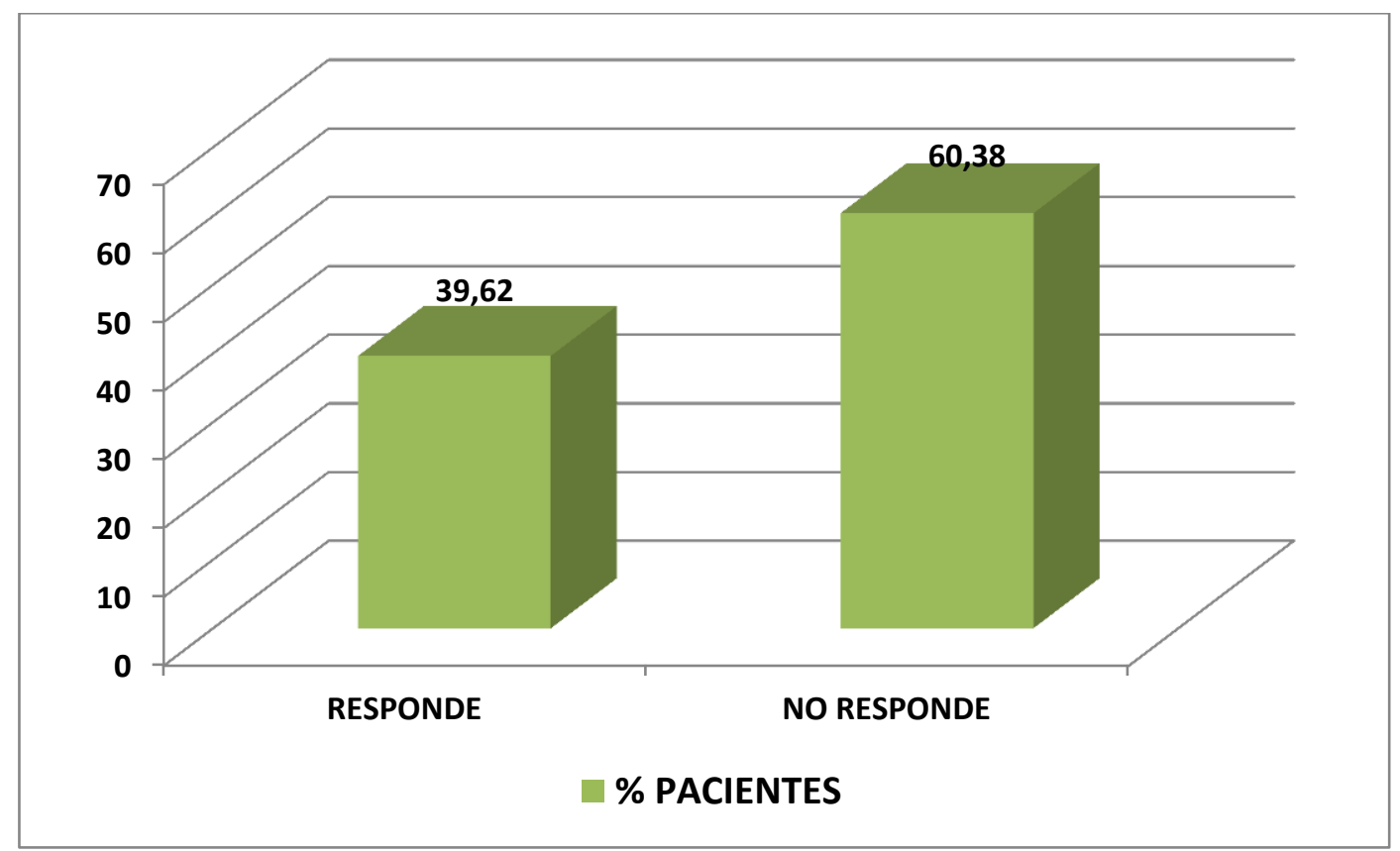

GRÁFICA 7. DISTRIBUCIÓN DE LOS PACIENTES (53) SEGÚN CLASIFICACIÓN RESPONDEDORES /NO RESPONDEDORES

\subsubsection{EN RELACIÓN A LA SINTOMATOLOGÍA PRESENTE A LOS 6 MESES TRAS LA}

\section{PRIMERA PUNCIÓN}

Aparte de la persistencia de la proctalgia en 38 pacientes (33 no respondedores y 5 respondedores), con una intensidad variable mencionada en el apartado anterior, en la entrevista clínica llevada a cabo a partir de los 6 meses tras la primera punción, han sido referidos los siguientes síntomas:

-EYACULACIÓN DOLOROSA en 2 pacientes no respondedores.

-VULVODINIA-DISPAREUNIA en 2 pacientes(1 de ellos respondedor )

-INCONTINENCIA URINARIA en 1 paciente no respondedor.

-CISTALGIA en 3 pacientes ( 2 de ellos no respondedores)

-POLAQUIURIA en 2 pacientes (1 de ellos no respondedor)

-SENSACIÓN DE OCUPACIÓN RECTAL en 1 paciente no respondedor. 


\subsubsection{EN RELACIÓN A LA SEGUNDA "TANDA" DE PUNCIONES ANESTÉSICAS}

En el momento actual, 16 pacientes no respondedores han sido o están siendo tributarios de una segunda "tanda" de punción. Los 18 pacientes restantes, por el momento no desean o no se ha considerado oportuno una segunda "tanda" de punciones, a la espera de observar evolución.

\subsubsection{EN RELACIÓN A LAS COMPLICACIONES DE LAS PUNCIONES ANESTÉSICAS} DEL NERVIO PUDENDO

Se han descrito cuatro complicaciones en las 159 punciones-hidrodistensiones del nervio pudendo practicadas (lo que supone el 2,51\% de las mismas), que son 2 amenorreas, 1 sangrado vaginal y 1 síncope vasovagal, problemas que evolucionaron satisfactoriamente a las pocas horas tras la punción. Las alteraciones ginecológicas se consultaron con el servicio de Ginecología siendo atribuido al uso de corticoides. 


\subsection{ESTUDIO COMPARATIVO ENTRE PACIENTES RESPONDEDORES/NO RESPONDEDORES A LA PUNCIÓN ANESTÉSICA.}

\subsubsection{EN RELACIÓN AL SEXO.}

Según que los pacientes hayan sido respondedores (21 pacientes) o no (32 pacientes) a la punción, la distribución por sexos ha sido la siguiente :

. En el grupo de respondedores (21):

- 13 MUJERES $(61,90 \%)$ Y 8 VARONES $(38,10 \%)$

. En el grupo de no respondedores (32):

- 17 MUJERES $(53,125 \%)$ Y 15 VARONES $(46,875 \%)$

. Es decir, en el grupo de varones (23 pacientes):

- 8 han sido RESPONDEDORES $(34,78 \%)$ y 15 NO RESPONDEDORES $(65,22 \%)$ tal y como puede observarse en en la gráfica 8.

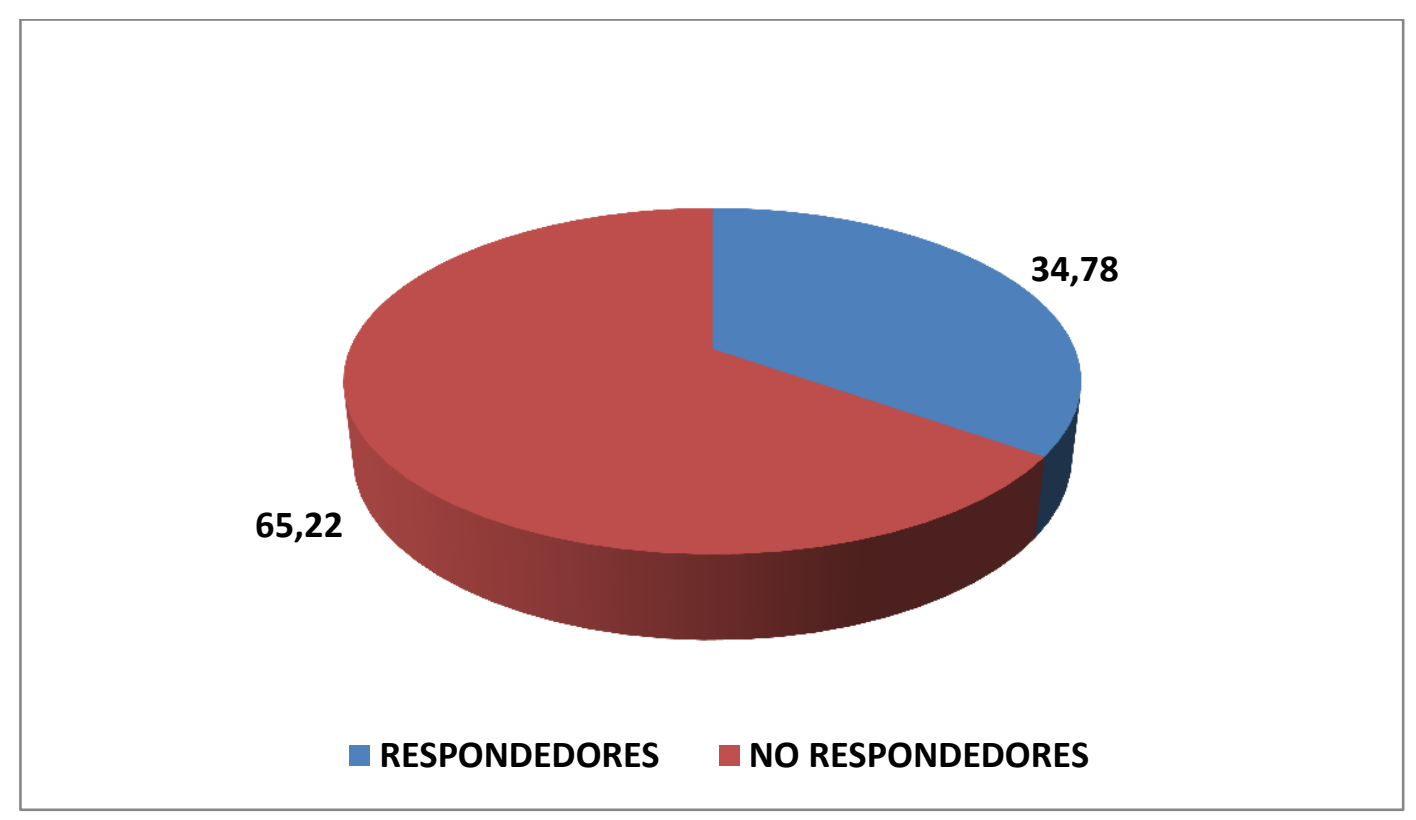

GRÁFICA 8. DISTRIBUCIÓN DE VARONES EN RESPONDEDORES/ NO RESPONDEDORES (\%) 
.En el grupo de mujeres (30 pacientes):

-13 han sido RESPONDEDORAS (43,33\%) y 17 NO RESPONDEDORAS $(5,67 \%)$ como queda reflejado en la gráfica 9.

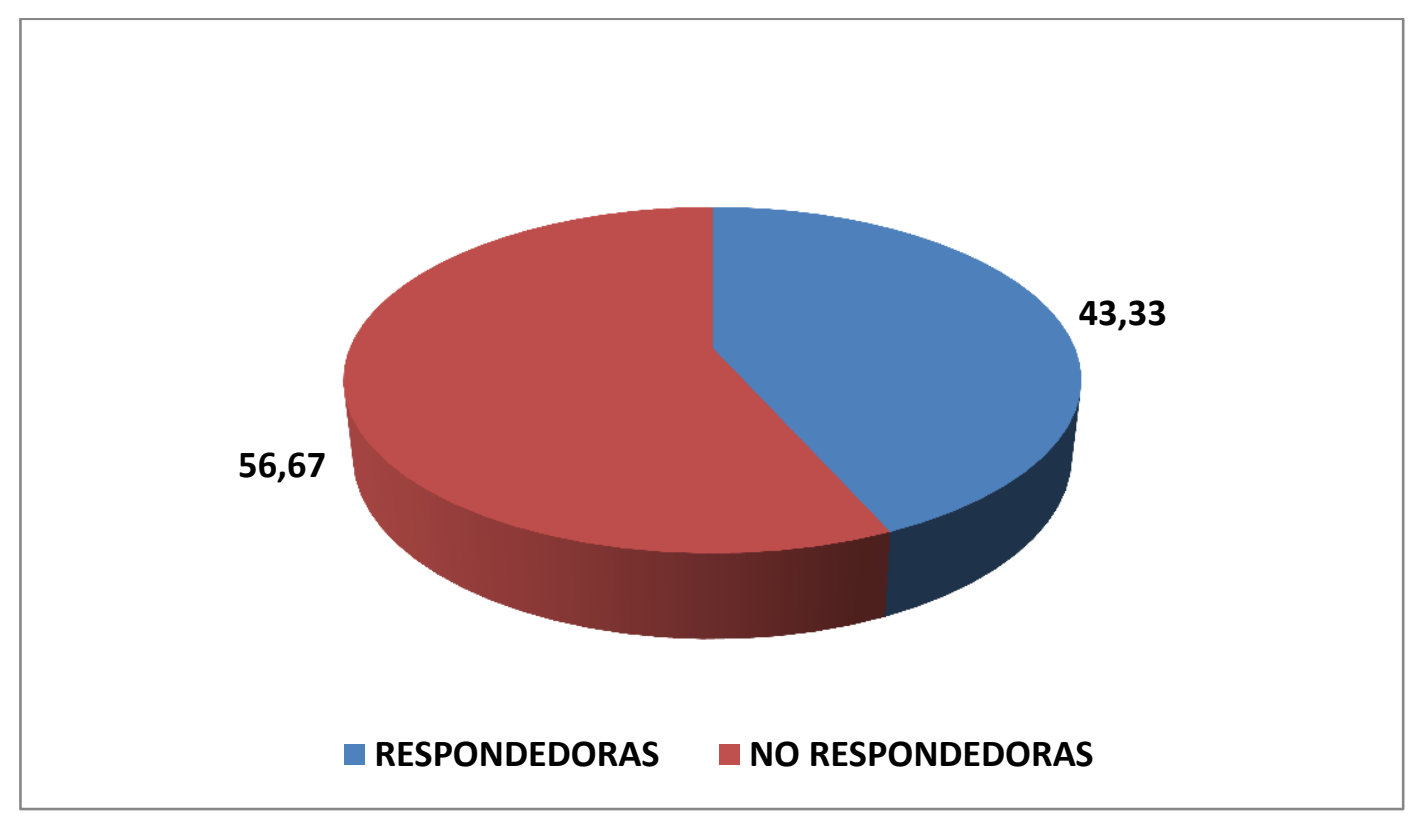

GRÁFICA 9. DISTRIBUCIÓN DE MUJERES EN RESPONDEDORAS/NO RESPONDEDORAS (\%)

\subsubsection{EN RELACIÓN CON LA EDAD}

En el grupo de pacientes respondedores, la edad media ha sido de 58,57 años con un rango que va de los 33 a los 85 años.

En el grupo de los no respondedores, la edad media ha sido de 55,53 años con un rango que se distribuye entre los 24 y los 82 años. 


\subsubsection{EN RELACIÓN CON LOS ANTECEDENTES PERSONALES}

Centrándonos en los antecedentes personales quirúrgicos en el grupo de no respondedores tras la punción se han distribuido de la siguiente forma (gráfica 10):

- 20 pacientes sin antecedentes quirúgicos de interés para el proceso actual $(62,5 \%)$

- ANTECEDENTES QUIRÚRGICOS:

- GINECOLÓGICOS (16,67\%)

- Cuatro histerectomias y dos cirugias de suelo pélvico.

- $\operatorname{ANORRECTALES~}(18,75 \%)$

- Cinco fisuras anales y un sinus pilonidal.

Los antecedentes quirúrgicos en el grupo de respondedores tras la punción se han distribuido de la siguiente manera:

- 15 pacientes sin antecedentes quirúrgicos de interés para el proceso actual $(71,42 \%)$

- ANTECEDENTES QUIRÚRGICOS

- GINECOLÓGICOS (23,5\%)

- Tres histerectomia y una cirugía de suelo pélvico.

- ANORRECTALES $(23,5 \%)$

- Tres fisuras anales y una amputación abdóminoperineal.

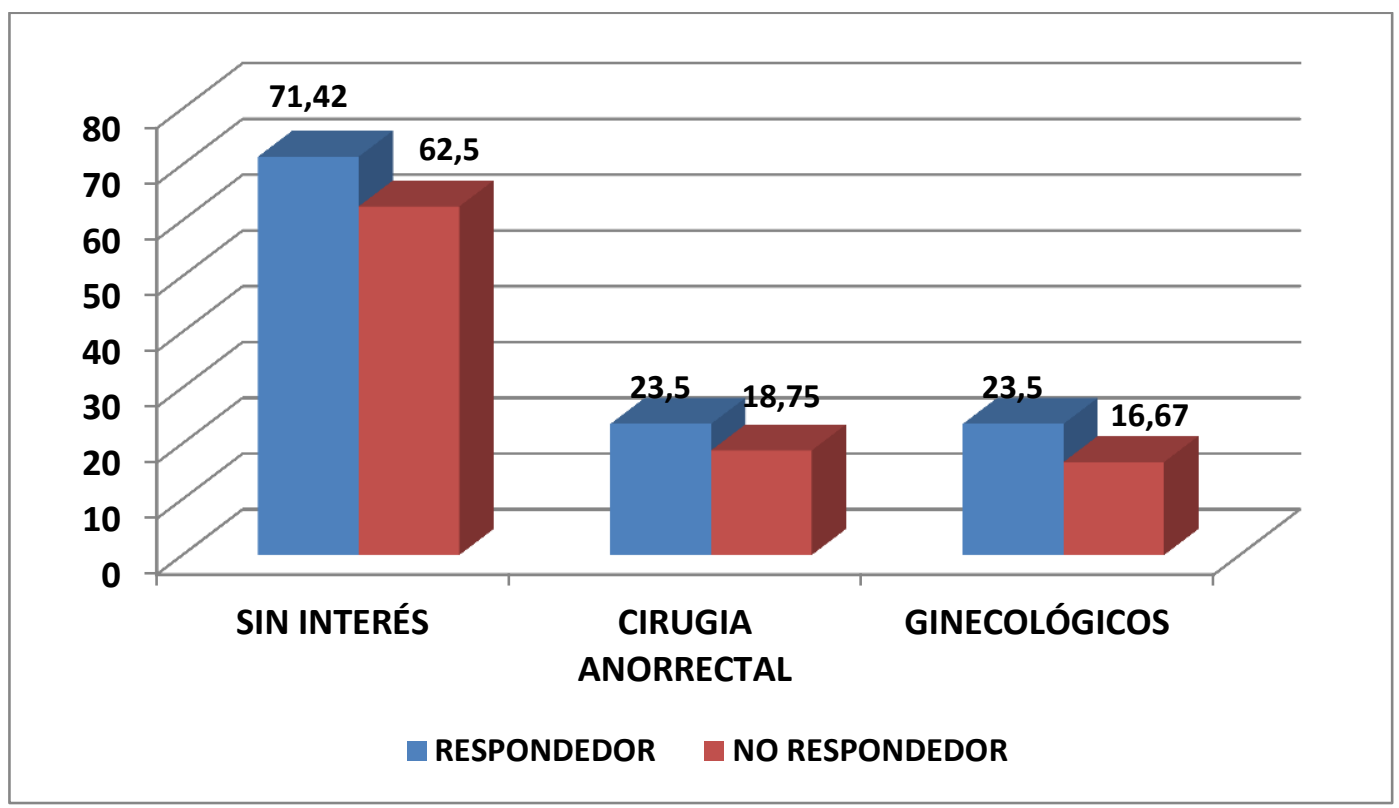

GRÁFICA 10. COMPARATIVO DE ANTECEDENTES PERSONALES EN RESPONDEDORES Y NO RESPONDEDORES (\%) 


\subsubsection{EN RELACIÓN A LAS RAMAS AFECTAS}

Diferenciando entre respondedores y no respondedores, la distribución de la afectación de las ramas acompañantes se ha efectuado de la siguiente forma (gráfica 11):

\section{PACIENTES RESPONDEDORES (21):}

- RAMA ANTERIOR + MEDIA + POSTERIOR: 12 PACIENTES lo que supone el $35,29 \%$ del total de pacientes con tres ramas afectas.

- 2 RAMAS AFECTAS: 8 PACIENTES, lo que supone el $50 \%$ del total de pacientes con 2 ramas afectas

- SÓlO RAMA POSTERIOR: 1 PACIENTES, lo que supone el 33,33\% del total de pacientes con rama posterior única afecta.

\section{PACIENTES NO RESPONDEDORES (32):}

- RAMA ANTERIOR + MEDIA + POSTERIOR: 22 PACIENTES lo que supone el $64,71 \%$ del total de pacientes con tres ramas afectas.

- 2 RAMAS AFECTAS: 8 PACIENTES, lo que supone el $50 \%$ del total de pacientes con 2 ramas afectas

- SÓlO RAMA POSTERIOR: 2 PACIENTES, lo que supone el 66,67\% del total de pacientes con rama posterior única afecta.

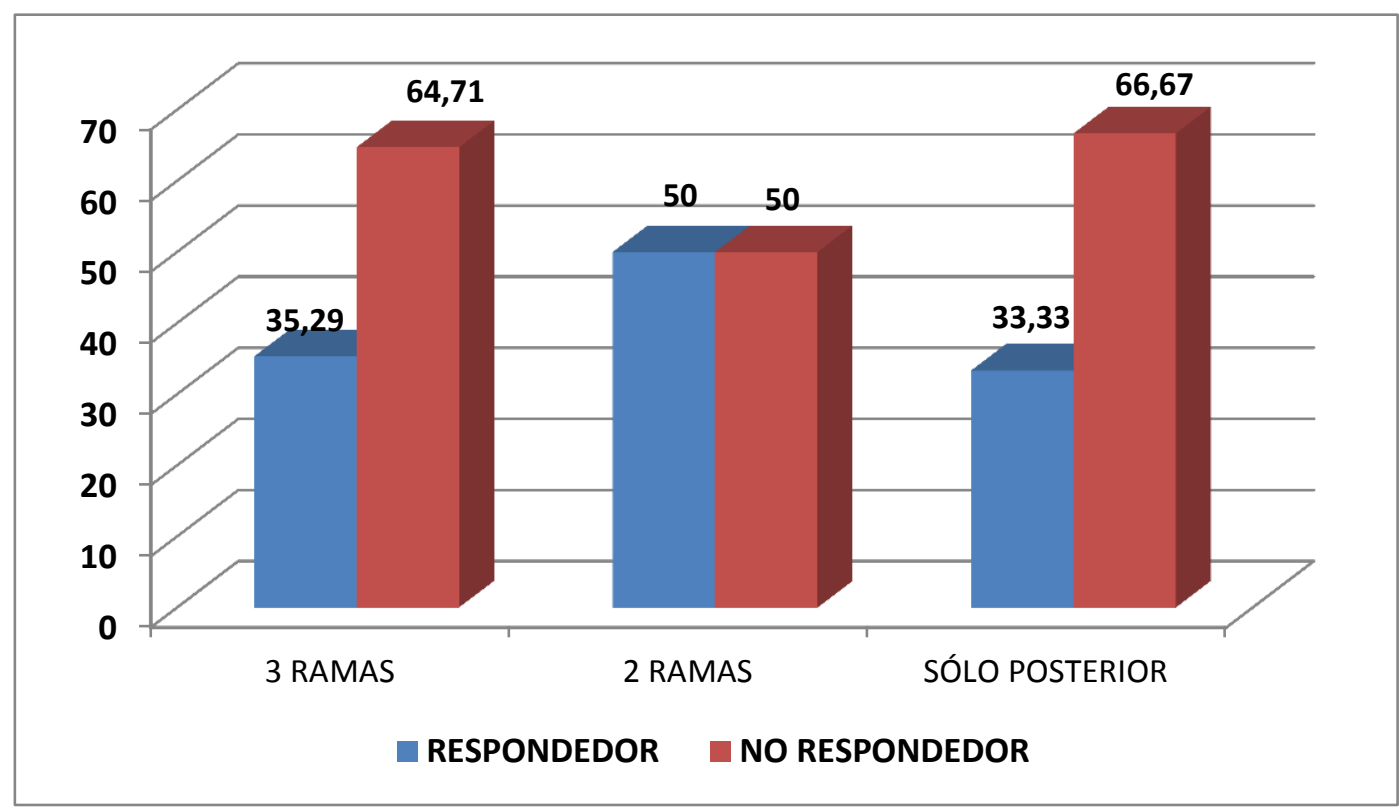

GRÁFICA 11. DISTRIBUCIÓN DE PACIENTES SEGÚN RAMAS Y COMPARACIÓN ENTRE RESPONDEDORES Y NO RESPONDEDORES (\%) 


\subsubsection{EN RELACIÓN CON LOS SIGNOS CLÍNICOS}

- SIGNO DE TINEL:

Los resultados del signo de Tinel han sido debidamente comentados anteriormente en el apartado de resultados descriptivos.

- ROLLING TEST:

De los 32 pacientes no respondedores, 12 mostraron un Rolling test positivo (37,5\% de dicho grupo, gráfica 12) y en el grupo de 21 pacientes respondedores, 8 presentaron dicho test afirmativo (38,09\%de dicho grupo, gráfica 13$)$

Dicho de otro modo, de los 20 pacientes con Rolling Test positivo, 8 fueron respondendores lo que supone el $40 \%$ dentro de este grupo.

De los 33 pacientes con Rolling Negativo, 20 fueron no respondedores $(62,5 \%)$.

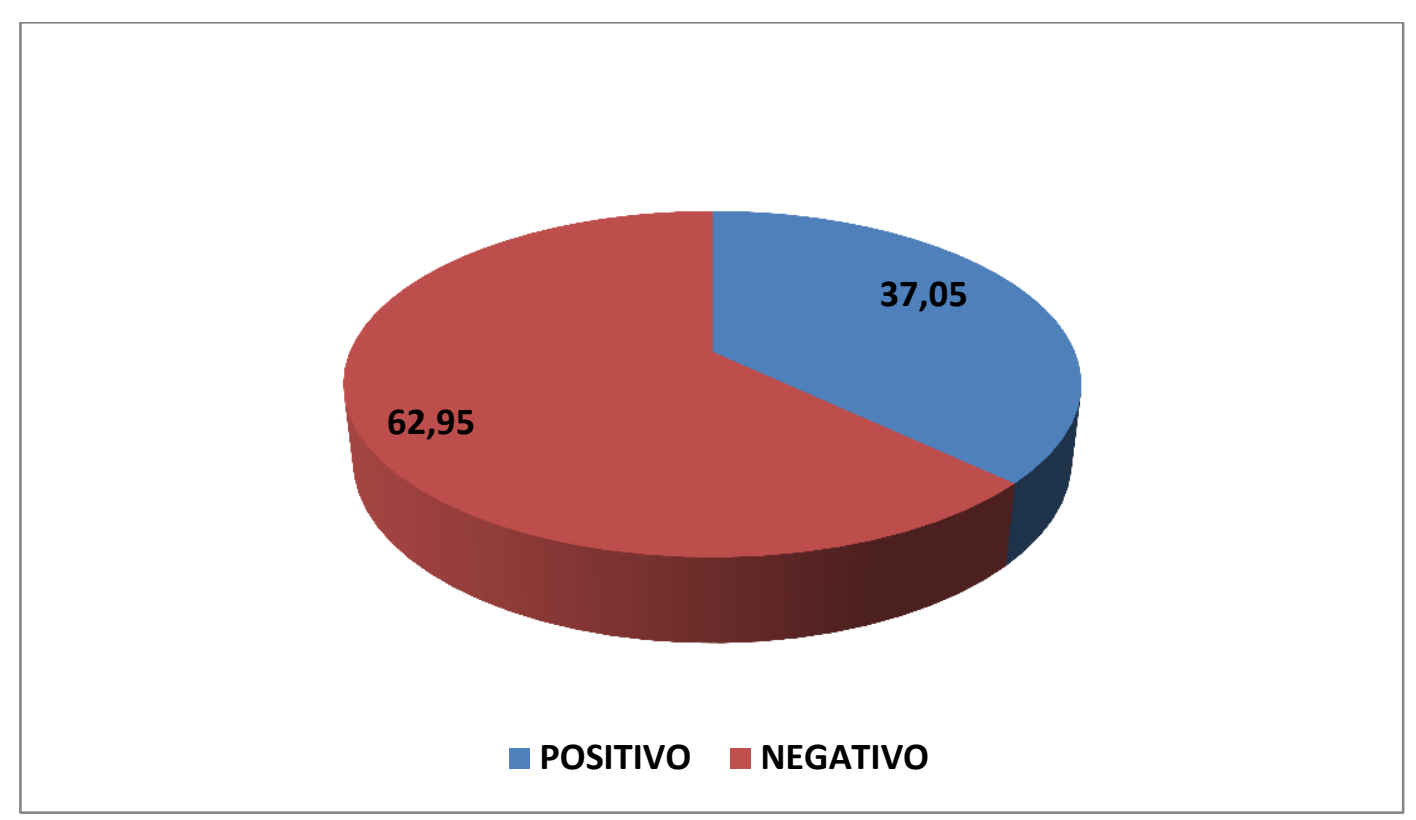

GRÁfICA 12. RESULTADOS DEL ROLLING TEST EN EL GRUPO DE PACIENTES NO RESPONDEDORES (\%) 


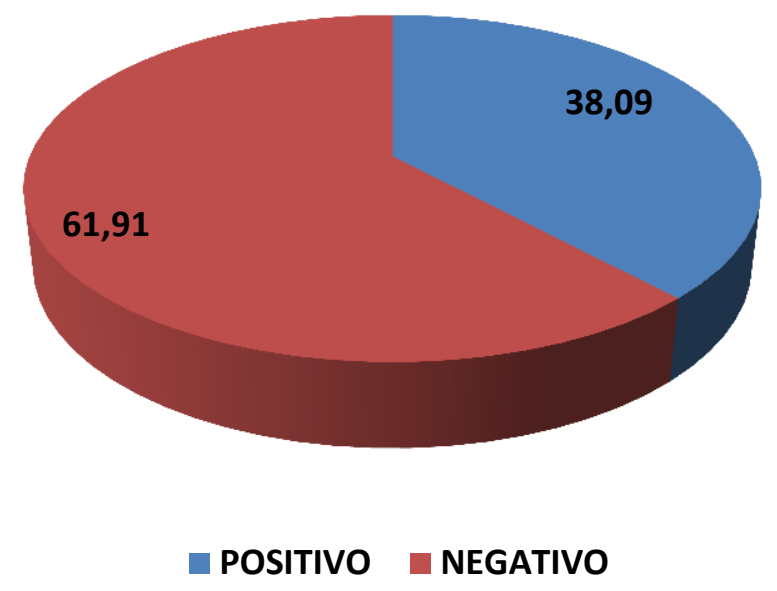

GRÁfICA 13. RESULtAdos DEL ROLLING teSt EN EL GRUPO DE PACIENTES RESPONDEDORES (\%)

\subsubsection{EN RELACIÓN AL TEST DE LATENCIA MOTORA DISTAL DEL NERVIO}

Los resultados obtenidos con el test de latencia motora distal de nervio o test de St. Mark's han sido los siguientes:

En el grupo de los no respondedores (32 pacientes), el test ha resultado patológico en 29 pacientes, lo que supone el 90,625\% de los mismos, como se puede observar en la gráfica 14.

En el grupo de respondedores (21 pacientes) , 1 paciente mencionado anteriormente no permitió la exploración, y en 17 casos fue patológico lo que supone el $80,95 \%$ de los casos (gráfica 15).

Dicho de otra forma, del porcentaje de test de St. Mark's patológicos (46 casos), 17 han sido respondedores, lo que supone el $36,96 \%$ de los pacientes con test patológico. Asimismo, de los 6 casos de St Mark's normal, 3 han sido no respondedores, lo que supone el $50 \%$ del total de pacientes con St Mark's normal. 


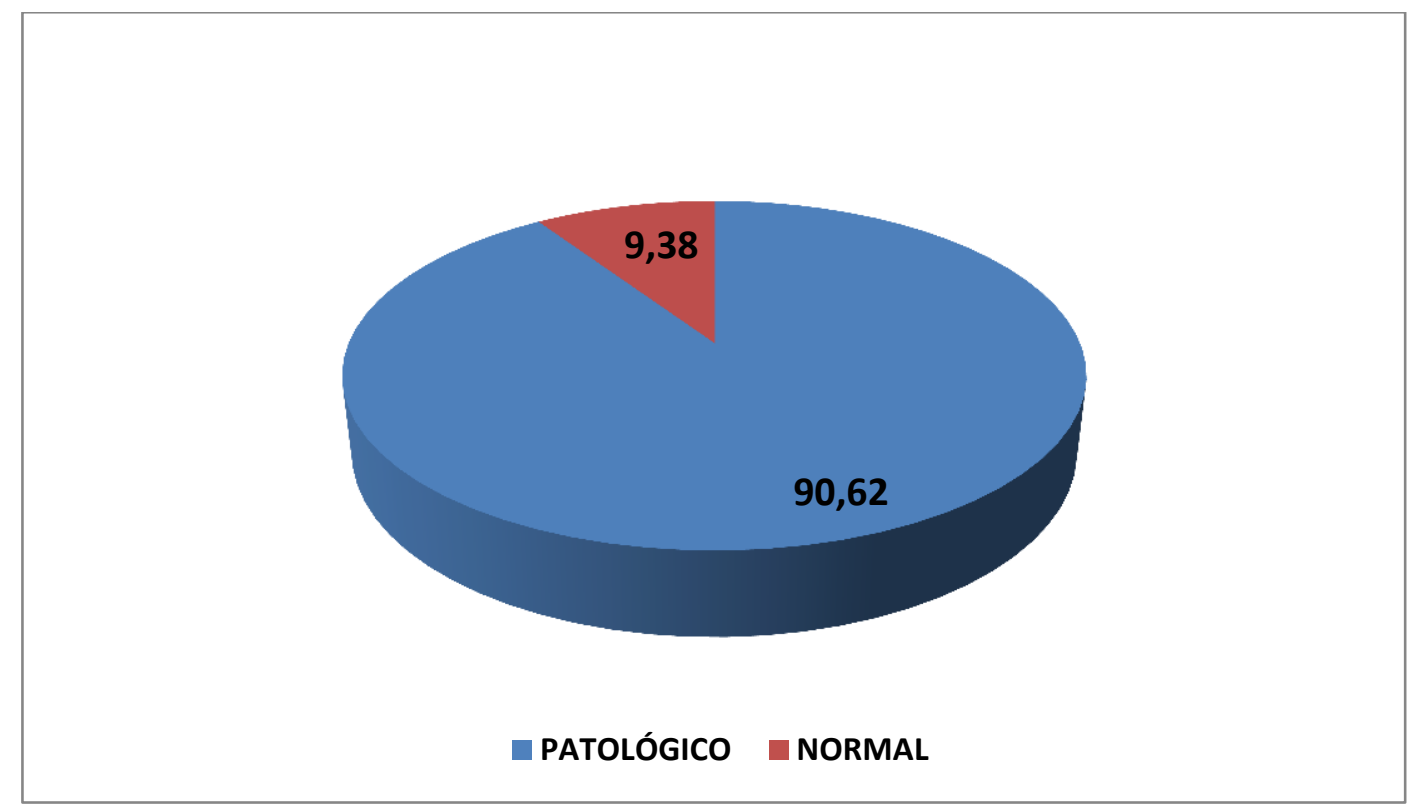

GRÁFICA 14. RESULTADOS DEL TEST DE ST. MARK'S EN EL GRUPO DE PACIENTES NO RESPONDEDORES (\%)

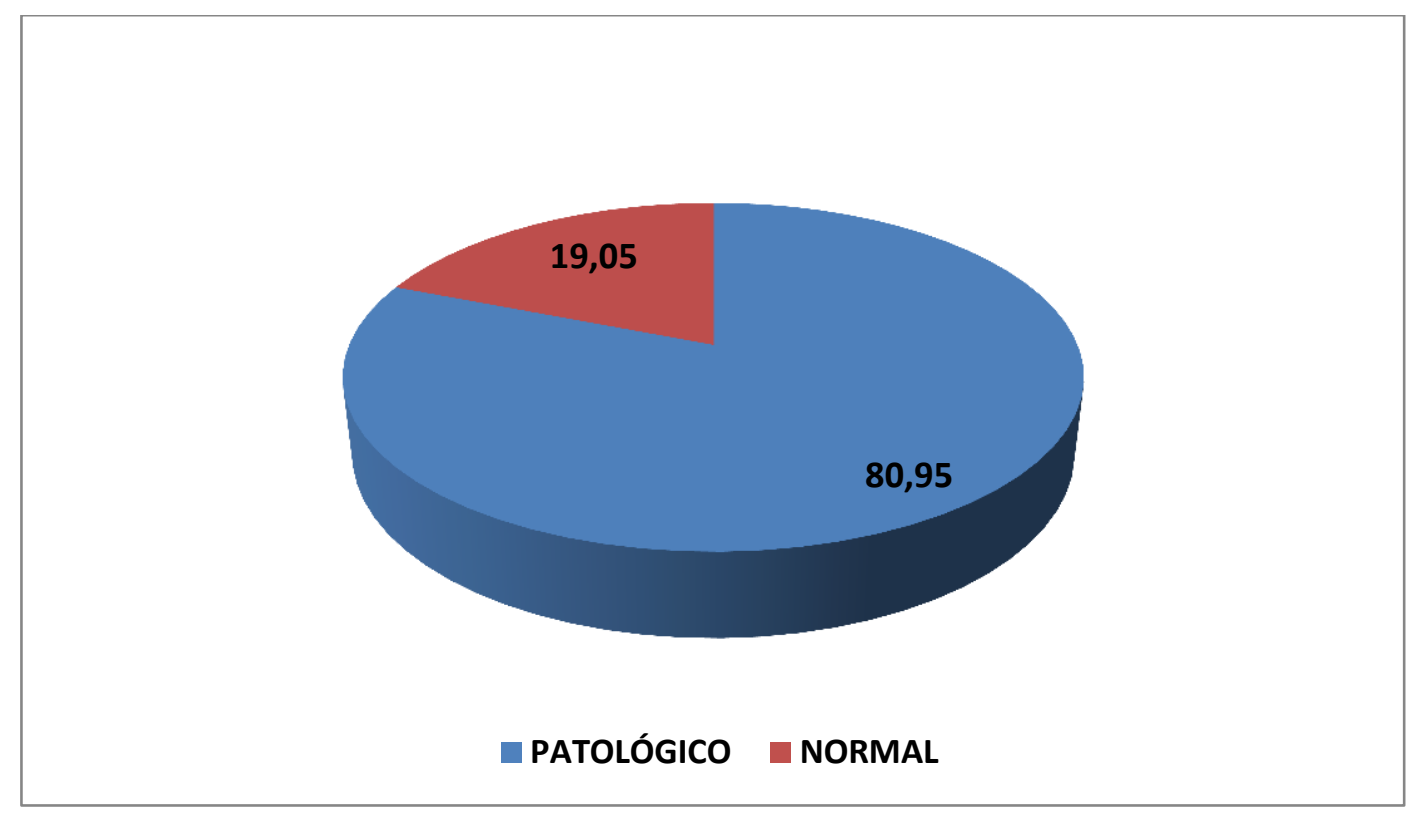

GRÁFICA 15. RESULTADOS DEL TEST DE ST. MARK'S EN EL GRUPO DE PACIENTES RESPONDEDORES (\%) 


\subsubsection{EN RELACIÓN A LA PUNTUACIÓN EN ESCALA EVA}

\subsubsection{EN RELACIÓN A LA PUNTUACIÓN EVA PREPUNCIÓN}

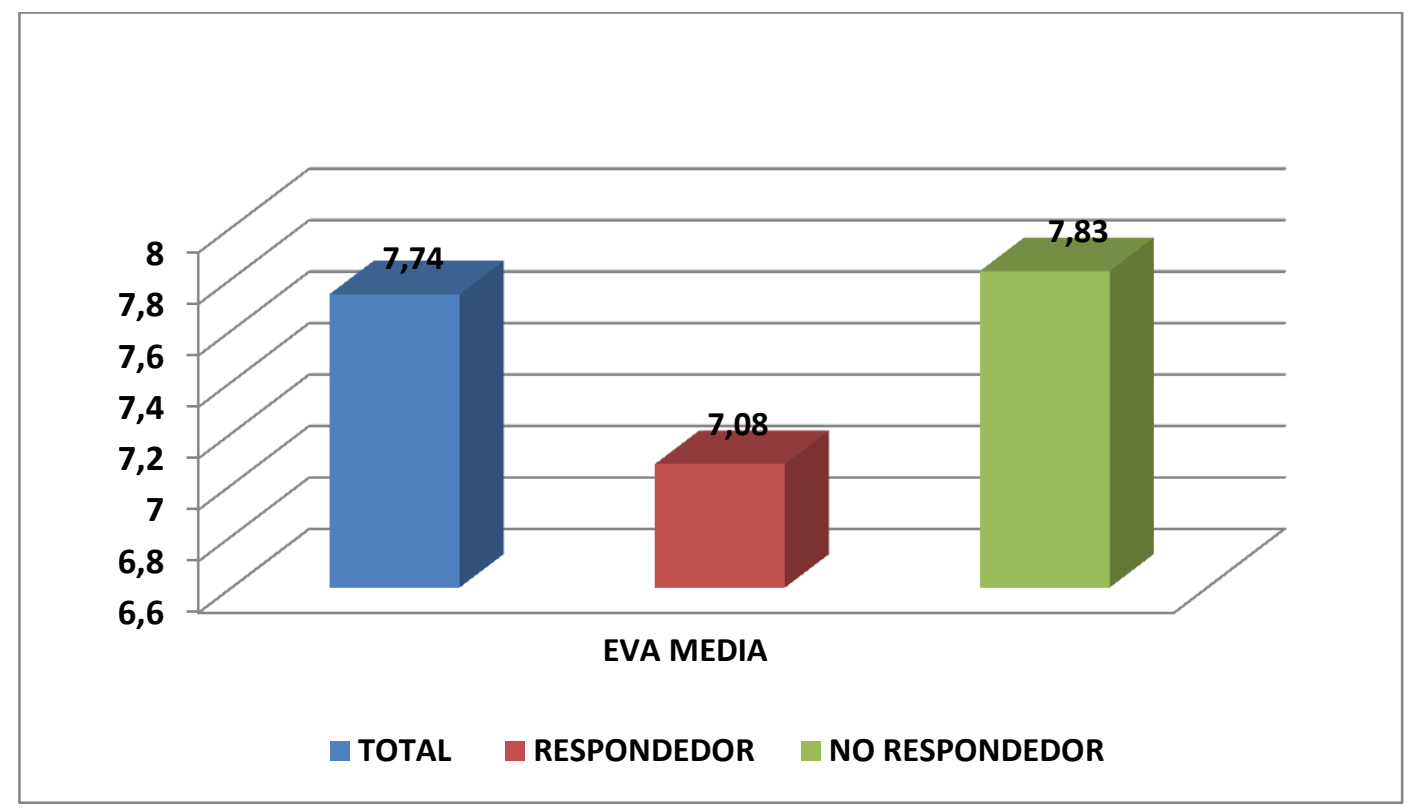

GRÁFICA 16. PUNTUACIÓN EVA MEDIA EN LA MUESTRA TOTAL, GRUPO DE RESPONDEDORES Y GRUPO DE NO RESPONDEDORES

La puntuación media en la escala EVA prepunción en el grupo de pacientes respondedores ha sido de 7,08 con un rango de 2,8 a 10 .

La puntuación media en la escala EVA prepunción en el grupo de pacientes no respondedores ha sido de 7,83 con un rango de 4,1 a 10 (gráfica 16). 


\subsubsection{EN RELACIÓN A LA PUNTUACIÓN EVA INMEDIATA}

POSTPUNCIÓN

En el grupo de respondedores la puntuacion EVA inmediata tras las punciones ha mostrado una media de 0,4 distribuyéndose de la siguiente forma:

. 18 pacientes han referido EVA inmediata post-punción $\mathbf{0}(\mathbf{8 8 , 7 1 \% )}$.

. 3 pacientes han referido puntuación media de $\mathbf{2 , 8}(0,4-4)(\mathbf{1 4 , 2 8 \% )}$.

En el grupo de los no respondedores, la puntuación EVA inmediata tras las punciones ha mostrado una media de 1,72 distribuyéndose de la siguiente forma :

.24 pacientes han referido EVA inmediata $\mathbf{0}$ (75\%)

.8 pacientes han presentado EVA media de 6,87 (2-10) (25\%)

La distribución de la puntuación EVA media referida inmediatamente tras las punciones queda reflejada en la gráfica 17.

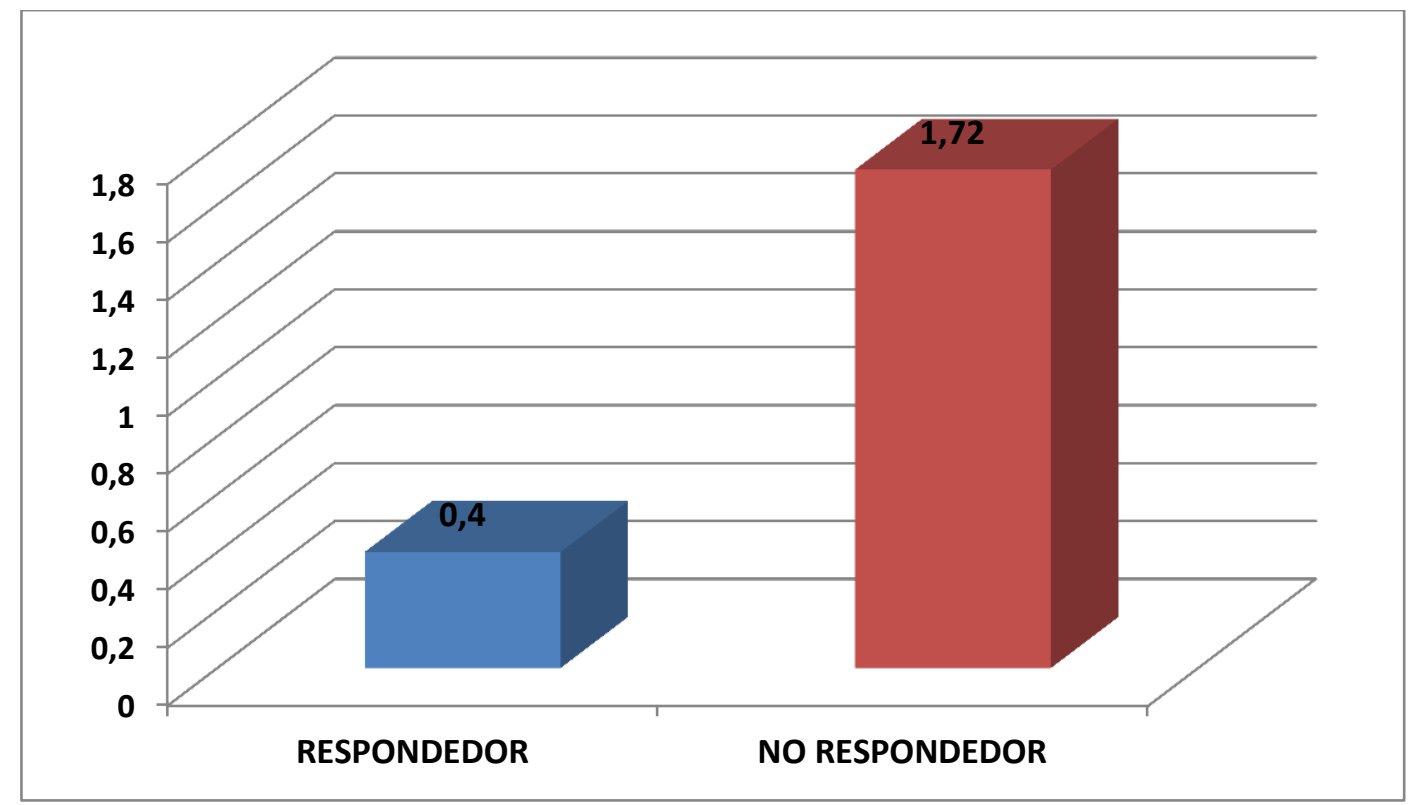

GRÁFICA 17. DISTRIBUCIÓN DE LA PUNTUACIÓN EVA INMEDIATA TRAS EL TRATAMIENTO CON PUNCIONES 


\subsubsection{EN RELACIÓN A LA PUNTUACIÓN EVA POST-PUNCIÓN A PARTIR DE LOS 6 MESES}

De acuerdo a lo mencionado anteriomente, nuestra muestra de 53 pacientes etiquetados de SANP se ha distribuido de la siguiente forma teniendo en cuenta la puntuación EVA referida a partir de los 6 meses de la primera punción (Gráfica 18-19):

- 32 pacientes han sido NO RESPONDEDORES, es decir, han mostrado una reducción de la puntuación EVA que refirieron antes de la punción, en relación a la proctalgia, menor al $30 \%$, lo que supone el $60,38 \%$ de los pacientes . La puntuación EVA media referida por estos pacientes ha sido de 8,18 con un rango que va del 4 al 10.

- 21 pacientes han sido RESPONDENDORES es decir, han mostrado una reducción de la puntuación EVA referida antes de la primera punción, en relación a la proctalgia,igual o superior al 30\%, lo que supone el $\mathbf{3 9 , 6 2 \%}$ de los pacientes estudiados. La puntuación EVA media referida por estos pacientes ha sido de 1,14 (0-7). Dentro de este grupo:

- 13 pacientes respondedores han referido una puntuación EVA 0 a partir de los 6 meses post-punción, mostrándose asintomáticos, lo que supone el $24,52 \%$ del total de pacientes estudiados.

- Los 8 pacientes respondedores que mostraron alguna puntuación EVA han presentado una media de 3 (2-7). 


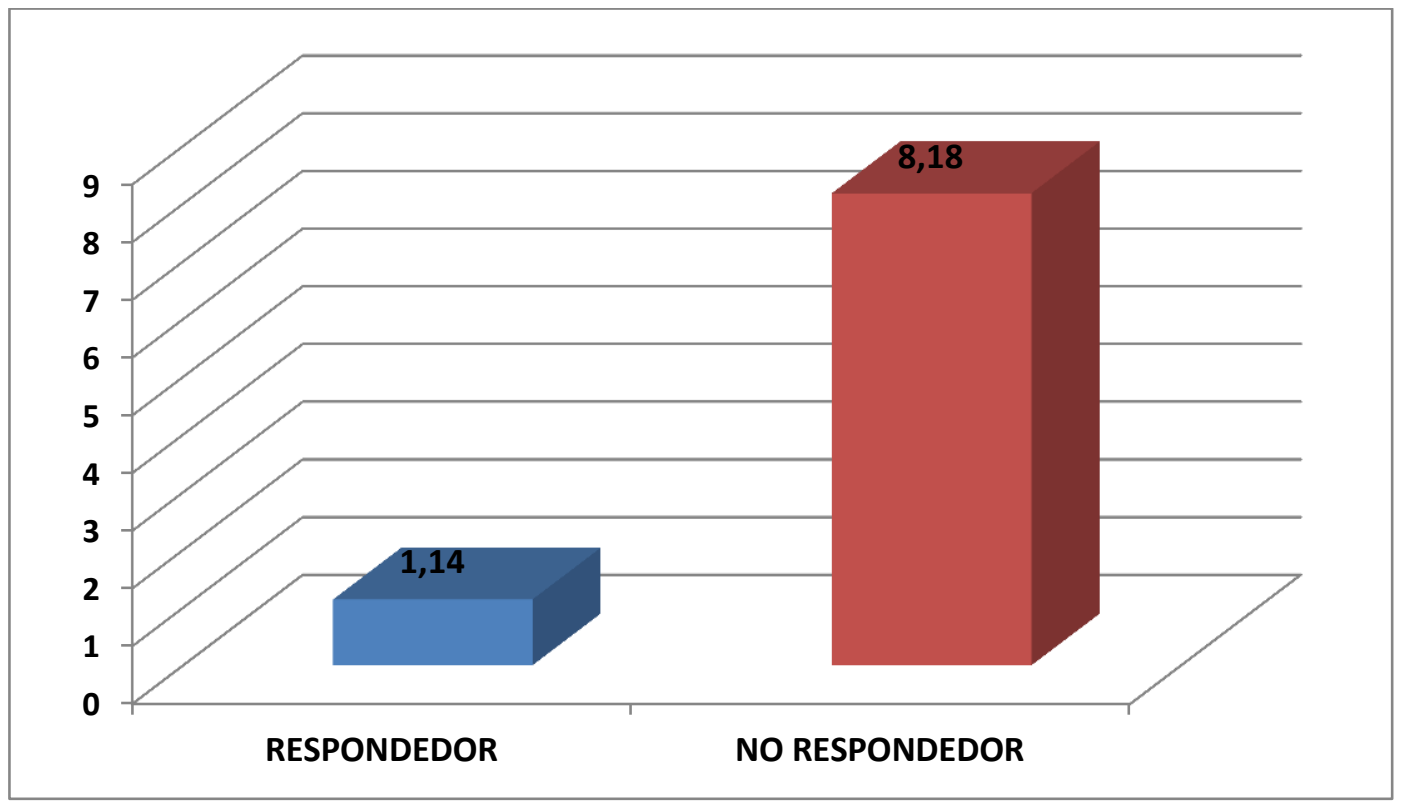

GRÁFICA 18. DISTRIBUCIÓN DE LA PUNTUACIÓN EVA MEDIA A PARTIR DE LOS 6 MESES TRAS EL TRATAMIENTO CON PUNCIONES

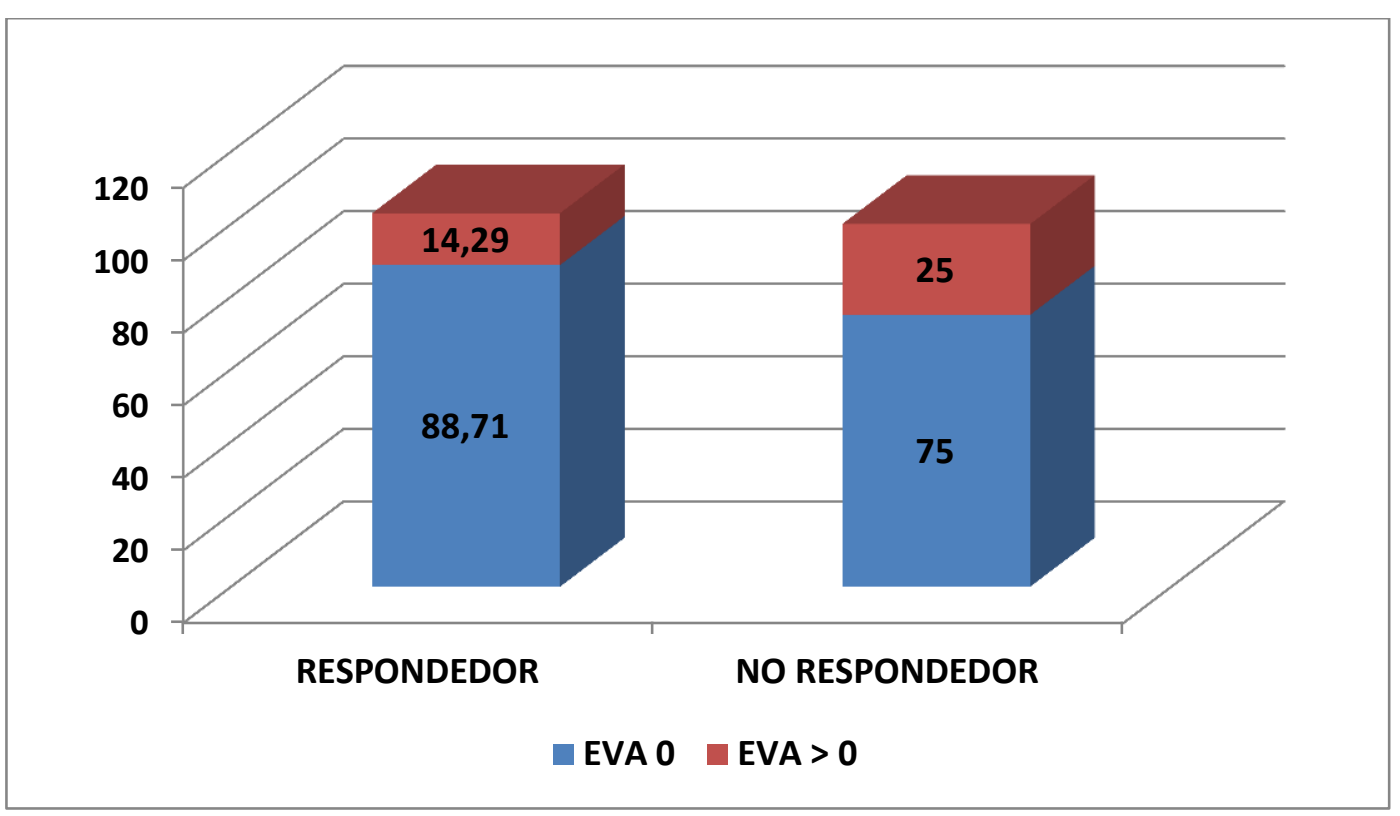

GRÁFICA 19. DISTRIBUCIÓN Y COMPARACIÓN DEL PORCENTAJE DE PACIENTES CON EVA $O$ Y EVA DISTINTO DE O EN EL GRUPO DE RESPONDEDORES Y DE NO RESPONDEDORES EN EL PERIODO INMEDIATO POST-PUNCIÓN (\%) 
5.3 PRUEBAS DE ASOCIACIÓN ESTADÍSTICA ENTRE VARIABLES Y RESPUESTA AL TRATAMIENTO

5.3.1 ASOCIACIÓN ENTRE VARIABLES Y RESPUESTA AL TRATAMIENTO SIN SIGNIFICACIÓN ESTADÍSTICA

Se han realizado pruebas de asociación estadística entre distintas variables y respuesta o no a las punciones corticoideoanestésicas no observando significación estadística en las detalladas a continuación en la tabla IV:

\begin{tabular}{|c|c|c|c|}
\hline$\underline{V A R I A B L E}$ & $\underline{\text { TEST }}$ & $\underline{P-V A L O R}$ & SIGNIFICATIVO? \\
\hline $\begin{array}{l}\text { SEXO/RESPUESTA AL } \\
\text { TRATAMIENTO }\end{array}$ & $\begin{array}{l}\text { CHI- } \\
\text { CUADRADO }\end{array}$ & 0,337 & NO \\
\hline $\begin{array}{l}\text { ANTECEDENTES } \\
\text { QUIRÚRGICOS/ RAMAS } \\
\text { AFECTAS }\end{array}$ & $\begin{array}{l}\text { CHI- } \\
\text { CUADRADO }\end{array}$ & 0,336 & NO \\
\hline $\begin{array}{l}\text { RAMAS } \\
\text { AFECTAS/RESPUESTA AL } \\
\text { TTO. }\end{array}$ & $\begin{array}{l}\text { CHI- } \\
\text { CUADRADO }\end{array}$ & 0,95 & NO \\
\hline $\begin{array}{l}\text { ASOCIACIÓN RAMAS/ } \\
\text { RESPUESTA TTO }\end{array}$ & $\begin{array}{l}\text { V de } \\
\text { CRAMER }\end{array}$ & 0,467 & NO \\
\hline $\begin{array}{l}\text { SIGNO } \\
\text { TINEL/RESPUESTA }\end{array}$ & $\begin{array}{l}\text { V de } \\
\text { CRAMER }\end{array}$ & 0,432 & NO \\
\hline $\begin{array}{l}\text { ROLLING } \\
\text { TEST/RESPUESTA }\end{array}$ & $\begin{array}{l}\text { CHI- } \\
\text { CUADRADO }\end{array}$ & 0,749 & NO \\
\hline ST. MARK'S/RESPUEST & $\begin{array}{l}V \quad d e \\
\text { CRAMER }\end{array}$ & 0,467 & NO \\
\hline
\end{tabular}

TABLA IV . RELACIÓN DE VARIABLES ESTUDIADAS EN RELACIÓN A LA RESPUESTA AL TRATAMIENTO SIN MOSTRAR SIGNIFICACIÓN ESTADÍSTICA 


\subsubsection{VARIACIÓN PORCENTUAL DE EVA}

Asimismo, se ha analizado la variación porcentual de la puntuación EVA según el sexo y según los antecedentes quirúrgicos sin observar diferencias significativas (tabla $\vee$ y VI).

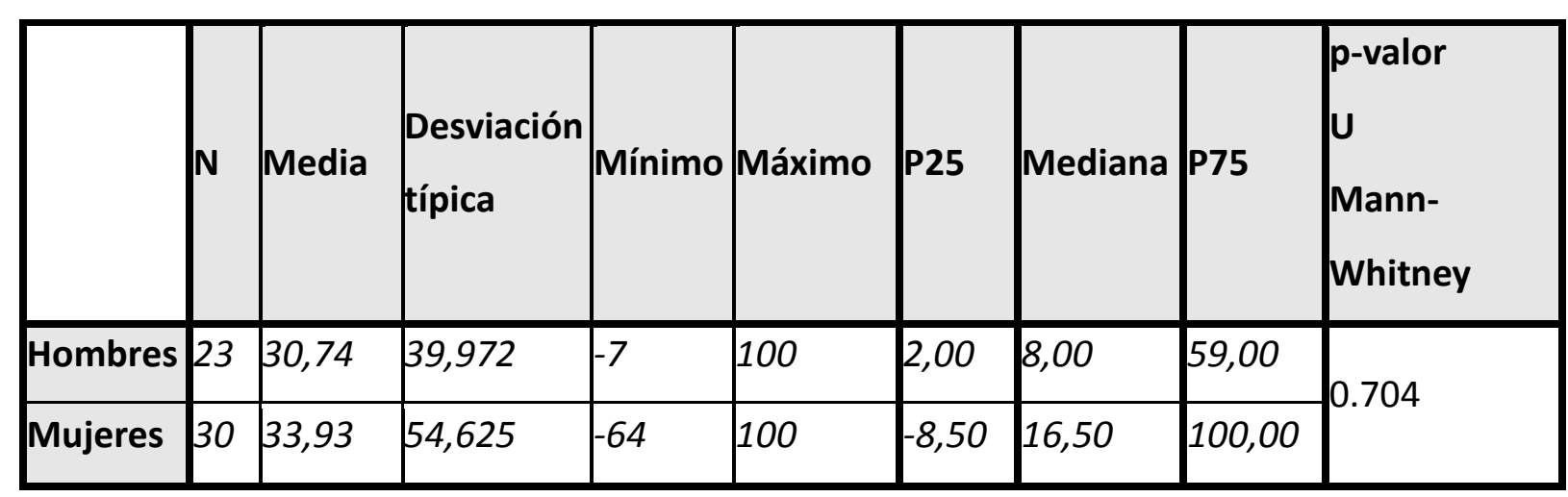

TABLA V. VARIACIÓN PORCENTUAL DE EVA SEGÚN EL SEXO

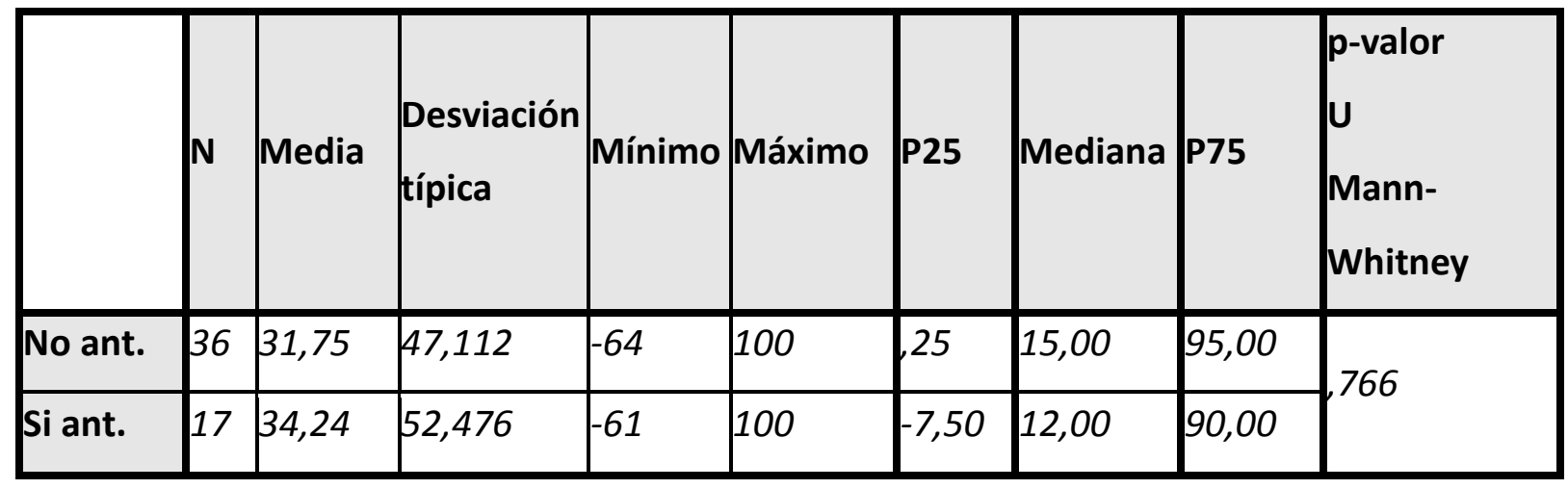

TABLA VI. VARIACIÓN PORCENTUAL DE EVA SEGÚN ANTECEDENTES QUIRÚRGICOS 


\subsubsection{ASOCIACIÓN EVA PREPUNCIÓN/ POST-PUNCIÓN}

Sin embargo, aplicando dichas pruebas estadísticas y comparando estadísticamente los valores en la puntuación EVA prepunción con respecto a la puntuación EVA postpunción, se observa, tal y como que reflejado en la tabla VII , que los valores de EVA han descendido significativamente de 8 puntos de mediana (IQR 9.1-6.1) a 7 puntos de mediana (IQR 9.00-1.00) en la muestra global.

\begin{tabular}{|l|l|l|l|l|l|l|l|l|l|}
\hline & $\mathbf{N}$ & Media & $\begin{array}{l}\text { Desviación } \\
\text { típica }\end{array}$ & $\begin{array}{l}\text { Mínim } \\
\mathbf{0}\end{array}$ & $\mathbf{0}$ & $\mathbf{0}$ P25 & Mediana & P75 & $\begin{array}{l}\text { p-valor } \\
\text { Wilcoxon }\end{array}$ \\
\hline EVA PRE & 53 & 7,706 & 1,8975 & 2,8 & 10,0 & 6,100 & 8,000 & 9,100 & 0,00003 \\
\hline EVA POST & 53 & 5,40 & 3,886 & 0 & 10 & 1,00 & 7,00 & 9,00 & \\
\hline
\end{tabular}

TABLA VII. EVOLUCIÓN DE PUNTUACIÓN EVA PRE/POSTINFILTRACIÓN PARA LA MUESTRA GLOBAL

Asimismo, analizando la puntuación EVA prepunción con respecto a la EVA postpunción distinguiendo por separado entre hombres y mujeres, vemos que los valores de EVA han descendido significativamente de 8 puntos de mediana (IQR 9.0-6.0) a 6 puntos de mediana (IQR 8.00-3.00) en la muestra de hombres (tabla VIII) y que los valores de EVA han descendido significativamente de 8.45 puntos de mediana (IQR 9.65-6.175) a 7.50 puntos de mediana (IQR 9.25-0.00) en la muestra de mujeres (tabla IX)

\begin{tabular}{|l|l|l|l|l|l|l|l|l|l|}
\hline & N & Media & $\begin{array}{l}\text { Desviación } \\
\text { típica }\end{array}$ & $\begin{array}{l}\text { Mínim } \\
\mathbf{0}\end{array}$ & Máxim & $\mathbf{0} 25$ & Mediana & P75 & $\begin{array}{l}\text { P-valor } \\
\text { Wilcoxon }\end{array}$ \\
\hline EVA PRE & 23 & 7,470 & 1,9807 & 2,8 & 10,0 & 6,000 & 8,000 & 9,000 & 0,0003 \\
\hline EVA POST & 23 & 5,46 & 3,447 & 0 & 10 & 3,00 & 6,00 & 8,00 & \\
\hline
\end{tabular}

TABLA VIII. EVOLUCIÓN DE PUNTUACIÓN EVA PRE/POST-PUNCIÓN PARA LA MUESTRA DE VARONES 


\begin{tabular}{|l|l|l|l|l|l|l|l|l|l|}
\hline & $\mathbf{N}$ & Media & $\begin{array}{l}\text { Desviación } \\
\text { típica }\end{array}$ & $\begin{array}{l}\text { Mínim } \\
\mathbf{0}\end{array}$ & $\mathbf{0}$ & $\mathbf{0} 25$ & Mediana & P75 & $\begin{array}{l}\text { p-valor } \\
\text { Wilcoxon }\end{array}$ \\
\hline EVA PRE & 30 & 7,887 & 1,8444 & 4,5 & 10,0 & 6,175 & 8,450 & 9,650 & \multirow{2}{*}{005} \\
\hline EVA POST & 30 & 5,35 & 4,249 & 0 & 10 & 00 & 7,50 & 9,25 & \\
\hline
\end{tabular}

TABLA IX. EVOLUCIÓN DE PUNTUACIÓN EVA PRE/POST-PUNCIÓN PARA LA MUESTRA DE MUJERES 
6. DISCUSIÓN 
El SANP es una entidad poco conocida descrita por primera vez hacia el año 1987 por el parisino Dr. Amarenco en un paciente ciclista que presentaba un dolor perineal invalidante, y con el apoyo de determinadas pruebas electrofisiológicas, le dió el nombre originario de Síndrome de Parálisis Perineal del Ciclista (1).

En 1991 el egipcio A. Shafik, gran estudioso de esta patología, describió una técnica para su tratamiento, fundamentada y apoyada en el gran conocimiento anatómico del recorrido del nervio pudendo, dando lugar a lo que actualmente se conoce con el nombre de técnica transperineal o procedimiento Shafik (2).

Posteriormente distintos científicos como Bautrant, Robert, Beco, Benson, etc han arrojado luz en los distintos aspectos relacionados con el síndrome, bien sea con su etiología, bien con su diagnóstico y tratamiento. Pese a todo ello, en nuestros días quedan muchos aspectos por esclarecer en relación a su etiología, fisiopatología, y sobre todo, descubrir procedimientos terapéuticos más efectivos.

\subsection{DE LA INCIDENCIA}

En todas las series publicadas se señala que tanto la incidencia como la prevalencia del SANP resulta DESCONOCIDA, probablemente debido a que a menudo esta patología resulta infradiagnosticada siendo el tiempo medio estimado para su diagnóstico de unos 4 años con un rango que va de 1 a 15 años. Durante este lapso de tiempo, los paciente son valorados por un amplio número de médicos de distintas especialidades (cirujanos, ginecólogos, urólogos, etc) los cuales, muchas veces debido al desconocimiento de este síndrome, no llegan a dar un diagnóstico certero ofreciendo al paciente soluciones parciales y poco efectivas, con lo que se prolonga el tiempo medio de diagnóstico con el consiguiente empeoramiento de la calidad de vida de los pacientes y el gasto innecesario de recursos sanitarios mal dirigidos.

Los 53 casos forman una serie amplia constituida por pacientes propios de nuestro área sociosanitaria junto a aquellos que son remitidos de otros centros hospitalarios de la geografía española, lo que nos permite realizar un estudio o línea de investigación más amplio. 


\subsection{DEL SEXO}

En cuanto a la distribución por sexos, autores como R. Lema (50) señalan que el SANP es una patología que de una forma clara se presenta más frecuentemente en el sexo femenino llegando a afirmar que en los próximos años en Europa y América, 1 de cada 7 mujeres desarrollarán un SANP. Algunos autores estiman que 7 de cada 10 pacientes afectos por este síndrome son mujeres (60). Todo ello probablemente sea debido a que gran parte de los factores etiológicos conocidos y establecidos hasta el momento son más propios en el sexo femenino como la larga lista de causas ginecológicas que parecen implicadas en su etiología.

Así, los resultados obtenidos en nuestro estudio concuerdan con lo publicado y lo anteriormente dicho, ya que, en nuestra muestra el $56,6 \%$ de los pacientes son mujeres frente a un $43,4 \%$ de pacientes varones, confirmando que el SANP ES ALGO MÁS FRECUENTE EN EL SEXO FEMENINO.

Sin embargo, al analizar estadísticamente en nuestra muestra la variable sexo en relación con ser respondedor o no a las infiltraciones corticoideo-anestésicas, no se ha objetivado significación estadística.

Analizando el grupo de varones y de mujeres, observamos que en el grupo de varones responden a las infiltraciones el $34,78 \%$ de los mismos, mientras que en el grupo de mujeres consideramos respondedoras al $43,33 \%$ de las mismas, por lo que de acuerdo a nuestros datos observamos que en nuestra serie, las mujeres responden mejor a las infiltraciones corticoideo-anestésicas aunque sin significación estadística.

\subsection{DE LA EDAD}

Referente a la edad, las series publicadas coinciden en señalar que en el SANP no existe una predilección definida por ningún grupo de edad ni se establece un rango de años donde la frecuencia del síndrome aumente. No hay ningún estudio publicado que analice la edad relacionada con nuestra patología objeto de estudio. Como ejemplo, Ricci (63) analiza una serie de infiltraciones del nervio pudendo en 5 pacientes donde la edad media de los mismos era de 45 años. En nuestra muestra, la edad media de los pacientes ha sido de 56,8 años con un rango que va desde los 24 años el paciente más joven hasta los 85 del más longevo, por lo que deducimos que el abanico de edades es muy amplio sin establecer un rango de edad determinado donde el SANP sea más frecuente. 


\subsection{DE LOS ANTECEDENTES PERSONALES}

En el SANP existen documentadas muchas y variadas causas implicadas en su etiología.

En primer lugar, al ser descrito por primera vez en síndrome en un ciclista, se implicó como causa aquellas actividades profesionales o deportivas que impliquen tiempo prolongado en posición de sedestación como hípica, ciclismo, etc $(1,12,13)$. En nuestra muestra hemos objetivado que 4 pacientes son ciclistas profesionales ( 2 hombres y 2 mujeres) lo que supone el 7,5\% del total de casos, lo cual nos hace recordar la relación del ciclismo con las primeras descripciones del síndromes expuestas por el Dr. Amarenco, aunque por supuesto, la profesión de los pacientes estudiados es muy variada.

Otro gran apartado en la etiología del síndrome lo componen todas aquellas causas ginecológicas-obstétricas como el parto vaginal, episiotomía, cirugía pelviana, cirugía vaginal, etc $(15,16,17)$ en las que tradicionalmente, $y$ de forma repetida se ha observado mayor incidencia de esta patología. En nuestra serie hemos constatado 10 mujeres con antecedentes ginecológicos reseñables lo que supone el 33,3\% del total de pacientes mujeres. Entre dichos antecedentes destacan las histerectomías y las cirugías vaginales. En relación a la cirugía anorrectal, pocos estudios analizan dicha causa en la etiología del SANP, aunque ya Bautrant (22) señalaba la cirugía pélvica en conjunto como una de las causas más frecuentes del síndrome. En nuestra serie, 10 pacientes ( 5 mujeres, 5 hombres) presentaban antecedentes de cirugia anorrectal, lo que supone el $18,86 \%$ de los casos, tratándose en 8 de los mismos de cirugía de la fisura anal, intervención indicada al atribuir de forma errónea la sintomatología presente.

Entre la larga lista de causas del SANP se incluyen también las enfermedades autoinmunes. Hemos de señalar al respecto que hemos detectado 4 pacientes con fibromialgia ( $7,5 \%$ de la muestra), un caso de lupus y un paciente con amiloidosis, lo cual rememora la relación del SANP con procesos inmunes.

Otros procesos claramente relacionados con el síndrome son los traumatismos perineales (14), radioterapia pelviana, defectos congénitos de región perineal, prolapso rectal, etc, de los cuales no hemos objetivado representación en nuestra muestra. 
También es de destacar la existencia de muchos casos de SANP en los que no se identifica con claridad una causa destacable. Así en nuestra muestra, 18 pacientes no presentaban antecedentes personales de interés, entre ellos, 10 mujeres lo que supone el $33,33 \%$ de la muestra de mujeres y 8 hombres, lo que supone el $34,78 \%$ de la muestra de varones, porcentaje que se extrapola a las series publicadas ya que, como en otras tantas patologías, en muchas ocasiones no se objetiva un antecedente desencadenante.

Como quedó expuesto en el apartado resultados, en nuestra muestra responden mejor a la punción corticoideo-anestésica aquellos pacientes sin antecedentes quirúrgicos reseñables.

Al relacionar estadísticamente la presencia o no de antecedentes patológicos con ser o no respondedor a las infiltraciones anestésicas del nervio no hemos objetivado significación estadística.

\subsection{DE LA CLÍNICA- RAMAS AFECTAS}

En el apartado de introducción se expuso que la clínica fundamental y por la cual consultan la inmensa mayoría de los pacientes con SANP es el DOLOR en el territorio del nervio pudendo, que puede ser rectal, perineal, uretral, genital, etc. Este dolor tiene unas características clínicas peculiares que ayudan al diagnóstico del síndrome ya que, generalmente empeora a lo largo del día y al sentarse, mejorando al acostarse. Dicho dolor puede referirse como quemazón, descarga eléctrica, cuerpo extraño, etc, y puede ser uni o bilateral y de instauración clásicamente lenta y progresiva aunque también se han constatado casos en los que la instauración fue de manera brusca.

En nuestro estudio la proctalgia es la constante fundamental de estudio a la que puede añadirse sintomatogía de otras ramas del nervio $(23,24,25,26)$. Así mismo como síntomas específicos de rama posterior, a parte de la proctalgia, puede añadirse problemas de continencia defecatoria, sensación de cuerpo extraño rectal, etc (26).

En un estudio publicado por Beco en 2004 (26) se analizó la asociación entre incontinencia fecal, incontinencia urinaria y dolor perineal (es decir, afectación de una o varias ramas del nervio pudendo ) y observó que el $71 \%$ de los pacientes de su serie 
presentaban dos de estos síntomas mientras que el $13 \%$ presentaban los tres. En nuestra muestra, en contraposición a los hallazgos de Beco, 34 pacientes presentaban sintomatología de las tres ramas (64,15\%), 9 de rama media y posterior, 7 de rama anterior y posterior (siendo la afectación de 2 ramas el 30,18\% de los casos) y 3 pacientes referían únicamente síntomas de rama posterior (5,67\%). Distribuyendo en nuestra muestra a los pacientes en respondedores y no respondedores, observamos que en el grupo de pacientes que presentan sintomatología de las tres ramas se incluye un mayor porcentaje de pacientes no respondedores $(65,71 \%$ de ellos no responden) frente a aquéllos que presentan afectación de 2 ramas ( $50 \%$ de no respondedores), con lo cual observamos peor respuesta en los pacientes con afectación de 3 ramas. La comparativa con los pacientes que presentan sintomatología únicamente de rama posterior resulta poco valorable ya que el número de pacientes incluidos en esta categoría es muy reducido. Así mismo, al aplicar el análisis estadístico mediante el test de la chi cuadrado y $\mathrm{V}$ de Cramer a la relación entre la presencia de ramas afectas (solas o asociadas) y el ser o no respondedor, no se ha observado significación estadística.

\subsection{DE LOS SIGNOS CLÍNICOS}

En relación a la exploración física, hemos comentado que existen 2 signos clínicos fundamentales: el signo de Tinel y el Rolling Test.

SIGNO DE TINEL

Este signo lo consideramos en nuestra muestra un signo valioso, muy sensible, ya que el $98,1 \%$ de nuestros pacientes presentan signo de Tinel positivo siendo un único paciente, que posteriormente se observó no respondedor, el que mostró este signo negativo, con lo cual, demuestra además ser un signo específico.

\section{ROLLING TEST}

Referente al Rolling Test o Test de la pinza rodada (26), fue positivo únicamente en el $37,73 \%$ de los pacientes de nuestra muestra, no observando diferencias significativas al diferenciar los resultados del test en el grupo de respondedores y de no respondedores, por lo que consideramos este signo como poco sensible y poco específico. 


\subsection{DEL TEST DE LATENCIA MOTORA DISTAL DEL NERVIO (ST. MARK'S)}

El estudio más importante es el de la vía motora representado en el Test de Latencia Motora Distal del nervio o test de St. Mark's que se basa en la medición de la velocidad de conducción nerviosa del nervio considerando como valor superior normal 2,2 mseg, no siendo útil para valorar la extensión de la lesión $(29,30,31)$.

En nuestra muestra, de los 52 test de St. Mark's realizados, 46 resultaron patológicos, lo que supone el $88,46 \%$ de los casos. Si además distinguimos entre respondedores y no respondedores, en los primeros resultó patológico en el $80,95 \%$ de los casos mientras que en los segundos mostró valores patológicos en el 90,625\% de los pacientes con lo que se confirma que es un test sensible y específico.

Así, a la vista de nuestro datos, podemos deducir que cuando los pacientes presentan un test de St Mark's normal responden mejor y cuando presentan un test patológico responden peor.

Dicho de otro modo, en nuetra serie, de los 46 test patológicos, 17 ha sido en pacientes respondedores lo que supone el 36,95\% de los casos, mientras que en los 6 casos de test normal, 3 han sido no respondedores lo cual supone el 50\% dentro de este grupo. Asimismo al aplicar pruebas estadísticas como la prueba $V$ de Cramer para analizar la relación entre la presencia de Test de St. Mark's patológico y ser o no respondedor, no hemos obtenido significación estadística.

En resumen, podemos afirmar que es un buen test diagnóstico para el para el SANP.

\subsection{DE OTRAS PRUEBAS COMPLEMENTARIAS}

El resto de pruebas electrofisiológicas que se pueden realizar para estudiar la función del nervio pudendo son la electromiografía de los músculos inervados por el mismo, determinación de reflejos sacros (6), etc, todas ellas pruebas muy específicas y no disponibles de manera rutinaria en nuestros centros hospitalarios.

Resulta fundamental para el diagnóstico de exclusión del SANP realizar otras pruebas de imagen como TAC o RMN. Así en nuestra muestra se realizó TAC en 14 de los 53 casos y RMN en todos los casos. 
En nuestra serie, se ha realizado ecografia endorrectal en 49 pacientes descartando anormalidades en el tamaño de los esfínteres y otras causas anales potencialmente productoras de proctalgia, estando este proyecto en fase experimental (amplia curva de aprendizaje).

Otros autores como Mollo (32) han estudiado y aplicado el Doppler color en la arteria pudenda interna como apoyo para el diagnóstico de SANP. Asimismo se han descrito bloqueos diagnósticos del nervio pudendo para afianzar el diagnóstico (asumiendo que en nuestro medio la primera punción además de diagnóstica resulta terapéutica). También se han realizado estudios urodinámico en 41 casos con afectación de la rama media del nervio pudendo asociada a la proctalgia.

\subsection{DEL TRATAMIENTO}

A grandes rasgos el tratamiento del SANP se fundamenta en 3 pilares, el tratamiento sintomático del dolor, punciones corticoideo anestésicas y la intervención quirúrgica.

En nuestra serie todos los pacientes han recibido tratamiento médico utilizando gran variedad de analgésicos, destacando llamativamente la utilización de antidepresivos como amitriptilina y de antiepilépticos como la pregabalina o la gabapentina ampliamente utilizadas en las series publicadas $(37,38,39)$.

El fundamento de nuestro estudio es analizar el tratamiento con punciones corticoideo-anestésicas $(41,42,43,44,63)$. Dichas punciones-hidrodistensiónes practicadas en todos nuestros pacientes, se pueden llevar a cabo hasta un máximo de tres infiltraciones reevaluando entonces al paciente y valorar si consideramos o no que le vaya a ser útil recibir una segunda "tanda" de punciones o no. Consideramos que es una técnica segura, ya que sólo hemos objetivado 4 complicaciones menores de un total de 159 punciones realizadas. Con respecto al tratamiento quirúrgico, en nuestro país no está desarrollado aunque determinados centros como el Hospital de Vigo está comenzando la curva de aprendizaje de la técnica quirúrgica de descompresión del nervio pudendo por vía transglútea. Así, dos casos de nuestra serie presentado, en los que era patente el fracaso de tratamiento con varias tandas de infiltraciones han sido remitidos a Francia para valorar tratamiento quirúrgico, puesto que a fecha de hoy, allí está más desarrollado que en nuestro país. 


\subsection{DE LA PUNTUACIÓN EN ESCALA EVA PREPUNCIÓN}

La medida de la variable dolor siempre ha resultado un reto en el campo de la medicina. Nosotros hemos utilizado la escala visual analógica del dolor, en nuestro caso aplicada a la proctalgia, porque consideramos que se trata de un método fácil, sencillo para el paciente, reproducible, comparable entre observadores y que refleja fielmente la realidad. En nuestro estudio hemos utilizado esta escala en tres puntos esenciales del proceso de tratamiento de cada paciente que son prepunción, post-punción inmediata y post-punción a partir de los 6 meses tras la primera punción.

Así hemos obtenido una puntuación media prepunción de 7,74 con un rango que va de 2,8 a 10 , variabilidad también encontrada en las series publicadas (62). Si distinguimos entre respondedores y no respondedores, en el primer grupo la puntuación media en la escala EVA ha sido de 7,08 con un rango de 2,8 a 10. En el grupo de no respondedores la puntuación media de 7,83 con un rango de 4,1 a 10 con lo que ya en el periodo prepunción observamos una ligera tendencia a presentar una puntuación EVA más alta en el grupo de pacientes no respondedores a las punciones anestésicas.

\subsection{DE LA PUNTUACIÓN EVA INMEDIATA POST-PUNCIÓN}

Hemos registrado la puntuación en la escala EVA en el periodo inmediato tras la punción practicada. En nuestra muestra, la puntuación EVA media en dicho momento ha sido de 1,19 con un rango que va de 0 a 10. Asimismo es de destacar, que en 42 de los 53 pacientes estudiados, la puntuación EVA inmediata post-punción ha sido de 0 , de lo que puede deducirse que la técnica es efectiva a corto plazo.

Sin embargo al analizar la evolución de la puntuación EVA, observamos que muchos pacientes de los que han mostrado respuesta favorable, e incluso puntuación 0 en el momento inmediato post-punción, con el paso del tiempo se vuelven sintomáticos y alcanzan una puntuación EVA igual o superior a la referida en el periodo prepunción Así por ejemplo, de los 42 con puntuación 0 en el periodo inmediato post-punción, 13 de ellos siguen manteniendo una puntuación 0 a partir de los seis meses.

Con todo lo expuesto, añadiendo lo que se observará posteriormente a partir de los 6 meses de la primera punción, se observa que la puntuación en la escala EVA inmediata post-punción no es un buen indicador de respuesta a largo plazo. 


\subsection{DE LA PUNTUACIÓN EVA POST-PUNCIÓN A PARTIR DE LOS 6 MESES}

Tal y como ha quedado expuesto anteriormente, en los 53 pacientes en los que se ha realizado seguimiento a partir de los 6 meses tras la primera punción, se ha obtenido una puntuación media en escala EVA de 5,39 con un rango que va de 0 a 10. En 13 de estos casos la puntuación ha sido de 0 lo que supone el 30,952\% de los pacientes. Como dijimos en el apartado resultados, hemos obtenido 32 pacientes no respondedores lo que supone el 60,38\% de los casos y 21 pacientes respondedores $(39,62 \%)$. De estas cifras deducimos que, aunque la respuesta no sea completa a largo plazo en todos los casos de respondedores, mantienen una mejoría no despreciable a lo largo del tiempo tras la primera punción. Este hecho es de gran trascendencia ya que, muchos de nuestros pacientes llevan tantos años con sintomatología invalidante, refractaria a todo tipo de tratamiento convencional, formando parte de un periplo de especialistas que bien por desconocimiento o falta de experiencia, no son capaces de ofrecer al paciente una solución a sus problemas, por lo que una mejoría en su nivel del dolor de más del $30 \%$ en su puntuación en la escala EVA prepunción, les supone tanto alivio, satisfacción y agradecimiento que lo consideramos un gran avance y una solución que aunque muchas veces no sea total, mejora mucho la calidad de vida de los pacientes afectos de SANP.

Aplicando el análisis estadístico con la prueba de Wilcoxon y comparando los valores en la puntuación EVA prepunción con respecto a la puntuación EVA post-punción a partir de los 6 meses, tanto para la muestra global como subdividiéndola para hombres y mujeres, se observa que los valores de EVA han descendido significativamente, lo cual nos reafirma en que la punción-hidrodistensión corticoideo-anestésica de las ramas terminales del nervio pudendo es una técnica eficaz que puede ofrecer mejoría completa y en otros casos parcial, a un importante porcentaje de pacientes.

En la literatura, apenas hay registradas series de punciones que evalúen como la nuestra el seguimiento más allá del periodo inmediato tras la primera punción. Así, Ricci (63), analiza la infiltración del nervio pudendo guiada por TC por vía transglútea y presenta una serie de cinco pacientes afirmando únicamente que todos ellos disminuyeron el dolor después de la infiltración, fenómeno observado en mayor o menor medida en nuestra serie, pero añadiendo, con gran acierto, que sólo el 
seguimiento permitirá evidenciar la mantención de buenos resultados o la necesidad de valorar otras terapias. Similares hallazgos obtuvieron Macdonald y Spigos (68) sin obtener datos a largo plazo.

Por lo tanto, afirmamos que en el $39,62 \%$ de nuestros pacientes, que hemos considerado como respondedores, la infiltración ha sido efectiva con lo que de nuestros datos deducimos que la técnica es eficaz disminuyendo el dolor en un porcentaje alto y significativo manteniendo la respuesta a medio plazo (a partir de 6 meses).

Fannucci (65) coincide con nosotros en que las punciones resultan un tratamiento seguro y reproducible pero obtienen una eficacia clínica superior a nosotros, en concreto del $92 \%$ a los 12 meses. Otros autores como Dehkharghani (66) demuestran en su estudio una elevada tasa de éxito, pero basándose únicamente en el resultado inmediato postinfiltración sin tener datos a largo plazo, lo que consideramos una conclusión poco realista para la solución contra el dolor, ya que tal y como hemos expuesto en nuestra serie, con el paso de los meses, muchos de estos pacientes reproducen de nuevo la sintomatologia. En el trabajo de Puget (67) se nos muestra la posibilidad de infiltrar simultáneamente a nivel de espina isquiática y canal de Alcock lo que permite, según él, una importante comodidad para los pacientes y demuestra que aquellos pacientes que presentan un cuadro clínico típico de neuralgia del pudendo (nuestros pacientes cumplían criterios de Nantes) obtienen mejores resultados que los que presentan una sintomatología atípica, de lo cual deducimos que fuese probablemente debido a que se incluyeran casos que no reunieran las condiciones para ser etiquetados de SANP.

Autores como Filler en 2009 (69) apuestan por el uso de la RMN para obtener imágenes precisas de la zona de atrapamiento del nervio y poder dirigir mejor las infiltraciones. Como se expuso en el material y métodos, nuestra técnica es guiada por ecografía. En la serie publicada por Rofael, Peng, Louis y Chan en 2008 (70) demuestran que la ecografía permite la visualización de puntos de referencia anatómicos tales como la espina isquiática, arteria pudenda interna y los ligamentos sacroespinoso y sacrotuberoso así como observar la difusión del anestésico local lo que permite mejorar la precisión y la seguridad de la técnica y reducir al mínimo las complicaciones (infecciosas, hemorrágicas...), por lo que nosotros nos adherimos a 
dicha técnica, que consideramos segura y con bajo coste.

Asimismo dichos autores observan que las puntuaciones en la escala de dolor se redujeron significativamente en la primera semana después del bloqueo pero no se realizó un seguimiento a largo plazo, por lo que disminuye el valor de sus hallazgos ya que como dijimos anteriormente, la resolución inmediata del dolor en el 100\% de los casos no se traduce en la permanencia de la mejoría a medio plazo.

Choi (71) estudió la aplicación de la fluoroscopia para mejorar la visión refiriendo una tasa de éxito del 100\%; los pacientes sometidos al estudio presentan bloqueo inmediato a la punción y en la evaluación del dolor en los 12 meses posteriores se observa una disminución de 2 puntos en la EVA del dolor en todos los pacientes infiltrados. Con respecto a este último estudio cabe señalar que una reducción de 2 puntos en la escala EVA no la hemos considerado en nuestro caso como exitosa en todos los pacientes ya que nos hemos basado en reducción de porcentaje sobre la puntuación basal en la escala EVA y muchos pacientes considerados en nuestra serie como no respondedores han presentado reducciones en la escala EVA mayores de 2 puntos por lo que consideramos muy discutible la definición de "éxito terapeútico" en el trabajo de Choi.

También existen publicaciones como la de Le Tallec de Certaines (72) en la que analizan el tiempo de evolución del dolor y la respuesta a la infiltración, concluyendo que existe un vínculo entre la antigüedad del dolor y el resultado positivo de la infiltración, observando que en los casos de neuralgia con un inicio del dolor inferior a 1 año se observan los mejores resultados. Analizando este dato, tal vez se debe a que el dolor de corta evolución, en muchas ocasiones "agudo" obedece a causas solucionables, transitorias en el tiempo, mientras que el dolor "crónico" puede deberse a causas "permanentes" de difícil o nula resolución. En nuestra serie, todos los casos refieren sintomatología desde hace más de 1 año, observando como queda expuesto, amplia variabilidad en los resultados, observando en el campo de los pacientes respondedores desde respuestas completas hasta mejorías parciales, nada despreciables, que en esta patología pueden suponen una gran mejora en la calidad de vida de los pacientes. 


\subsection{DE LA Sintomatología PRESENTE A PARTIR DE LOS 6 MESES TRAS LA PRIMERA PUNCIÓN}

En nuestra serie observamos persistencia de proctalgia en 38 casos $(67,85 \%)$, con intensidad variable (algunos incluso con EVA similar o en cuatro pacientes, superior al prepunción) y de otros síntomas, en mayor o menor cuantía, como son eyaculación dolorosa, vulvodinia, dispareunia, cistalgia, incontinencia urinaria, polaquiuria, ocupación rectal, etc...

Muchos de estos casos están pendientes de una segunda tanda de punciones o de valoración evolutiva tras ella.

\subsection{DE LAS OPCIONES DISPONIBLES TRAS EL FRACASO DE LA PRIMERA PUNCIÓN}

Actualmente, existen dos tendencias establecidas tras el fracaso de la primera punción. Éstas son, nueva "tanda" de punciones o derivar hacia cirugía descompresiva. En nuestro medio, optamos por una segunda "tanda" de punciones, por ser menos agresiva y así, en el momento actual 16 pacientes considerados como no respondedores han sido o están siendo tributarios de una segunda "tanda" de punción. En las series publicadas, autores como Popeney, Ansell y Renney (48) apuestan por la cirugía descompresiva exponiendo los buenos resultados presentados por medio centenar de pacientes. En 2007 Robert (73) demuestra mejores resultados con tratamiento quirúrgico vs tratamiento médico.

La razón por la que en nuestro medio optamos por reintentar tratamiento con punciones es porque hoy en día existe tendencia a tratamientos mínimamente invasivos y no directamente quirúrgicos que llevan implícitos más efectos secundarios, más morbilidad y grandes dificultades técnicas. Además, en nuestro país, la técnica quirúrgica está poco desarrollada hasta el momento y se necesitan nuevos estudios y líneas de investigación que comparen el tratamiento conservador con respecto al tratamiento quirúrgico.

Como otra opción tras el fracaso de las punciones del nervio, en algunas unidades especializadas en el dolor, se está investigando y desarrollando el uso de la radiofrecuencia pulsada del nervio pudendo o la utilización de neuromoduladores sacros, lo cual plantea nuevas líneas de investigación en el campo terapéutico de este síndrome. 


\section{CONCLUSIONES}


1. El Síndrome de Atrapamiento del Nervio Pudendo es una entidad dolorosa e invalidante, de incidencia y prevalencia desconocida e infradiagnosticada, más frecuente en el sexo femenino, sin establecer un rango de edad determinado para su presentación.

2. Existe un alto porcentaje de pacientes sin antecedentes personales de interés aunque existe un $\mathbf{1 8 . 8 6 \%}$ de pacientes con antecedentes de cirugía anorrectal y en mujeres, un 33,3\% de las mismas presentan antecedentes ginecológicos reseñables.

3. En relación a las ramas afectas, existe un mayor porcentaje de pacientes con afectación de las 3 ramas (64,15\%), seguido de aquéllos con 2 ramas afectas $(30,18 \%)$ y por último, existen pocos casos con afectación exclusiva de rama posterior (5,67\%), observando que el grupo que presenta 3 ramas afectas, además de ser el más frecuente, es el que responde peor.

4. El signo de Tinel es un signo valioso en el SANP, sensible y específico, que se comporta como buen criterio diagnóstico y que a nuestro juicio, debe ser incluido como criterio diagnóstico del SANP. Por el contrario, el Rolling Test, es poco sensible e inespecífico por lo que no debe formar parte de los criterios diagnósticos del síndrome.

El test de latencia motora distal del nervio es un buen test diagnóstico pero con menor valor como predictor de respuesta al tratamiento con punciones del nervio pudendo.

5. En nuestra experiencia, el tratamiento con punción-hidrodistensión corticoideoanestésica logra rescatar/mejorar a un importante porcentaje de pacientes afectos de proctalgia en el contexto de un SANP refractaria al tratamiento analgésico convencional, con buenos resultados a medio plazo (6 meses) aliviando el dolor al $39,62 \%$ de los pacientes y de forma estadísticamente significativa con relación al dolor prepunción. 
6. La técnica de punción es reproducible, segura, carente de grandes efectos secundarios, y que además supone un criterio diagnóstico a la vez que terapeútico. Es un medio al alcance de todos aquéllos profesionales sanitarios que deseen formarse.

7. El SANP es un gran campo de investigación multidisciplinar (que implica cirujanos, urólogos, anestesistas, neurólogos...) donde se pueden llevar a cabo grandes logros en la aplicación de nuevas y valiosas técnicas diagnósticas, y profundizar en el tratamiento médico y quirúrgico del mismo, aspecto que en nuestros días y en nuestro país, se encuentra poco desarrollado. 
8. BIBLIOGRAFÍA 
1. Amarenco G, Lanoe $\mathrm{Y}$, Perrigot M, Goudal H. A new canal syndrome: compression of the pudendal nerve in alcock's canal or perinal paralysis of cyclists. Presse Med. 1987; 16:399.

2. Shafik A. Pudendal canal syndrome: description of a new syndrome and its treatment. Report of seven cases. Coloproctology. 1991; 13:102-9.

3. Rober R, Prat-Pradal D, Labat JJ, Bensignor M, Raoul S, Rebai R, Leborgne J. Anatomic Basis of chronic perineal pain: role of the pudendal nerve. Surg Radiol Anat. 1998; 20:93-98.

4. Shafik A, Doss SH. Pudendal canal: surgical anatomy and clinical implications. Amer Surg 1999; 65: 176-180.

5. Shafik A, el-Sherif M, Youssef A, Olfat ES. Surgical anatomy of the pudendal nerve and its clinical implications. Clinical Anatomy 1995; 8(2)110-115.

6. Bisschop E, Bautrant E. EMG: Which one and why? Considerations regarding pudendal nerve terminal motor latencies. 31 meeting annual of the international urogynecological association (IUGA 2006).

7. Spinosa JP, Bisschop E, Laurencon J, Khun G, Dubuisson JB, Riederer BM. Sacral Staged reflexes to localize the pudendal compression: an anatomical validation of the concept. Rev Med Suisse. 2006 Oct 25; 2(84): 2416-8; 2420-1.

8. Butler DS. Movilización del sistema nervioso. Primera edición. Barcelona. Ed Paidotribo, 2002.

9. Sunderland S. Nerves and injuries. Ed. Churchill. Livingstone. Edingurgh, 1976

10. Spinner RJ. Outcomes for peripheral nerve entrapment syndromes.Clin Neurosurg. 2006;52: 285-94.

11. Lumborg G. Nerve injurie and repair. Ed.Churchill Livingstone. 1988

12. Silbert PL, Dunne JW, Edis RH, Stewart-Wynne EG. Bicycling induced pudendal nerve pressure neuropathy. Clin Exp Neurol. 1991; 28: 191-196

13. Antolak SJJ, Hough DM, Pawlina W, Spinner RJ. Anatomical basis of chronic pelvic pain syndrome: the ischial spine and pudendal nerve entrapment. Med Hypotheses. 2002; 59: 349-353.

14. Pisani R, Stubinski R, Datti R. Entrapment neuropathy of the internal pudendal nerve. Report of two cases. Scand J Urol Nephrol. 1997; 31: 407-410. 
15. Soga H, Nagata I, Murakami G, Yajima T, Takenaka A, Fujisawa M, Koyawa M. Histotopograpic study of the perineal body in elderly women: the surgical applicability of novel histological findings. Int Urogynecol J Pelvic Floor Dysfunct 2007 Jun 14.

16. Lien KC, Morgan DM, Delancey JO, Ashton- Miller JA. Pudendal Nerve Stretch during vaginal birth: a 3D computer simulation. Am J Obstet Gyencol 2005; 192(5):1669-76.

17. Benson JT, Mcclellan E. The effect of vaginal dissection on the pudendal nerve. Obstet Gynecol. 1993; 82: 387-389.

18. Kiff ES, Barnes PR, Swash M. Evidence of pudendal neuropathy in patients with perineal descent and chronic straining at stool. Gut. 1984; 25: 1279-1282.

19. Ho YH, Goh HS. The neurophysiological significance of perineal descent. Int J Colorectal Dis. 1995; 10: 107-111.

20. Shafik A. Pudendal canal descompression for the treatment of fecal incontinente in complete rectal prolapse. Am Surg 1996; 62(5): 339-43.

21. Shafik A. Pudendal canal descompression in the treatment of urinary stress incontinence. Int Urogynecol J 1994 (5): 215-220.

22. Bautrant E, De Bisschop E, Vaini-Elies V, Massonnat J, Aleman I, Buntinx J, et al. La prise en charge moderne des néuralgies pudendales. A partir d'une série de 212 patientes et 104 interventions de décompression. J Gynecol Obstet Biol Reprod $2003 ; 32: 705-12$.

23. Shafik A. Pudendal canal descompression in the treatment of the erectile dysfunction. Arch Androl 1994; 32(2):141-9.

24. Shafik A. Pudendal canal descompression in the treatment of the erectile dysfunction. 31 meeting of the international urogynecological association (IUGA 2006)

25. Loeser J. Terapeútica del dolor. Bonica Vol. II. Ed. Mc Graw-Hill. 2003

26. Kiff E, Swash M. Slowed conduction in the pudendal nerves in idiopathic (neurogénica) faecal incotinence. Br J Surg. 1984. Aug; 71(8): 614-6.

27. Kiff E, Swash M. Normal proximal and delayed distal condution in the pudendal nerves of patients with idiopathic (neurogénica) faecal incotinence. J Neurol. Neurosurg Psychiatry. 1984; 47:820-23. 
28. Snooks SJ, Badenoch DF, Tiptaft RC, Swash M. Perineal nerve damage in genuine stress urinary incontinente. An Electrophysiological Study. Br J Urol 1985; 57: 42226.

29. Amarenco G, Adba MA, D. DB, Bosc S, Denys P, Lacroix P, Kerdraon J. Explorations neurophysiologiques perineales. Dantec. Paris (France). Arud ; 1994.

30. Galaup JP. Dyschezia, pudendal neuropathy and functional pelvico-perineal disorders. Prog Urol 2000; 10 (1): 114-22.

31. González-Hidalgo M. Exploración neurofisiológica del suelo de la pelvis. Rev Neurol 1998; 26(151): 432-438.

32. Mollo M, Bautrant E, Rossi-Seignert A-K, Collet S, Boyer R, Thiers-Baurtrant D. Evaluation of diagnostic accuracy of Colour Duplex Scanning, compared to electroneuromyography, diagnostic score and surgical outcomes, in Pudendal Neuralgia by entrapment: a prospective study on 96 patients. PAIN 142 ( 2009) 159-163.

33. Labat JJ, Riant T, Robert R, Amarenco G, Lefaucheur JP, Rigaud J. Diagnostic Criteria for Pudendal Neuralgia by Pudendal Nerve Entrapment (Nantes Criteria). Neurourology and Urodynamics DOI 10.1002/nau

34. Nehme-Shuster H, Youssef C, Roy C, Brettes JP, Martin T, Pasquali JL, et al. Alcock's Canal Syndrome revealing endometriosis. Lancet $2005 ; 366$ (9492) : 1238.

35. Thomas E, Abiad L, Cytebal C, Gallix B, Taourel P, Bruel JM, et al. Metastic Pudendal nerve compression presenting as atypical sciatica. J Spinal Disord Tech 2002 ; 15(4) : 324-5.3.

36. Wallace JM. Update on pharmacotherapy guidelines for treatment of neurophatic pain. Curr Pain Headache Rep. 2007 Jun; 11 (3): 208-14.

37. Max MB, Culnane $M$, Schafer SC, et al. Amitriptyline relieves diabetic neuropathy pain in patients with normal and depressed mood. Neurology 1987; 37:589-96.

38. Bryson HM, Wilde MI. Amitriptyline. A review of its pharmacological propperties and therapeutic use in chronic pain states. Drugs \& Aging 1996; 8: 459-76.

39. Benson JT, Griffis K. Pudendal neuralgia. A severe pain syndrome. Am J Obstet Gynecol $2005 ; 192(5)$ : 1663-8. 
40. Sator-Katzenschlager SM, Scharbert G, Kress HG, Frickey N, Ellend A, Gleiss A, Kozek- Langeneckere SA. Chronic pelvic pain treated with gabapentin and amitriptyline: a randomized controlled pilot study. Wien Klin Wochenschr. 2005 Nov; 117 (21-22): 761-8.

41. Kovacs P, Gruber H, Piegger J, Bodner G.Ultrasound-Guided infiltration of the pudendal nerve: ultrasonographic technique. Dis Colon Rectum. 2001 Sep; 44(9): 1381-5.

42. Gruber H, Kovacs P, Piegger J, Brenner E. New, simple, ultrasound-guided infiltration of the pudendal nerve: topographic basics. Dis Colon Rectum. $2001 \mathrm{Sep}$; 44(9): 1376-80.

43. Thoumas D, Leroi AM, Mauillon J, Muller JM, Benozio M, Denis P, Freger P. Pudendal Neuralgia: ct-guided pudendal nerve block technique. Abdom Imaging. 1999 May-Jun; 24(6): 488-92.

44. Speed CA. Injection therapies for soft-tissue lesions. Best Pract Res Clin Rheumatol. 2007 Apr; 21 (2): 333-47.

45. Prendergast SA, Weiss JM. Physical therapy and pudendal nerve entrapment. Advance 2004; 15: 47.

46. Anderson RU, Wise D, Sawyer T, Chan CA. Sexual dysfunction in men with chronic prostatitis/chronic pelvic pain syndrome: improvement after trigger point release and paradoxical relaxation training. J Urol 2006 Oct; 176 (4 PT 1): 1534-8.

47. Sánchez Romero AM, Arroyo A, Pérez Vicente FA, Serrano P, Candela F, Calpena R. Tratamiento de la proctalgia fugax con toxina botulínica: resultados en 5 pacientes. Rev Clin Esp 2006; 206(3): 137-40.

48. Popeney C, Ansell V, Renney K. Pudendal entrapment as an etiology of chronic perineal pain: diagnosis and treatment. Neurourol urodyn. 2007 May 4.

49. Robert R, LAabat JJ, Bensignor M, Glemain P, Deschamps C, Raoul S, Hamel O. Decompression and transposition of the pudendal neuralgia: a randomized controlled trial and long-term evaluation. Eur Urol. 2005 Mar; 47(3): 403-8.

50. Lema R, Ricci PA. Atrapamiento del nervio pudendo: un síndrome por conocer. Rev Chil Obstet Ginecol 2006; 71 (3), 207-215. 
51. Weiss J. Treatment options for persistent pain following pudendal nerve decompression surgery. 31 meeting annual of the international urogynecological association (IUGA 2006).

52. Beco J. Transperineal pudendal nerve decompression with opening of the fascia linking the sacro-spinal and the sacro-tuberous ligament. Feasibility study and first results in perineology.

53. Robert R, Labat JJ, Lehur PA, Glemain P, Armstrong O, Leborgne J, Barbin JY. Clinical neurophysiologic and therapeutic remarks from anatomic data on the pudendal nerve in some cases of perineal pain. Chirurgie 1989; 115(8): 515-20.

54. Antolak S, JR. Observations on the transgluteal decompression of the pudendal nerve. 31 meeting annual of the international urogynecological association (2006).

55. Shafik A. Endoscopic pudendal canal decompression for the treatment of fecal incontinence due to pudendal canal syndrome. J Laparoendoscopic Adv Surg Tech A $1997 ; 7(4):$ 227-34.

56. Mauillon J, Thoumas D, Leroi AM, Freger P, Michot F, Denis P. Results of pudendal nerve neurolysistransposition in twelve patients suffering from pudendal neuralgia. Dis Colon Rectum 1999; 42(2): 186-92.

57. Beco J, Climov D, Bex M. Pudendal nerve descompression in perineology: a case series. BMC Surg 2004: 30 (4): 15.

58. Mouchel J, Mouchel T, Zaka P. Transperineal pudendal nerve descompression. 31 meeting anual of the international urogynecological association (IUGA 2006).

59. Weiss JM, Prendergast SA. Pitfalls in the effective diagnosis and treatment of pudendal nerve entrapment, Vision IPPS, Vol. 13, no 3, Jan 2006.

60. Itza Santos F, Zarza-Luciáñez D, Salinas J, Gómez Sancha F. Pudendal Nerve Entrapment syndrome. Urodinamia aplicada. Vol 20 n 4 Dic 2007

61. Dolopedia. Neuropetia del pudendo. Sociedad Europea de Anestesia Regional y tratamiento del Dolor (ESRA)

62. Benson JT, Griffes K. Pudendal Neuralgia, a severe pain syndrome. Am J Obstet Gynecol 2005; 192 (5): 1663-8. 
63. Ricci P, Lema R, Solá V, Wash A, Pardo J. Infiltración del nervio pudendo guiada por tomografia axial computerizada, por vía transglútea: terapia frente al dolor ocasionado por neuralgia del nervio pudendo. Rev Chil Obstet Ginecol 2009; 74 (2):94-101.

64. Lefaucheur JP. Neurophysiological testing in anorectal disorders. Muscle Nerve 2006; 33: 324-333.

65. Fannucci E, Manenti G, Ursone A, Fusco N, Mylonakou I, D’Urso S, et al . Role of interventional radiology in pudendal neuralgia: a description of techniques and review of the literature. Radiol Med. 2009; 114:3; 425-436.

66. Dehkharghani S, vanSonnenberg E, Moore M, Hedayati P, Oyola E, Hibner M. CTGuided Therapy of Refractory Pudendal Neuralgia: Indications, techniques and preliminare results. Am. J Roentgenol. 2007; 188:5, 114-118.

67. Puget J, Kastler B, Aubry S, Laborie L, Fergane B, Delabrousse E, et al. Infiltration scano-guideé en deux sites dans la néuralgie pudendale. J Radiol. 2009; 90:5, 577582.

68. Mc Donald JS, Spigos DG. Computed tomography-guided pudendal block for treatment of pelvic pain due to pudendal neuropathy. Obstet Gynecol. 2008; 95:2, 306-309.

69. Filler A. Diagnosis and management of pudendal nerve entrapment syndromes: Impact of MR neurography and open MR-guided injections. Neurosurg Q. 2008; 18:1, 1-6.

70. Rofaeel A, Peng P, Louis I, Chan V. Feasibility of real-time ultrasound for pudendal nerve block in patients with chronic perineal pain. Reg Anesth Pain Med. 2008; $33: 2 ; 139-145$.

71. Choi S-S, Lee P-B, Kim Y-C, Kim H-J, Lee S-C. C-arm-guided pudendal nerve block: a new technique. Int. J. Clin. Pract. 2006; 60:5, 553-556.

72. Le Tallec de Certains H, Veillard D, Dugast J, Estébe J-P, Kerdraon J, Toulouse P, et al. Comparaison entre la latence distale motrice du nerf pudendal, la topographie de la douleur perineale et le resultat d'infiltrations. Analyse pour 53 patients. Ann Readapt Med Phys. 2007; 50:2, 65-69.

73. Robert R, Labat JJ, Riant T, Khalfallah M, Hamel O. Neurosurgical treatment of perineal neuralgias. Adv Tech Stand Neurosur. 2007; 32, 41-59. 
L.D.V.G 